\title{
Demand Response Performance of GE Hybrid Heat Pump Water Heater
}

SH Widder GB Parker
JM Petersen

MC Baechler

July 2013

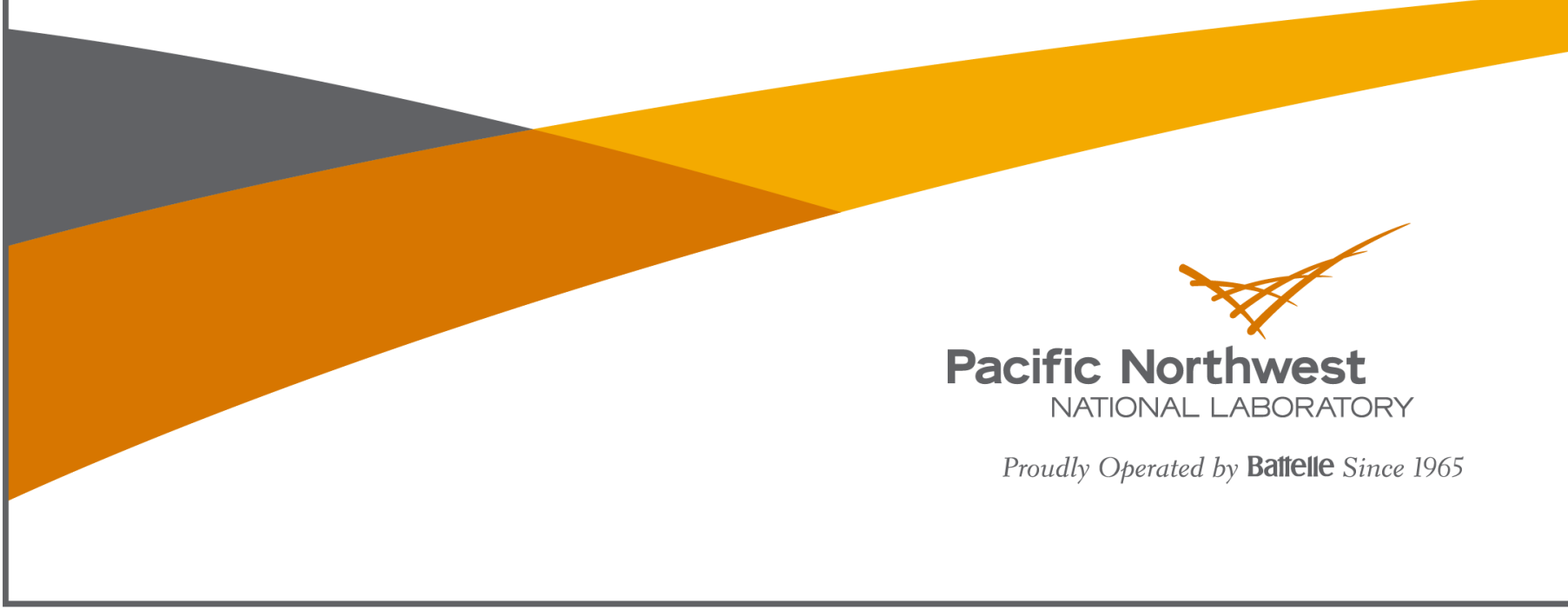




\title{
DISCLAIMER
}

This report was prepared as an account of work sponsored by an agency of the United States Government. Neither the United States Government nor any agency thereof, nor Battelle Memorial Institute, nor any of their employees, makes any warranty, express or implied, or assumes any legal liability or responsibility for the accuracy, completeness, or usefulness of any information, apparatus, product, or process disclosed, or represents that its use would not infringe privately owned rights. Reference herein to any specific commercial product, process, or service by trade name, trademark, manufacturer, or otherwise does not necessarily constitute or imply its endorsement, recommendation, or favoring by the United States Government or any agency thereof, or Battelle Memorial Institute. The views and opinions of authors expressed herein do not necessarily state or reflect those of the United States Government or any agency thereof.

\author{
PACIFIC NORTHWEST NATIONAL LABORATORY \\ operated by \\ BATTELLE \\ for the \\ UNITED STATES DEPARTMENT OF ENERGY \\ under Contract DE-AC05-76RL01830
}

Printed in the United States of America

Available to DOE and DOE contractors from the

Office of Scientific and Technical Information,

P.O. Box 62, Oak Ridge, TN 37831-0062;

ph: (865) 576-8401

fax: $(865)$ 576-5728

email: reports@adonis.osti.gov

Available to the public from the National Technical Information Service

5301 Shawnee Rd., Alexandria, VA 22312

ph: (800) 553-NTIS (6847)

email: orders@ntis.gov $<$ http://www.ntis.gov/about/form.aspx $>$

Online ordering: http://www.ntis.gov

This document was printed on recycled paper.

(8/2010) 


\title{
Demand Response Performance of GE Hybrid Heat Pump Water Heater
}

\author{
SH Widder \\ JM Petersen \\ GB Parker \\ MC Baechler
}

July 2013

Prepared for

the U.S. Department of Energy

under Contract DE-AC05-76RL01830

Pacific Northwest National Laboratory

Richland, Washington 99352 



\section{Summary}

Increasing penetration of heat pump water heaters (HPWHs) in the residential sector will offer an important opportunity for energy savings, with a theoretical energy savings of up to $63 \%$ per water heater ${ }^{1}$ and up to $11 \%$ of residential energy use (EIA 2009). However, significant barriers must be overcome before this technology will reach widespread adoption in the Pacific Northwest region and nationwide. One barrier is that the demand response (DR) performance and characteristics of HPWHs is unknown. Previous research has demonstrated the potential of electric resistance water heaters (ERWHs) to provide significant grid stability and control benefits through demand-side management, or DR, strategies (Diao et al. 2012). However, if ERWHs are to be replaced with HPWHs to improve residential energy efficiency, it is important to understand the DR characteristics of HPWHs and how these characteristics will impact DR programs and overall grid stability now and in the future.

This project evaluates and documents the DR performance of an HPWH as compared to an ERWH for two primary types of DR events: peak curtailments and balancing reserves. The experiments were conducted with General Electric (GE) second-generation "Brillion"TM"-enabled GeoSpring ${ }^{\mathrm{TM}}$ hybrid water heaters in the Pacific Northwest National Laboratory (PNNL) Lab Homes², with one GE GeoSpring water heater operating in "Standard" electric resistance mode to represent the baseline and one GE GeoSpring water heater operating in "Heat Pump" mode to provide the comparison to heat pump-only DR. Signals were sent simultaneously to the two water heaters in the side-by-side PNNL Lab Homes under highly controlled, simulated occupancy conditions. It is expected that "Hybrid" DR performance, which would engage both the heat pump and electric elements, could be interpolated from these two experimental extremes.

Based on the data collected in these DR experiments, both ERWHs and HPWHs are capable of performing peak curtailment and regulation services. However, their characteristics differ, as can be seen in Table 5.1, which shows the average impact on power use during the DR event, energy use during the DR event, and daily energy use for ERWH and HPWH for peak curtailment, 1-2 hour balancing events when generation and load are mismatched either due to higher load than generated power (INC events) or greater power generation than available load (DEC events). In general, the HPWH has much lower power use than the ERWH (587 Watts [W] versus 4,650 W) and provides approximately $38 \%$ of the potential to reduce load for peak curtailment or INC balancing events of the ERWH. The ERWH provides more dynamic response with a high magnitude of power increase or decrease per water heater. However, the HPWH has longer and more frequent operating times, which means the HPWH has a higher likelihood of being able to respond when an INC event or peak curtailment is called for. In addition, the inherent efficiency savings of HPWHs $(61.7 \pm 1.7 \%$, as measured in the PNNL Lab Homes) will result in some permanent peak savings as well.

However, the DEC response of the HPWH is limited during parts of the day when hot water use is especially high. During the night when there is little to no hot water draw activity, the HPWH has significant capacity to increase load, since it takes much longer for increases in tank temperature to saturate, as compared to an ERWH.

\footnotetext{
${ }^{1}$ Based on the DOE test procedure (10 CFR 430.32(d)) and comparison of an ERWH (Energy Factor, EF = 0.90) versus a HPWH $(\mathrm{EF}=2.4)$

${ }^{2}$ http://labhomes.pnnl.gov/
} 
Table S.1. Average Power Draw Impact (W), Average Energy Impact during DR Event $(\mathrm{W} \cdot \mathrm{h})$, and Average Daily Energy Impact $(\mathrm{W} \cdot \mathrm{h} /$ day) of Peak Curtailment, INC Balancing, and DEC Balancing Events for the HPWH and ERWH. ${ }^{1}$

\begin{tabular}{|c|c|c|c|c|c|c|}
\hline Experiment & Duration & $\begin{array}{c}\text { Water } \\
\text { Heater } \\
\text { Mode }\end{array}$ & $\begin{array}{c}\text { Average } \\
\text { Power } \\
\text { Draw } \\
\text { Impact }(W)\end{array}$ & $\begin{array}{c}\text { Average Energy } \\
\text { Impact During } \\
\text { DR Event } \\
(\mathbf{W} \cdot \mathbf{h})\end{array}$ & $\begin{array}{c}\text { Average Daily } \\
\text { Energy Impact } \\
(\mathbf{W} \cdot \mathbf{h} / \text { day })\end{array}$ & $\begin{array}{c}\text { Number } \\
\text { Equivalent } \\
\text { HPWH/ } \\
\text { ERWH }\end{array}$ \\
\hline Peak & 3 hours & HP & -439 & $-1,285$ & -498 & 2.64 \\
\hline Curtailment & & ER & $-1,158$ & $-3,320$ & 258 & \\
\hline \multirow{2}{*}{$\begin{array}{l}\text { INC } \\
\text { Balancing* }\end{array}$} & 1 hour & HP & -442 & -442 & -159 & 2.67 \\
\hline & & ER & $-1,185$ & $-1,185$ & 86 & \\
\hline DEC & 1 hour & HP & 220 & 220 & -158 & $17.1 * *$ \\
\hline Balancing & & ER & 1,174 & 1,174 & 1,543 & \\
\hline $\begin{aligned} & *=\text { does no } \\
& * *=\text { ranges } 1 \\
& \text { significantl }\end{aligned}$ & $\begin{array}{l}\text { lude } 2 \text { a.n } \\
2.12 \text { for } \\
\text { creased. }\end{array}$ & $\begin{array}{l}\text { C balc } \\
\text { l. ever }\end{array}$ & $\begin{array}{l}\text { g event, fo } \\
50.6 \text { for } 8\end{array}$ & $\begin{array}{l}\text { ch both water } \\
\text { EC event, wh }\end{array}$ & $\begin{array}{l}\text { s had zero load } \\
\text { WH ramping c }\end{array}$ & ty is \\
\hline
\end{tabular}

In Table S.1, the number of HPWHs that would be required to participate in a DR program to provide the same magnitude of power increase or reduction as a single ERWH is also tabulated.

Regarding occupant comfort, decreased hot water delivery temperature was monitored for all DR events and differences of up to $15^{\circ} \mathrm{F}$ (from $125^{\circ} \mathrm{F}$ to $110^{\circ} \mathrm{F}$ ) were observed for the HPWH during peak curtailment and INC events. However, an extremely high hot water draw profile of 130 gallons per day was implemented to exaggerate consumer impacts. Based on the results of these experiments, decreased hot water delivery temperature is not likely to be an issue for the majority of participants in a DR program providing peak curtailment or INC balancing services even when only the heat pump is used to heat water.

However, the DR performance explored in these experiments represents only an initial indication of the relative response of HPWHs as compared to ERWHs under a given, worst-case draw profile and with the GE GeoSpring Hybrid HPWH. To validate the extrapolation of these results to other sizes and types of water heaters and the variety of draw profiles experienced in the field, further research is required.

\footnotetext{
${ }^{1}$ Positive numbers indicate increased energy use and negative numbers indicate decreased energy use.
} 


\section{Acknowledgments}

This project was funded by the U.S. Department of Energy, Energy Efficiency and Renewable Energy Building America Program (Eric Werling and Sam Rashkin, Program Managers); the Bonneville Power Administration (Kacie Bedney, Project Manager); and the U.S. Department of Energy, Office of Electricity Delivery and Energy Reliability (Dan Ton, Program Manager). Additional support was provided by the project partners Northwest Energy Works (Tom Hews/Brady Peeks) and GE Appliances (Scott Schaeffer).

The authors also wish to acknowledge the contributions of other PNNL staff: Susan Sande for her assistance in procuring equipment and overseeing the Lab Homes modifications, Jamie Spangle for her financial expertise, Maura Zimmerschied for editorial support, Todd Samuel for his consistent and significant management support, Marye Hefty for her leadership and intuition, Nathan Bauman for his metering expertise, Viraj Srivastava for his assistance on commissioning the GE Nucleus ${ }^{\mathrm{TM}}$ energy

managers, Jeremy Brandstetter and Bora Akyol for their assistance with the Lab Homes wireless, Spencer Gilbride and Austin Winkelman for their assistance in implementing experiments, and other Lab Homes researchers who accommodated this experiment and abided by the schedule.

The authors also acknowledge the technical support provided by Greg Sullivan, Principal, Efficiency Solutions, LLC, Richland, Washington, for assistance with occupancy simulation development, metering, and data collection. 


\section{Acronyms and Abbreviations}

BA

BPA

CSA

DEC

DR

EF

ERWH

gal/day

GE

HPWH

HVAC

INC

$\mathrm{kW}$

LBNL

LHA

LHB

NEEA

PNNL

W

$\mathrm{W} \cdot \mathrm{h}$

WH

VDC
Building America

Bonneville Power Administration

Canadian Standards Association

increase load (decrease in generation capacity is needed)

demand response

Energy Factor

electric resistance water heater

gallons per day

General Electric

heat pump water heater

heating, ventilating and air conditioning

decrease load (increase in generation capacity is needed)

kilowatt

Lawrence Berkeley National Laboratory

Lab Home A

Lab Home B

Northwest Energy Efficiency Alliance

Pacific Northwest National Laboratory

watt

watt-hour

water heater

volts direct current 


\section{Contents}

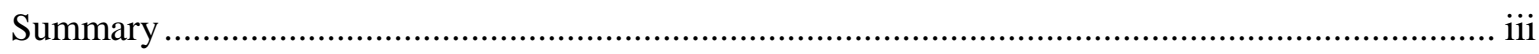

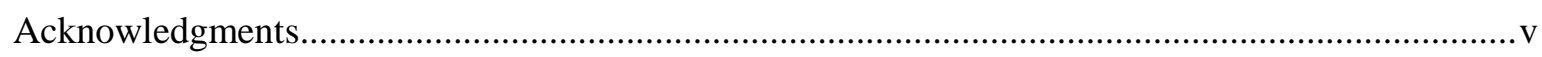

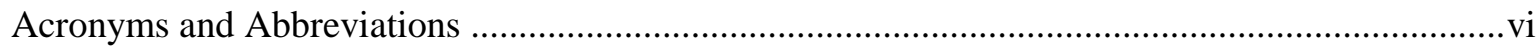

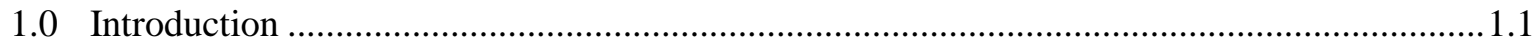

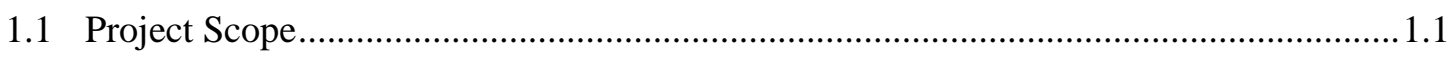

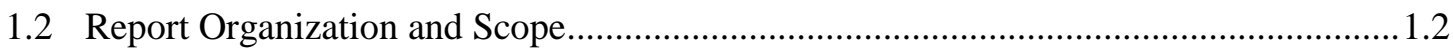

2.0 Background on Demand Response with Water Heaters ...................................................2.1

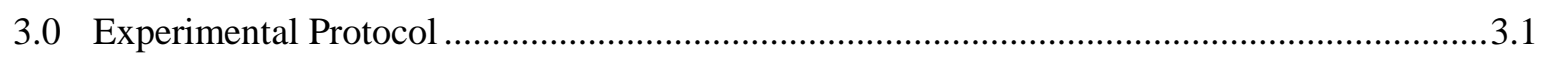

3.1 Demand Response Events ................................................................................... 3.1

3.2 GE Generation II GeoSpring Hybrid Water Heater .................................................... 3.3

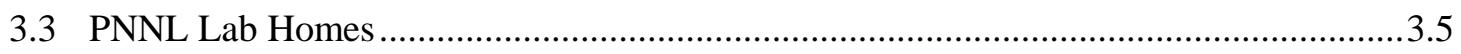

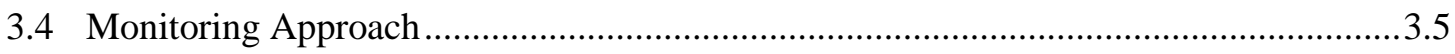

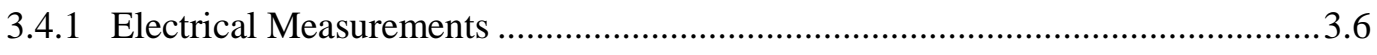

3.4.2 Temperature and Environmental Sensors........................................................ 3.6

3.4.3 Data Acquisition System ............................................................................. 3.7

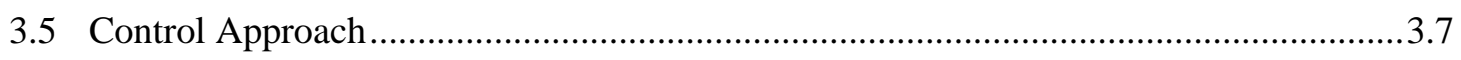

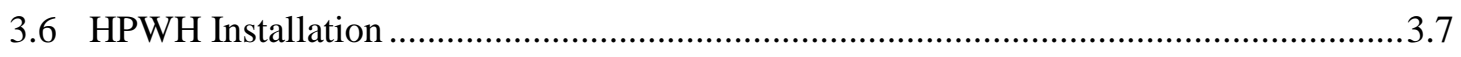

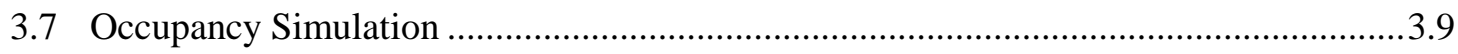

3.7.1 Hot Water Draw Profile ................................................................................ 3.9

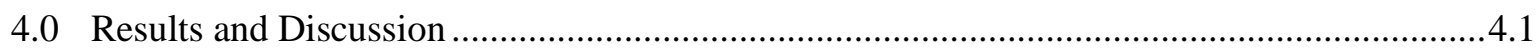

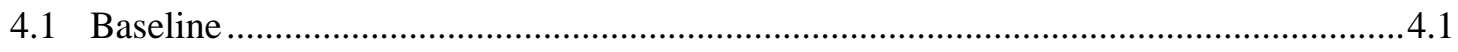

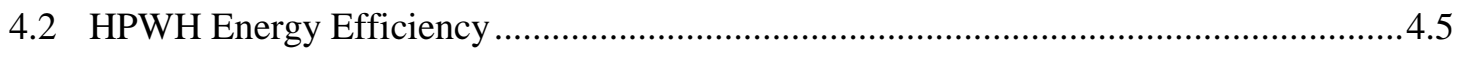

4.3 Peak Curtailment Events ................................................................................... 4.6

4.3.1 Afternoon Peak Curtailment.......................................................................... 4.6

4.3.2 Evening Peak Curtailment ......................................................................... 4.10

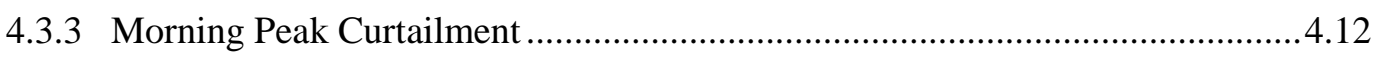

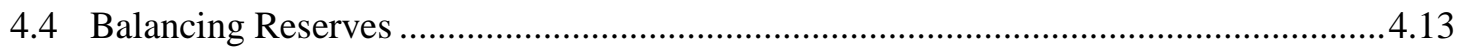

4.4.1 Generation INC Balancing Events ..............................................................4.14

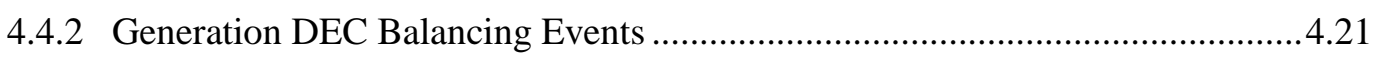

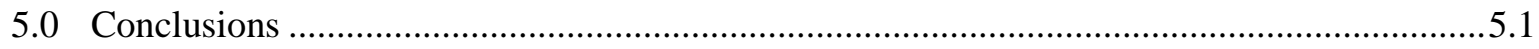

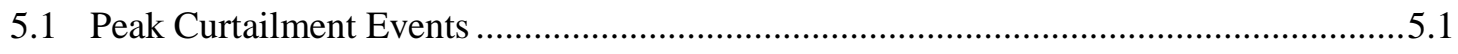

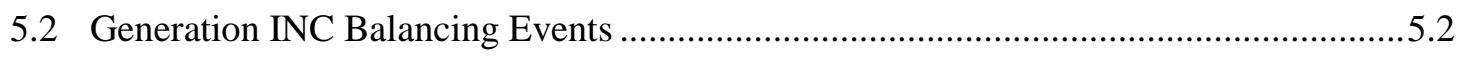

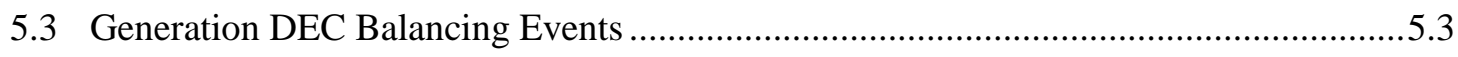

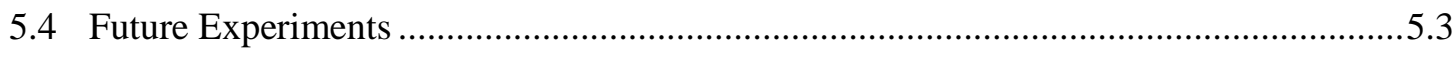

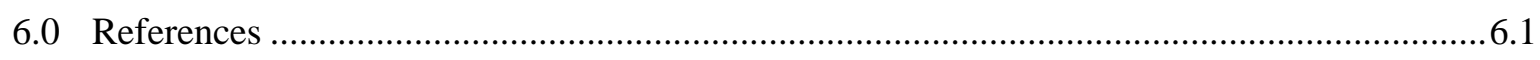

Appendix A - Occupancy Simulation: Electrical Loads ............................................................... A.1 
Appendix B - Alternate Hot Water Draw Profiles .............................................................. B. 1

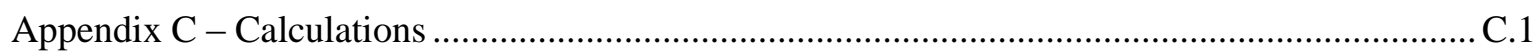

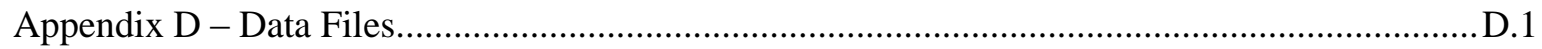




\section{Figures}

3.1. Example of Power Use where the DR Power Profile Receives and Responds to a DR Signal, as Compared to the Baseline Power Profile During a Peak Power Period for the Utility

Service Territory.

3.2. Diagram of Key Components in a Unitary HPWH................................................................... 3.3

3.3. GE's Nucleus Home Energy Management Approach Using "Brillion” Technology ...............3.4

3.4. GE Gen-II GeoSpring HPWH Installed in Lab Home Water Heater Closet ........................... 3.8

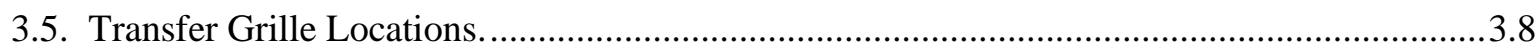

4.1. Lab Home A Electric Resistance Water Heater Daily and Average Load Profiles .................4.1

4.2. Lab Home B Electric Resistance Water Heater Daily and Average Load Profiles .................4.2

4.3. Lab Home A Heat Pump Water Heater Daily and Average Load Profiles ............................. 4.2

4.4. Lab Home B Heat Pump Water Heater Daily and Average Load Profiles ............................. 4.3

4.5. Average Daily Water Heater Energy Use Profile for Lab Home A and Lab Home B in Electric Resistance Mode.

4.6. Average Daily Water Heater Energy Use Profile for Lab Home A and Lab Home B in Heat Pump Mode.

4.7. Hourly Water Use and Energy Use of Unducted HPWHs in Lab Home A and Lab Home B for One Day during the Baseline Period.

4.8. GE GeoSpring HPWH Energy Use as Compared to an ERWH Under Baseline Operation with no DR Response.

4.9. Power Draw from ERWH and HPWH for One Day during the Peak Curtailment Events......4.7

4.10.Afternoon Peak Curtailment Hourly Average Water Heater Energy Use Profile for the HPWH and ERWH with and without DR Signals....

4.11.Hot Water Outlet Temperature of ERWH and HPWH during an Afternoon Peak Curtailment4.10

4.12.Evening Peak Curtailment Hourly Average Water Heater Energy Use Profile for the HPWH and ERWH with and without DR Signals.

4.13.Hot Water Outlet Temperature of ERWH and HPWH during an Afternoon Peak Curtailment4.12

4.14.Morning INC Balancing Event Hourly Average Water Heater Energy Use Profile for the HPWH and ERWH with and without DR Signals

4.15.Hot Water Outlet Temperature of ERWH and HPWH during Morning INC Balancing Event4.16

4.16.Afternoon INC Balancing Event Hourly Average Water Heater Energy Use Profile for the HPWH and ERWH with and without DR Signals.

4.17.Hot Water Outlet Temperature of ERWH and HPWH during Afternoon INC Balancing Event.

4.18.Evening INC Balancing Event Hourly Average Water Heater Energy Use Profile for the HPWH and ERWH with and without DR Signals

4.19.Hot Water Outlet Temperature of ERWH and HPWH during Evening INC Balancing Event4.20

4.20.Morning DEC Balancing Event Hourly Average Water Heater Energy Use Profile for the HPWH and ERWH with and without DR Signals

4.21.Power Draw from ERWH and HPWH for One Day during the Morning DEC Balancing Event. 
4.22.Afternoon DEC Balancing Event Hourly Average Water Heater Energy Use Profile for the HPWH and ERWH with and without DR Signals

4.23.Evening DEC Balancing Event Hourly Average Water Heater Energy Use Profile for the HPWH and ERWH with and without DR Signals

4.24.Hot Water Outlet Temperature of ERWH and HPWH during a Day When Morning and Evening DEC Balancing Events Were Implemented

4.25.Evening DEC Balancing Event Hourly Average Water Heater Energy Use Profile for the HPWH and ERWH with and without DR Signals

4.26.Late Night DEC Balancing Event Hourly Average Water Heater Energy Use Profile for the HPWH and ERWH with and without DR Signals .........................................................4.29 


\section{Tables}

S.1. Average Power Draw Impact, Average Energy Impact during DR Event, and Average Daily Energy Impact of Peak Curtailment, INC Balancing, and DEC Balancing Events for the HPWH and ERWH. .

3.1. Schedule of Type, Duration, and Purpose of Demand-Response Experiments ........................3.2

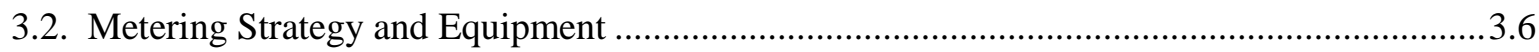

3.3. Domestic Hot Water Heater Daily Use by End Use ..........................................................10

4.1. Baseline Daily Energy Use for HPWH and ERWH and 95\% Confidence Interval................4.4

4.2. Average Power Draw Impact, Average Energy Impact during DR Event, and Average Daily Energy Impact of Afternoon Peak Curtailment for the HPWH and ERWH.....

4.3. Average Power Draw Impact, Average Energy Impact during DR Event, and Average Daily Energy Impact of Evening Peak Curtailment for the HPWH and ERWH.

4.4. Average Power Draw Impact, Average Energy Impact during DR Event, and Average Daily Energy Impact of Morning Peak Curtailment for the HPWH and ERWH.

4.5. Average Power Draw Impact, Average Energy Impact during DR Event, and Average Daily Energy Impact of Morning INC Balancing Event for the HPWH and ERWH.

4.6. Average Power Draw Impact, Average Energy Impact during DR Event, and Average Daily Energy Impact of Afternoon INC Balancing Event for the HPWH and ERWH.

4.7. Average Power Draw Impact, Average Energy Impact during DR Event, and Average Daily Energy Impact of Evening INC Balancing Event for the HPWH and ERWH.

4.8. Average Power Draw Impact, Average Energy Impact during DR Event, and Average Daily Energy Impact of Late Night INC Balancing Event for the HPWH and ERWH.

4.9. Average Power Draw Impact, Average Energy Impact during DR Event, and Average Daily Energy Impact of Morning DEC Balancing Event for the HPWH and ERWH.

4.10.Average Power Draw Impact, Average Energy Impact during DR Event, and Average Daily Energy Impact of Afternoon DEC Balancing Event for the HPWH and ERWH.

4.11.Average Power Draw Impact, Average Energy Impact during DR Event, and Average Daily Energy Impact of Evening DEC Balancing Event for the HPWH and ERWH.

4.12. Average Power Draw Impact, Average Energy Impact during DR Event, and Average Daily Energy Impact of Late Night DEC Balancing Event for the HPWH and ERWH.

5.1. Average Power Draw Impact, Average Energy Impact during DR Event, and Average Daily Energy Impact of Peak Curtailment, INC Balancing, and DEC Balancing Events for the HPWH and ERWH. 



\subsection{Introduction}

Water heating represents approximately $18 \%$ of residential energy consumption, or 1.8 Quads annually (EIA 2009) and efficient water heater options are necessary to achieve significant energy savings in the residential sector. Heat pump water heaters (HPWH) offer the only efficient option for the $41 \%$ of homes with electrically heated water heaters, with a theoretical energy savings of up to $63 \%{ }^{1}$ Previous research has demonstrated the laboratory performance of HPWHs and has shown savings of 47 to $63 \%$ are possible, based on standardized testing protocols (BPA 2011).

However, significant barriers must be overcome before this technology will reach widespread adoption in the Pacific Northwest region and nationwide. One barrier noted by the Northwest Energy Efficiency Alliance (NEEA) is that HPWH products are not ideal for northern climates, especially when installed in conditioned spaces, as there may be complex interactions with the homes' space conditioning systems for units installed in conditioned spaces (Kresta 2012). Modeling studies performed for the Pacific Northwest indicate that the installation location of HPWHs can significantly impact their performance and the resultant whole-house energy savings (Hadley et al. 2012). As a result, NEEA's Northern Climate HPWH Specification, which describes the characteristics a HPWH must have to be incentivized in cold climates in the Pacific Northwest, requires exhaust ducting for their Tier II product (NEEA 2012a).

In addition, if exhaust ducting on HPWHs is found to be beneficial in some or all climates, it will be important to understand the source of supply air and the implications for interior depressurization, particularly for tight homes and homes in high-radon areas. NEEA's Northern Climate HPWH Specification requires full ducting for a Tier III product and new Northwest Energy Efficient Manufactured Housing (NEEM) specifications may need similar requirements (Larson et al. 2012).

Another barrier is the impact of HPWHs on demand-response (DR) programs, since HPWH DR characteristics are currently unknown. Many utilities currently employ electric resistance water heaters (ERWHs) to reduce peak load by turning off the water heater during times of peak demand. Some utilities are also demonstrating the potential of using HPWHs to increase load for areas with high renewable energy penetration and to provide additional balancing and ancillary (voltage regulation) services. There is a need to understand DR characteristics of HPWHs as compared to ERWHs, including dispatchable kilowatts $(\mathrm{kW})$, thermal capacity and response time, to effectively integrate HPWHs with utility DR programs.

\subsection{Project Scope}

This HPWH demonstration examines the overall performance and operation of HPWHs in a conditioned space with a number of supply and/or exhaust ducting configurations and the interactions between the HPWH and the home's heating/cooling system. Space conditioning impacts of HPWHs include the impact on the heating, ventilating and air conditioning (HVAC) system and whole-house energy consumption, as well as thermal comfort issues that could affect occupant satisfaction and market acceptance of these technologies. The project compares the performance of an HPWH with no ducting,

\footnotetext{
${ }^{1}$ Based on the DOE test procedure (10 CFR 430.32(d)) and comparison of an ERWH (Energy Factor, EF = 0.90) versus a HPWH $(\mathrm{EF}=2.4)$
} 
exhaust ducting, and full ducting (supply and exhaust) under identical occupancy schedules and hot water draw profiles in the Pacific Northwest National Laboratory (PNNL) Lab Homes. In addition, this project characterizes the DR of this second-generation HPWH to various price signals.

The General Electric (GE) second-generation GeoSpring hybrid water heater is "Brillion"-enabled and therefore is grid-friendly and operates as part of the GE Nucleus configuration of smart-grid-enabled appliances. That is, the HPWH can accept price signals and respond accordingly to either INC (decrease load) or DEC (increase load) events to help respond to variable renewable resources or temporary mismatches of load and generation capacity on the grid (e.g., from excess wind generation). It is important that utilities and grid operators understand how HPWHs can provide DR services given that they operate differently from a conventional ERWH and their penetration in the Pacific Northwest and across the nation is anticipated to grow substantially over the next decade.

The results of this project are analysis based on independent field data that can be applied in several ways, both regionally and nationwide, to help enable to deployment of HPWHs. Key analysis results include: quantification of the whole-house energy impacts of installing an HPWH in a conditioned space with and without exhaust ducting, calibration and refinement of whole-house energy models to characterize the performance of HPWHs in DR programs, and results that support the deployment and market penetration of new, high-performance manufactured and site-built homes with HPWHs in all climate zones.

\subsection{Report Organization and Scope}

This report presents the results of the HPWH DR evaluation, which documents the DR capability of the GE GeoSpring HPWH for peak load reduction and regulation services. The following sections describe the experimental protocol and test apparatus used to collect data, present the baselining procedure, discuss the results of the simulated DR events for the HPWH and ERWH, and provide key conclusions based on the collected data. A final report presenting the results of the experiments evaluating the HPWH performance and space conditioning impacts of exhaust and full ducting will be available in December 2013. For more information regarding these experiments as they are conducted, contact the research team at labhomes@pnnl.gov. 


\subsection{Background on Demand Response with Water Heaters}

Traditionally, the electric power grid has been operated such that generation resources are controlled to match the variable demand of residential, commercial, and industrial loads on continuous basis. This includes services such as meeting peak demand; regulation and contingency services for providing consistent and reliable power; and frequency response to make sure the frequency of supplied power remains within a tight tolerance of 60 Hertz. However, with the increased communication and control capabilities inherent in the smart grid, it is now possible to dynamically modulate loads to match supply more conveniently and cost-effectively than the previous generation-side control. Such a strategy, of controlling demand rather than supply, is referred to as demand-side management or DR (Lu et al. 2011).

DR benefits include increased system reliability, defrayed cost of new infrastructure investment, improved system efficiency, and decreased carbon emissions through increased penetration of intermittent renewable resources (Lu et al. 2011).

When considering grid stability, reliability and economics, several types of DR are required:

- Peak curtailment, or peak load reduction, which drops noncritical loads for a period of 4-6 hours during the time when power use is highest and the strain on the grid is greatest. This can decrease use of inefficient, fossil fuel-fired "peaking plants" that exist solely to generate electricity during the peak 4-6 hour period and are otherwise turned down or off.

- Balancing reserves, or load following, responds to hourly or sub-hourly changes in generation capacity either due to inherent variability in the generation resource or due to large disturbances in the grid (e.g., transmission fault) (Diao et al. 2012). As increasing amounts of wind and solar are introduced on the grid, the need for balancing to respond to fluctuations in wind speed or insolation will be needed (Konodoh et al. 2011). Using DR for balancing reserves can also increase overall grid efficiency and decrease stress on mechanical generators from frequent ramping (Konodoh et al. 2011).

- Ancillary services, or regulation support, which consists of adapting to sub-minute fluctuations in voltage or frequency to maintain consistent electricity service and distribution. Previous studies have also demonstrated a strong link between increased renewable penetration and ancillary service requirements (Ela et al. 2011; Makarov et al. 2009; Loutan 2009).

In a residential environment, inertial loads such as water heaters, air conditioners, and refrigerators accommodate DR most easily because their electrical energy input can be changed with minimal impact on the customer or the utility of the appliance (Saker et al. 2011). Specifically, residential ERWHs have been identified as ideal candidates for DR because they contain significant thermal storage, they contribute a significant amount of the residential load, they have relatively high power consumption and a large installed base, and they follow a consistent load pattern that is often coincident with utility peak power periods (Sepulveda et al. 2010; Diao et al. 2012). Also, an ERWH is essentially a resistor, which is not affected by frequent switching and does not require reactive power support to operate (Diao et al. 2012). 
Several modeling studies have previously evaluated the potential of ERWH to provide peak curtailment, load following and ancillary services and found significant potential and benefit for ERWH to perform these grid functions (Mathieu et al. 2012; Sepulveda et al. 2010; Konodoh et al. 2011; Diao et al. 2012; Saker et al. 2011; Lu et al. 2011). However, no extensive field evaluation has verified these model results.

In addition, new HPWH technology has the potential to dramatically decrease the electricity use of residential water heating. However, use of more efficient heat pump technology may impact potential of water heaters to perform grid services. While utilities and efficiency advocates have significant interest in encouraging the adoption of HPWHs, no modeling or field studies were identified that evaluated the DR potential of HPWHs in comparison to that provided by ERWHs. If ERWHs are to be replaced with HPWHs to improve residential energy efficiency, it is important to understand how such a change will impact DR programs and overall grid stability now and in the future. 


\subsection{Experimental Protocol}

The purpose of this project is to evaluate the energy performance and DR characteristics of GE's second-generation GeoSpring ${ }^{\mathrm{TM}}$ hybrid water heater in controlled experiments in PNNL's matched pair of Lab Homes. ${ }^{1}$ The performance of the HPWH as it responds to DR signals simulating peak curtailment events and balancing reserves will be measured and compared to those of a conventional 50-gallon ERWH. During these experiments, both homes will deploy identical simulated occupancy and hot water use schedules so that the performance and effects of the HPWH will be isolated from all other variables.

The following sections describe the research protocol in more detail, the key experimental resources and equipment, the control and monitoring approach, the HPWH installation, and the identical occupancy schedules implemented in both homes.

\subsection{Demand Response Events}

The experimental plan to evaluate and document the DR performance of an HPWH as compared to an ERWH consists of two primary types of DR events: peak curtailments and balancing reserves.

Peak curtailments, or peak load reduction events, are typically 4-6 hours in length and represent the time when the load is highest on a given day and throughout the year. An example of a "generic" peak curtailment event is depicted in Figure 3.1 where the red dashed line indicates the power use when a "conserve" signal is responded to. As Figure 3.1 shows, the conserve signal reduces the power use at the time associated with the peak power demand for the entire service territory (the green dashed line indicates the baseline power profile for the BPA service territory).

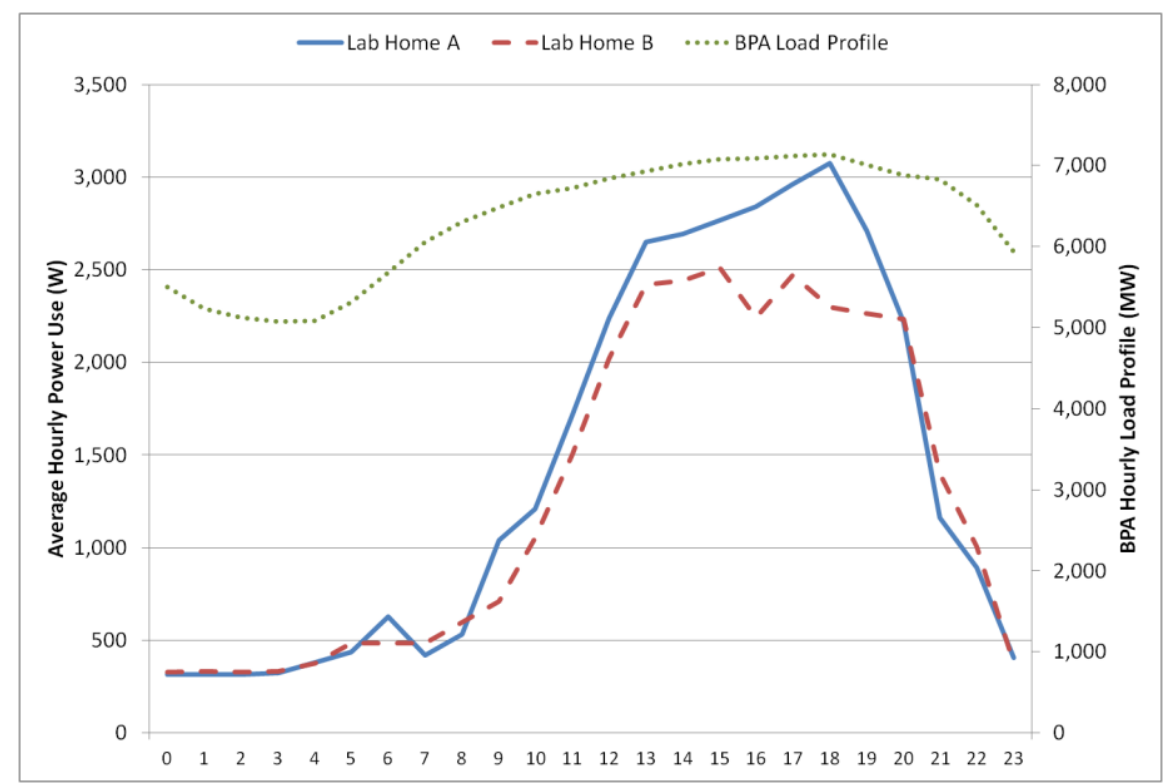

Figure 3.1. Example of Power Use where the DR Power Profile (red dashed line) Receives and Responds to a DR Signal, as Compared to the Baseline Power Profile (blue solid line) During a Peak Power Period for the Utility Service Territory (green dotted line).

\footnotetext{
${ }^{1}$ (http://labhomes.pnnl.gov)
} 
Peak curtailment events are typically required in the afternoon or evening in most parts of the country, corresponding with the hottest part of the day when many working families are returning home. However, peak power periods can also occur in the morning, when many people are getting up, showering, and preparing for the day's activities. The Bonneville Power Administration (BPA), for example, has its most significant peak in the morning during the winter months. As a result, morning (7:00 a.m. to 10:00 a.m.), afternoon (2:00 p.m. to 5:00 p.m.), and evening (6:00 p.m. to 9:00 p.m.) events were simulated in the Lab Homes, as described in Table 3.1.

Balancing reserves or load following events are typically 1-2 hours in length and are typical of those necessary for renewable integration. In addition, balancing reserves can be implemented for either a generation shortage or surplus. These two types of balancing reserves (generation shortage or generation surplus) are called INC and DEC, respectively. For INC events, electricity demand is greater than supply and load shedding is required. For DEC events, generation is outpacing electricity demand and increasing load will help to stabilize the grid. Balancing reserves can be called on at any time. Therefore, morning (8:00 a.m.), afternoon (2:00 p.m.), evening (8:00 p.m.), and late night (2:00 a.m.) events were simulated to generally characterize the water heater's response at different times of day. It is anticipated that the general findings from these periods could be extrapolated to other time periods based on the simulated hot water draw for that hour and the expected hot water usage pattern for other times of day.

Table 3.1. Schedule of Type, Duration, and Purpose of Demand-Response Experiments

\begin{tabular}{|c|c|c|c|c|}
\hline Experiment & $\begin{array}{l}\text { Experiment } \\
\text { Description }\end{array}$ & Time & Duration & Purpose of Experiment \\
\hline $\begin{array}{l}\text { A.M. Peak } \\
\text { Curtailment }\end{array}$ & $\begin{array}{l}\text { Turn off heating } \\
\text { elements }\end{array}$ & 7:00 a.m. & 3 hours & $\begin{array}{l}\text { Evaluate HPWH load shedding potential } \\
\text { (dispatchable kW and thermal capacity) } \\
\text { as compared to electric resistance baseline } \\
\text { to manage peak load }\end{array}$ \\
\hline $\begin{array}{l}\text { P.M. Peak } \\
\text { Curtailment }\end{array}$ & $\begin{array}{l}\text { Turn off heating } \\
\text { elements }\end{array}$ & 2:00 p.m. & 3 hours & $\begin{array}{l}\text { Evaluate HPWH load shedding potential } \\
\text { (dispatchable kW and thermal capacity) } \\
\text { as compared to electric resistance baseline } \\
\text { to manage peak load }\end{array}$ \\
\hline $\begin{array}{l}\text { EVE Peak } \\
\text { Curtailment }\end{array}$ & $\begin{array}{l}\text { Turn off heating } \\
\text { elements }\end{array}$ & 6:00 p.m. & 3 hours & $\begin{array}{l}\text { Evaluate HPWH load shedding potential } \\
\text { (dispatchable kW and thermal capacity) } \\
\text { as compared to electric resistance baseline } \\
\text { to manage peak load }\end{array}$ \\
\hline $\begin{array}{l}\text { INC } \\
\text { Balancing }\end{array}$ & $\begin{array}{l}\text { Turn off heating } \\
\text { elements }\end{array}$ & $\begin{array}{l}\text { 2:00 a.m. } \\
\text { 8:00 a.m. } \\
\text { 2:00 p.m. } \\
\text { 8:00 p.m. }\end{array}$ & 1 hour & $\begin{array}{l}\text { Evaluate HPWH potential to provide } \\
\text { balancing reserves for dispatchable } \mathrm{kW} \text { as } \\
\text { compared to electric resistance baseline }\end{array}$ \\
\hline $\begin{array}{l}\text { DEC } \\
\text { Balancing }\end{array}$ & $\begin{array}{l}\text { Set tank temp to } \\
135^{\circ} \mathrm{F}\end{array}$ & $\begin{array}{l}\text { 2:00 a.m. } \\
\text { 8:00 a.m. } \\
\text { 2:00 p.m. } \\
\text { 8:00 p.m. }\end{array}$ & 1 hour & $\begin{array}{l}\text { Evaluate thermal capacity of HPWH, as } \\
\text { compared to ERWH, when temperature } \\
\text { set point is increased to } 135^{\circ} \mathrm{F}\end{array}$ \\
\hline
\end{tabular}

During peak curtailment and INC balancing events, disabling the heating function (electric resistance elements or heat pump) was accomplished by changing the water heater mode to "Vacation" and the thermostat setting to $60^{\circ} \mathrm{F}$. Temperatures lower than $100^{\circ} \mathrm{F}$ are only accessible using the "Vacation" 
mode and subsequent testing confirmed that $60^{\circ} \mathrm{F}$ was sufficiently low to simulate turning off the water heater for the duration of the DR events.

Also, all events were performed two to three times to verify consistent operation and validate repeatability and reliability of the DR signal observed in the data. Where the specific DR event was repeated, the average response from all the days implementing that event is reported.

\subsection{GE Generation II GeoSpring Hybrid (Heat Pump) Water Heater}

HPWHs work by transferring heat from the ambient air to the water in the tank via a refrigeration cycle, similar to heat pumps that condition air. This process provides more energy to the water than it uses in electricity. Figure 3.2 shows the key components in an HPWH . Fourteen manufacturers produce unitary HPWHs that qualify for NEEA's Northern Climate Specification (NEEA 2012b). Of these, only one offers commercially available exhaust air ducting, and none offer supply ducting as an option (AirGenerate). Also, only one manufacturer offers integrated DR capability in its unit.

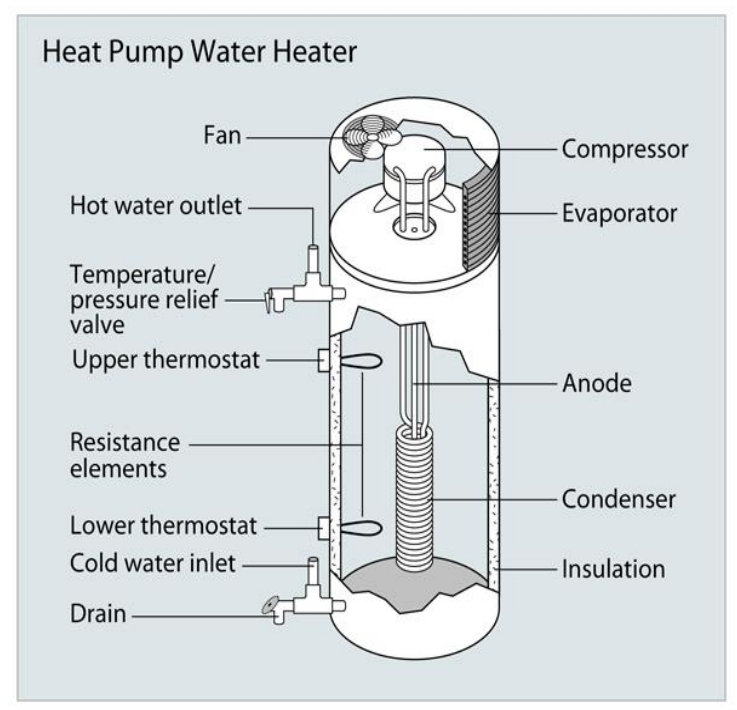

Figure 3.2. Diagram of Key Components in a Unitary HPWH. Source: U.S. DOE; energysavers.gov.

The HPWH selected for evaluation in this project is the second-generation GE GeoSpring Hybrid

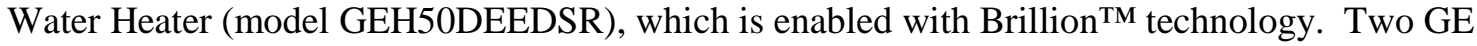
GeoSpring HPWHs were purchased for this project, both of which were manufactured in Louisville, Kentucky. The GE GeoSpring HPWH has a nominal 50-gallon tank and two methods of heating water: a compressor with a coefficient of performance of 2.4 and two 4500 Watt (W) electric elements. The unit is equipped with onboard controls that dictate which heating mode is used to heat water. These modes consist of "Heat Pump," "Hybrid," "High Demand," "Standard," and "Vacation." The specific control strategies employed in each of these modes are explained in detail in documentation on the GE website (GE Appliances 2012) and have been evaluated in the laboratory by Larson and Logsdon (2012). The GE GeoSpring HPWH has a typical operating range between $100^{\circ} \mathrm{F}$ and $140^{\circ} \mathrm{F}$, although temperatures lower than $100^{\circ} \mathrm{F}$ are accessible in the "Vacation" setting. 
To facilitate DR, the GE GeoSpring HPWH receives communication from the Nucleus ${ }^{\mathrm{TM}}$, GE's Home Energy Management System, via ZigBee® communication protocol. The mode and tank set points can be controlled through the Nucleus either by a homeowner or utility employing "conserve" signals or peak pricing. The Nucleus receives these directions wirelessly over the internet from GE's server or through a hard-wired laptop with an Ethernet connection. GE's Brillion technology is designed to operate with a suite of demand-responsive technologies, as depicted in Figure 3.3.

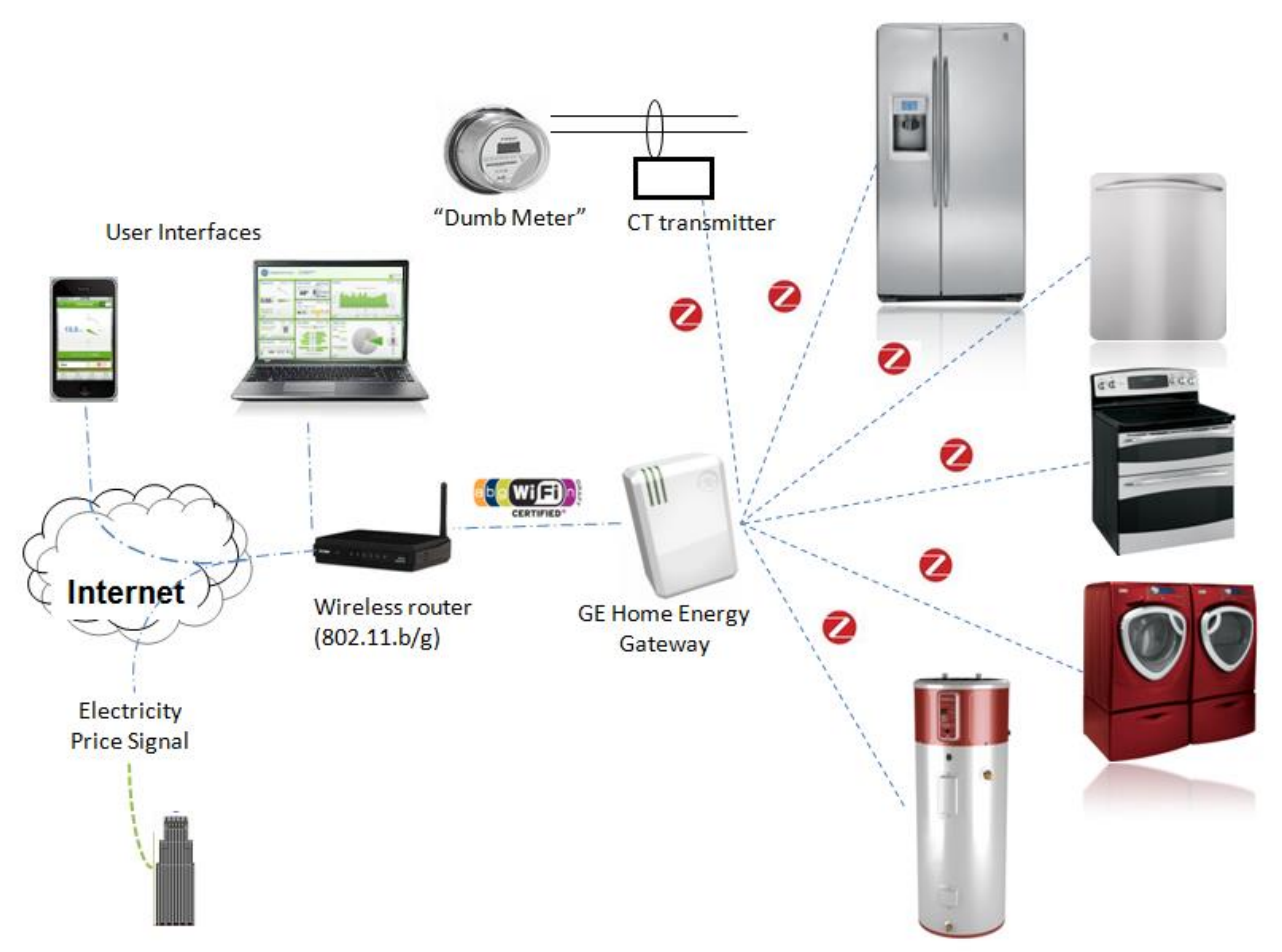

Figure 3.3. GE’s Nucleus Home Energy Management Approach Using “Brillion” Technology

Since the primary goal of the DR experiments in this project is to compare the performance of an ERWH responding to DR signals to the performance of an HPWH responding to similar signals, the HPWH was operated in Heat Pump mode, which disables use of the electric resistance elements. This minimizes the energy use, and thus minimizes the power draw of the HPWH at any time. In this way, Heat Pump mode represents the most extreme divergence from the ERWH performance. It is expected that Hybrid mode DR performance could be derived from a combination of the ERWH and HPWH data, as it would deploy both the heat pump and electric resistance elements at different times. The relative use of electric resistance elements and heat pump is strongly dependent on the draw profile in the home, and will vary in the field. Thus, a comparison of HPWH in Heat Pump mode was considered to be an extreme characterization of the DR performance of an HPWH as compared to an ERWH. As a hybrid HPWH would operate as some combination of the HPWH and ERWH responses, these two data sets are believed to represent the extremes of response for electric water heating technologies to signals from the grid. Further experiments could verify the field performance of an HPWH in Hybrid mode, utilizing both electric resistance elements and heat pump, either with the controls inherent to the HPWH or with controls optimized to perform grid stability services. For example, the HPWH could have DR controls that limited the "rebound" of the HPWH by locking out the electric resistance elements when the HPWH 
was coming back to temperature after a curtailment event, and could have both the heat pump and the electric resistance elements as separate options when calling for load in a DEC event.

The GE GeoSpring HPWH operating in electric resistance only (i.e., Standard) mode serves as the electric resistance baseline for comparison. "Standard" mode is a user-selectable mode that disables the HP operation. The control characteristics of the GE GeoSpring HPWH in Standard mode are believed to be equivalent to a conventional ERWH with an EF of 0.9. ${ }^{1}$ Hereafter, any reference to "ERWH" will refer to the GE GeoSpring HPWH operating in Standard electric resistance mode.

\subsection{PNNL Lab Homes}

The water heaters were installed and the DR experiments were implemented in the PNNL Lab Homes. The PNNL Lab Homes are a unique platform in the Pacific Northwest region for conducting experiments on residential-sector technologies. These electrically heated and cooled 1500 square-foot homes are sited adjacent to one another on the PNNL campus in Richland, Washington, and are fully instrumented with end-use metering (via a 42-circuit panel), indoor and outdoor environmental sensors, and remote data collection. They can be operated to simulate occupancy and thus can evaluate and manage any occupant effects on equipment performance using the control features in the homes. The unique nature of this side-by-side comparison means the homes experience the same weather. This allows for comparison of efficient measures in the experimental home with "baseline" equipment in the baseline home under identical environmental (indoor and outdoor) conditions over the same time period. In addition to providing accurate calculation of the energy consumption and savings associated with a specific technology, the independence of the data from weather allows weather-related factors, such as outdoor air temperature and wind speed, and their effects on savings, to be evaluated as independent variables rather than confounding variables.

For this experiment, the two GE GeoSpring water heaters were installed in the water heater closet in the conditioned space in Lab Home A and Lab Home B. The homes were modified by PNNL for this experiment as described in Section 3.6.

\subsection{Monitoring Approach}

The monitoring approach included metering and system-control activities taking place at both the electrical panel and at the hot water end use or point of use. Monitoring was broken into electrical and temperature/other. Table 3.2 highlights the performance metric (the equipment/system being monitored), the monitoring method and/or point, the monitored variables, the data application, and whether the monitoring existed in the Lab Homes or was newly installed and commissioned as part of this HPWH DR evaluation. All metering was done using Campbell@ Scientific data loggers at 1-minute, 15-minute, and hourly intervals. Metering points in the PNNL Lab Homes not relevant to the HPWH DR experiments and further technical specifications on the controllable breaker panel, data acquisition system, and relevant sensors are described in detail in a previous report (Widder et al. 2012).

\footnotetext{
${ }^{1}$ Determined in accordance with the DOE Test Procedure for Residential Water Heaters (10 CFR 430.23(e)).
} 
Table 3.2. Metering Strategy and Equipment

\begin{tabular}{|c|c|c|c|c|}
\hline Monitored Parameter & $\begin{array}{c}\text { Monitoring } \\
\text { Method/Points }\end{array}$ & $\begin{array}{c}\text { Monitored } \\
\text { Variables }\end{array}$ & Data Application & $\begin{array}{l}\text { Existing or } \\
\text { New? }\end{array}$ \\
\hline \multicolumn{5}{|c|}{ Electrical Power Measurements } \\
\hline $\begin{array}{l}\text { Whole House Electrical } \\
\text { Power and Circuit Level } \\
\text { Power }\end{array}$ & \multirow{4}{*}{$\begin{array}{l}1 \text { Campbell data } \\
\text { acquisition system with } \\
42 \text { current transducers } \\
\text { at electrical power } \\
\text { mains and panel }\end{array}$} & \multirow{4}{*}{$\mathrm{kW}$, amps, volts } & \multirow{4}{*}{$\begin{array}{l}\text { Comparison and } \\
\text { difference } \\
\text { calculations } \\
\text { between homes of } \\
\text { - power } \\
\text { profiles } \\
\text { - time-series } \\
\text { energy use } \\
\text { - differences } \\
\text { and savings } \\
\end{array}$} & \multirow{4}{*}{ Existing } \\
\hline HPWH Electrical Power & & & & \\
\hline $\begin{array}{l}\text { Electric Power for } \\
\text { HPWH Fan }\end{array}$ & & & & \\
\hline $\begin{array}{l}\text { Power for Electric } \\
\text { Heaters }\end{array}$ & & & & \\
\hline \multicolumn{5}{|c|}{ Temperature Measurements } \\
\hline Inlet Water Temperature & Insertion thermocouple & Temp., ${ }^{\circ} \mathrm{F}$ & $\begin{array}{l}\text { Characterize } \\
\text { impact of } \\
\text { incoming water } \\
\text { temperature on } \\
\text { HPWH } \\
\text { performance } \\
\end{array}$ & New \\
\hline $\begin{array}{l}\text { Outlet Water } \\
\text { Temperature }\end{array}$ & Insertion thermocouple & Temp., ${ }^{\circ} \mathrm{F}$ & $\begin{array}{l}\text { Monitor outlet } \\
\text { water temperature } \\
\text { as proxy for tank } \\
\text { temperature }\end{array}$ & New \\
\hline \multicolumn{5}{|c|}{ Flow Rate Measurements } \\
\hline Outlet Water Flow Rate & $\begin{array}{c}\text { Turbine flow meter, in } \\
\text { line with hot water } \\
\text { outlet prior to mixing } \\
\text { valve }\end{array}$ & $\begin{array}{l}\text { Flow rate, } \\
\text { gallons per } \\
\text { minute (gpm) }\end{array}$ & $\begin{array}{l}\text { Verify water } \\
\text { draws are in } \\
\text { accordance with } \\
\text { specified profile }\end{array}$ & New \\
\hline
\end{tabular}

\subsubsection{Electrical Measurements}

In each home, all 42 of the panel electrical breakers were monitored for amperage and voltage. The resulting data were used to calculate apparent and real power $(\mathrm{kVA} / \mathrm{kW})$. All data were captured at 1-minute intervals by the Campbell Scientific data logger.

\subsubsection{Temperature and Environmental Sensors}

Water Temperature. Water temperatures were recorded for the incoming water to the tank and the outgoing water delivered to the fixture. All temperature measurements were taken with type T thermocouples at 1-minute intervals by the Campbell data logger. The inlet water temperature is located on the cold water supply immediately preceding the water heater and the outlet water temperature is located just as the water heater is leaving the tank. Given the close proximity of the outlet hot water temperature measurement to the tank, the hot water delivery temperature is treated as a proxy for tank temperature when water is flowing.

Water Flow Rate. The water flow rate was measured using a low-flow impeller-type flow meter with 375 to 1380 pulses per gallon (0.07-5 gallon or 0.2-20 gallon range, depending on the model) with a 6-24 volts direct current (VDC) output. This data was important to verify that the water draw schedule 
was identical in both homes and to verify overall draw volumes and rates. After installation, it was determined that the meters required field calibration. After field calibration, the flow meter in Lab Home A had a K-factor of 480 and in Lab Home B had a K-factor of 1,371.

\subsubsection{Data Acquisition System}

Data from all sensors were collected via two data acquisition systems, one for environmental sensors and one for energy sensors in each home. Data were downloaded using Internet Protocol (IP) cellular modems. A polling computer, located in the metering lab on the PNNL campus, was connected to each logger using Campbell Scientific software. Data were recorded on 1-minute, 15-minute, and hourly intervals. One-minute data was used for all analysis to capture any short-duration changes in energy use within the home - for example, from a heating element cycling on - and to limit error introduced from averaging over longer time periods. Fifteen-minute and hourly data were not used directly in this experiment. Instead, data were averaged over 1-hour intervals for analysis. Calculated hourly averages were compared to the recorded hourly data as part of the data quality assurance process.

\subsection{Control Approach}

The GE water heaters were controlled via modulating the water heater set point in the Nucleus software platform. Specific DR events were simulated with a preset schedule that was communicated to water heaters from the GE cloud-based server, to simulate how signals would be sent and received in the field. The present schedule was loaded into the Nucleus control servers by GE engineers, due to the fixed and temporary nature of the experiment. As mentioned previously, the set point changes are communicated from the GE server to the Nucleus using WiFi and communicated from the Nucleus to the water heater using ZigBee. Due to internet connectivity issues ${ }^{1}$ experienced at the Lab Homes, the schedule was also checked and implemented manually, as reasonable and feasible. For example, the 2:00 a.m. changes were not implemented manually as it was deemed infeasible to have staff onsite at that time to change the water heater settings. The water heater connectivity issues and limitations of manual changes resulted in some loss of data. Specifically, the morning peak curtailment was not captured in the experimental data. However, the DR performance of the event was estimated based on the afternoon and evening peak curtailment events. See Section 4.3.3 for more details.

\subsection{HPWH Installation}

From December 2012 through February 2013, the Lab Homes were modified to each be equipped with a GE GeoSpring HPWH and a mixing valve. The mixing valve was installed to allow for tank temperatures higher than $140^{\circ} \mathrm{F}$ should elevated tank temperatures be desired in future experiments. The HPWHs were installed in the water heater closet in both homes, as shown in Figure 3.4. Installation of the HPWHs was in accordance with regional protocols developed by NEEA for the Northern Climate Specifications and the GE product installation instructions (Hadley et al. 2012; NEEA 2012a).

\footnotetext{
${ }^{1}$ The network signal at the Lab Homes is both weak and secure, such that sending and receiving signals from unidentified networks is not possible without special permissions to bypass the PNNL firewall.
} 


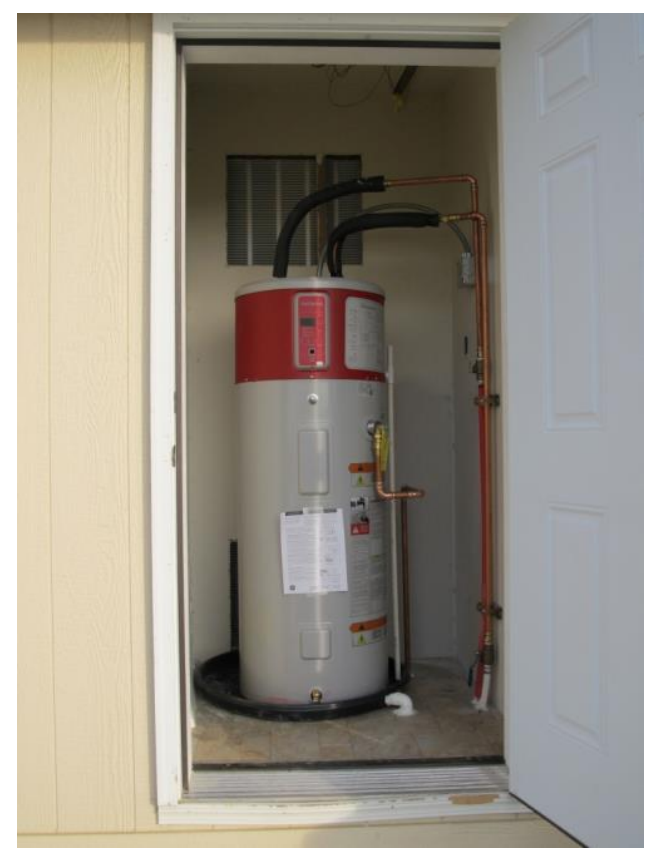

Figure 3.4. GE Gen-II GeoSpring HPWH Installed in Lab Home Water Heater Closet

The water heater closet was modified to allow free airflow with two sets of two 25 " $\times 20$ " metal transfer grilles into the master bedroom closet (adjacent to the water heater closet) and the hallway (adjacent to the master bedroom closet), as indicated in Figure 3.5.
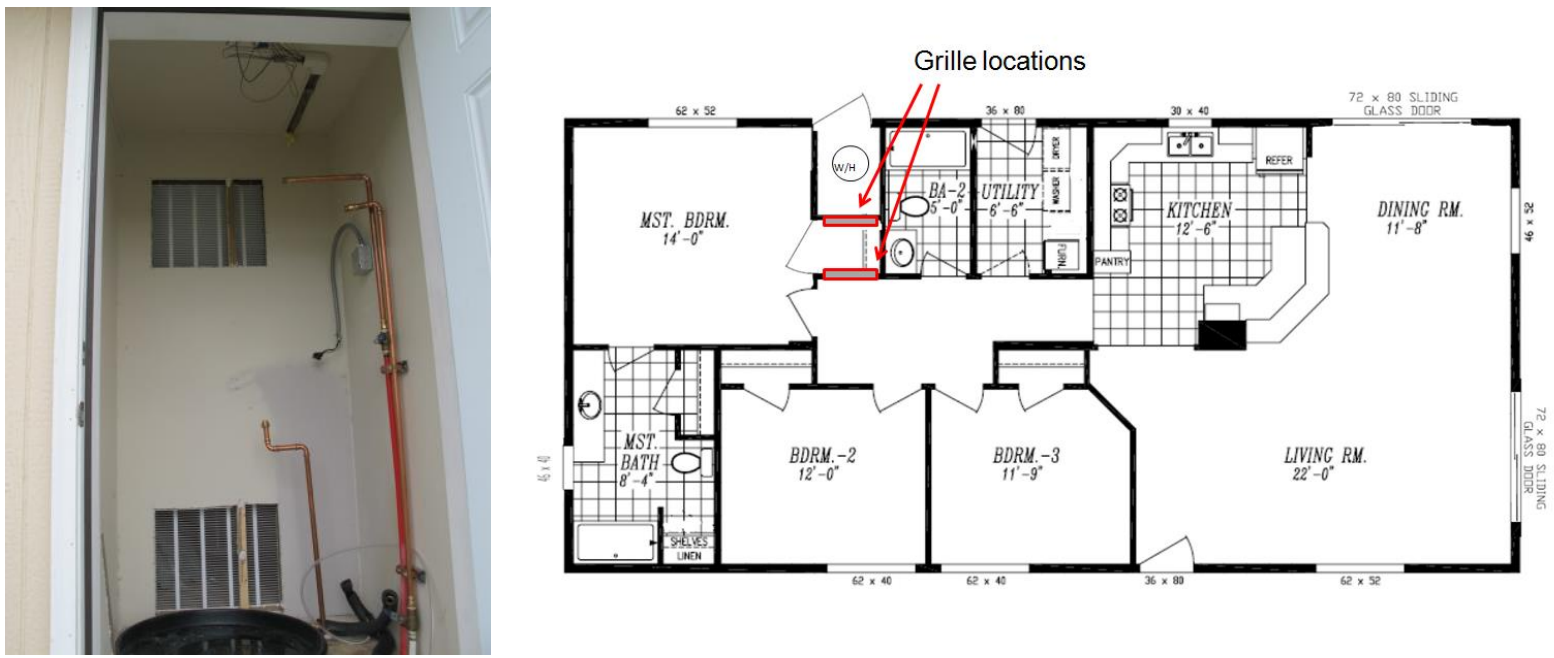

Figure 3.5. Transfer Grille Locations. Left: transfer grilles $(25 " \times 20$ ") installed between water heater closet and adjacent master bedroom closet. Right: location of grilles on wall 1) between water heater closet and master bedroom closet and 2) between master bedroom closet and hallway to provide sufficient free airflow to the water heater closet

One grille was installed low on the wall and one high, to help induce mixing. They were provisioned with magnetic covers to allow for blocking one of the airflow paths to study the impact of grille placement and size on HPWH performance. Each grille area is greater than $100 \%$ of the requirement specified in the GE product literature of 240 square inches (GE Appliances 2013). 
In addition, both GE GeoSpring HPWHs were modified with new control panels and thermal cutouts to enable the tank temperature to be elevated above $140^{\circ} \mathrm{F}$, which is the maximum temperature achievable on the commercially available units. The new control panel and thermal cutouts enable the tank to reach $170^{\circ} \mathrm{F}$, which was the thermostat set point used to validate the ability of these HPWHs in both Standard and Heat Pump mode to provide additional DEC balancing potential; see Section 4.4.2.5.

\subsection{Occupancy Simulation}

To simulate occupancy for the DR experiments, hot water draw profiles were implemented identically in both homes. The hot water draws used a modulating solenoid valve at the kitchen sink hot water supply and were controlled via the Campbell data acquisition system. Other occupancy loads in the homes were simulated via a programmable breaker panel (one per home) employing motorized breakers to simulate sensible loads associated with occupancy, lighting, and equipment and appliance loads. While these loads were implemented identically for the duration of the DR experiments, they are not relevant to the HPWH DR experimental results and key outcomes. The selection of the hot water draw profile is described in the following section. Further information on the other loads used to simulate occupancy is provided in Appendix A.

\subsubsection{Hot Water Draw Profile}

Water heater efficiency is dependent on hot water draw pattern, particularly draw volume and duration. However, the efficiency of tanked hot water heaters is more dependent on long water draws than that of tankless water heaters, which are more sensitive to short, frequent water draws. To select the hot water draw profile in the Lab Homes for the HPWH experiment, PNNL researched other draw profiles implemented by previous research, available standards, and data on typical field usage. The draw profile PNNL selected is described in this section and the full results of PNNL's analysis are presented in Appendix B.

PNNL selected a hot water draw profile that was representative of a typical daily draw pattern for a population of homes, rather than a single home and that was feasible to implement reliably and repeatably using existing equipment in the PNNL Lab Homes. PNNL selected the draw profile based on the Building America House Simulation Protocols, which specify typical daily draw volumes for different appliances based on the number of bedrooms, and an hourly draw pattern based on fraction of total daily load (Hendron and Engebrecht 2010). For a three-bedroom, two-bathroom Lab Home, the Building America House Simulation Protocol recommended a total hot water use of 78.51 gallons per day (gal/day), ${ }^{1}$ assuming a hot water tank temperature of $125^{\circ} \mathrm{F}$ and a delivered (mixed hot and cold) temperature of $110^{\circ} \mathrm{F}$ for showers, baths, and sinks, as shown in Table 3.3.

\footnotetext{
${ }^{1}$ Number of bedrooms $(\mathrm{Nbr})=3$ and number of office units (Nunit $=0$ )
} 
Table 3.3. Domestic Hot Water Heater Daily Use by End Use. Source: Hendron and Engebrecht 2010.

\begin{tabular}{|c|c|c|c|c|}
\hline End Use & $\begin{array}{c}\text { End Use } \\
\text { Water } \\
\text { Temperature }\end{array}$ & Water Use & $\begin{array}{l}\text { Sensible Heat } \\
\text { Gain }\end{array}$ & Latent Heat Gain \\
\hline Clothes washer & $\begin{array}{c}\text { water heater } \\
\text { setpoint }\end{array}$ & $\begin{array}{c}2.35+0.78 \times \mathrm{N}_{\text {br }} \text { gal/day } \\
\text { (hot only) }\end{array}$ & $0^{*}$ & $0^{*}$ \\
\hline Common laundry & $\begin{array}{l}\text { water heater } \\
\text { setpoint }\end{array}$ & $\begin{array}{c}2.47 \mathrm{gal} / \text { day/housing } \\
\text { unit } \\
\text { (hot only) }\end{array}$ & $0^{*}$ & $0^{*}$ \\
\hline Dishwasher & $\begin{array}{c}\text { water heater } \\
\text { setpoint }\end{array}$ & $\begin{array}{c}2.26+0.75 \times \mathrm{N}_{\text {br }} \text { gal/day } \\
\text { (hot only) }\end{array}$ & $0^{*}$ & $0^{*}$ \\
\hline Shower & $110^{\circ} \mathrm{F}$ & $\begin{array}{c}14.0+4.67 \times \mathrm{N}_{\mathrm{br}} \text { gal/day } \\
\text { (hot and cold) }\end{array}$ & $\begin{array}{c}741+247 \times \mathrm{N}_{\mathrm{br}} \\
\text { Btu/day }\end{array}$ & $\begin{array}{c}703+235 \times \mathrm{N}_{\mathrm{br}} \\
\text { Btu/day }(0.70+0.23 \\
\left.\times \mathrm{N}_{\mathrm{br}} \text { pints/day }\right)\end{array}$ \\
\hline Bath & $110^{\circ} \mathrm{F}$ & $\begin{array}{c}3.5+1.17 \times \mathrm{N}_{\mathrm{br}} \text { gal/day } \\
\text { (hot and cold) }\end{array}$ & $\begin{array}{c}185+62 \times \mathrm{N}_{\mathrm{br}} \\
\text { Btu/day }\end{array}$ & $0^{* *}$ \\
\hline Sinks & $110^{\circ} \mathrm{F}$ & $\begin{array}{c}12.5+4.16 \times \mathrm{N}_{\mathrm{br}} \text { gal/day } \\
\text { (hot and cold) }\end{array}$ & $\begin{array}{c}310+103 \times \mathrm{N}_{\mathrm{br}} \\
\text { Btu/day }\end{array}$ & $\begin{array}{c}140+47 \times \mathrm{N}_{\mathrm{br}} \\
\text { Btu/day }(0.14+0.05 \\
\left.\times \mathrm{N}_{\mathrm{br}} \text { pints/day }\right)\end{array}$ \\
\hline Office/public sink & $110^{\circ} \mathrm{F}$ & $\begin{array}{l}0.028 \times \mathrm{N}_{\text {units }} \text { gal/day } \\
\text { (hot and cold) }\end{array}$ & $\begin{array}{l}0.69 \times \mathrm{N}_{\text {units }} \\
\text { Btu/day }\end{array}$ & $\begin{array}{c}0.314 \times \mathrm{N}_{\text {units }} \\
\text { Btu/day }\left(3.14 \times 10^{-4}\right. \\
\left.\times \mathrm{N}_{\text {units }} \text { pints/day }\right)\end{array}$ \\
\hline
\end{tabular}

* Sensible and latent heat gains from appliances are included in the section titled, "Appliances and Miscellaneous Electric Loads."

* Negligible compared to showers and sinks.

PNNL determined the hot-only portion of the $110^{\circ} \mathrm{F}$ water draws based on an energy balance, to define the daily flow rate of $125^{\circ} \mathrm{F}$ to provide the stated volume of $110^{\circ} \mathrm{F}$ water at the tap.

A $125^{\circ} \mathrm{F}$ set point was selected based on the recent Lawrence Berkeley National Laboratory (LBNL) evaluation of field hot water use data, which found that $122.7^{\circ} \mathrm{F}$ was the average tank temperature (Lutz and Melody 2012). The LBNL report also concluded that, based on the available field data, the majority of draws were between approximately 1 and $1.5 \mathrm{gpm}$ and between 1 and 4 minutes in length (Lutz and Melody 2012). The report also defined low, medium, and high daily hot water draws of 29.38, 60.52, and $98.04 \mathrm{gal} / \mathrm{day}$, respectively.

For this comparison of ERWH and HPWH DR performance, PNNL elected to simulate a "high" usage scenario and a profile similar to the Building America House Simulation Protocol. A high draw volume was chosen to create a worst-case scenario to evaluate the potential for customer impact from decreased hot water delivery temperatures and the ability of the water heaters to meet DR and load demands from the hot water draw profile. Thus, for the HPWH experiment, the daily hot water draw was adjusted by increasing the number of bedrooms in the Building America House Simulation Protocol calculations to five bedrooms, which results in hot water use of approximately $97 \mathrm{gal} / \mathrm{day}$ at the $125^{\circ} \mathrm{F}$ set point. However, after significant effort calibrating the water control meters used in the homes, it was found that the valves used to restrict flow and provide a standardized flow rate were more accurate and precise at higher flow rates. Thus, the hot water flow rate was increased identically in each home from $1.5 \mathrm{gpm}$ to $2.0 \mathrm{gpm}$, for a total draw volume of $130 \mathrm{gal} / \mathrm{day}$. This draw profile was deemed a "worst case scenario" regarding the impact of DR events on tank temperature and homeowner satisfaction, but was 
within the range of the daily hot water use data reported in the LBNL meta-analysis ${ }^{1}$ (Lutz and Melody 2012). The experimental data generated using this worst-case draw profile will verify whether lower hot water temperatures or other issues will be significant for homes with high daily hot water usage. If the experiments find minimal issues, we can conclude that this will be the case for all participating homes. If issues are identified, further research utilizing different draw volumes and profiles could help identify specific load characteristics to be considered when implementing a DR program.

Because the draw profile simulated in the Lab Homes needs to remain constant throughout the experiment to remove water draw profile as a variable from the comparison, choosing a draw pattern representative of aggregate average hot water use, such as the Building America House Simulation Protocol, seemed most appropriate. In addition, this "average" draw profile represents what a utility would experience from their aggregate residential load and makes the calculation of DR performance for one water heater transferable to a population of water heaters (see discussion in section 4.3.1). Future work could explore the performance of HPWHs as a function of variable hot water draw patterns.

\footnotetext{
${ }^{1}$ The highest daily draw volume measured in the LBNL analysis was 163.21 gal/day.
} 



\subsection{Results and Discussion}

The following sections present the experimental results for the baseline period, the energy efficiency performance of the HPWH compared to the ERWH, and the power (W) and energy (W.h) impact of the HPWH during the types of DR and different DR event timing simulated in this experiment, specifically, afternoon and evening peak load curtailment events; morning, afternoon, evening, and late night INC and DEC balancing reserves; and more aggressive DEC experiments that require significant elevation of the tank temperature.

\subsection{Baseline}

Prior to initiation of the DR experiments, equivalent performance of water heaters in both homes was verified for both electric resistance (Standard mode) and heat pump (Heat Pump Only mode) operation. Also, DR testing occurred following thermal experiments as part of the same research activity, which included significant null testing of the thermal characteristics of the Lab Homes, including insulation and air leakage levels, and HVAC performance. However, since only the water heater performance was of interest in this experiment those results are not included here.

The electric resistance mode baseline, with the water heaters in both homes set to Standard mode with a $125^{\circ} \mathrm{F}$ setpoint, was compared over several days for both water heaters. The daily profiles and average energy use for Lab Home A and Lab Home B are shown in Figure 4.1 and Figure 4.2, respectively.

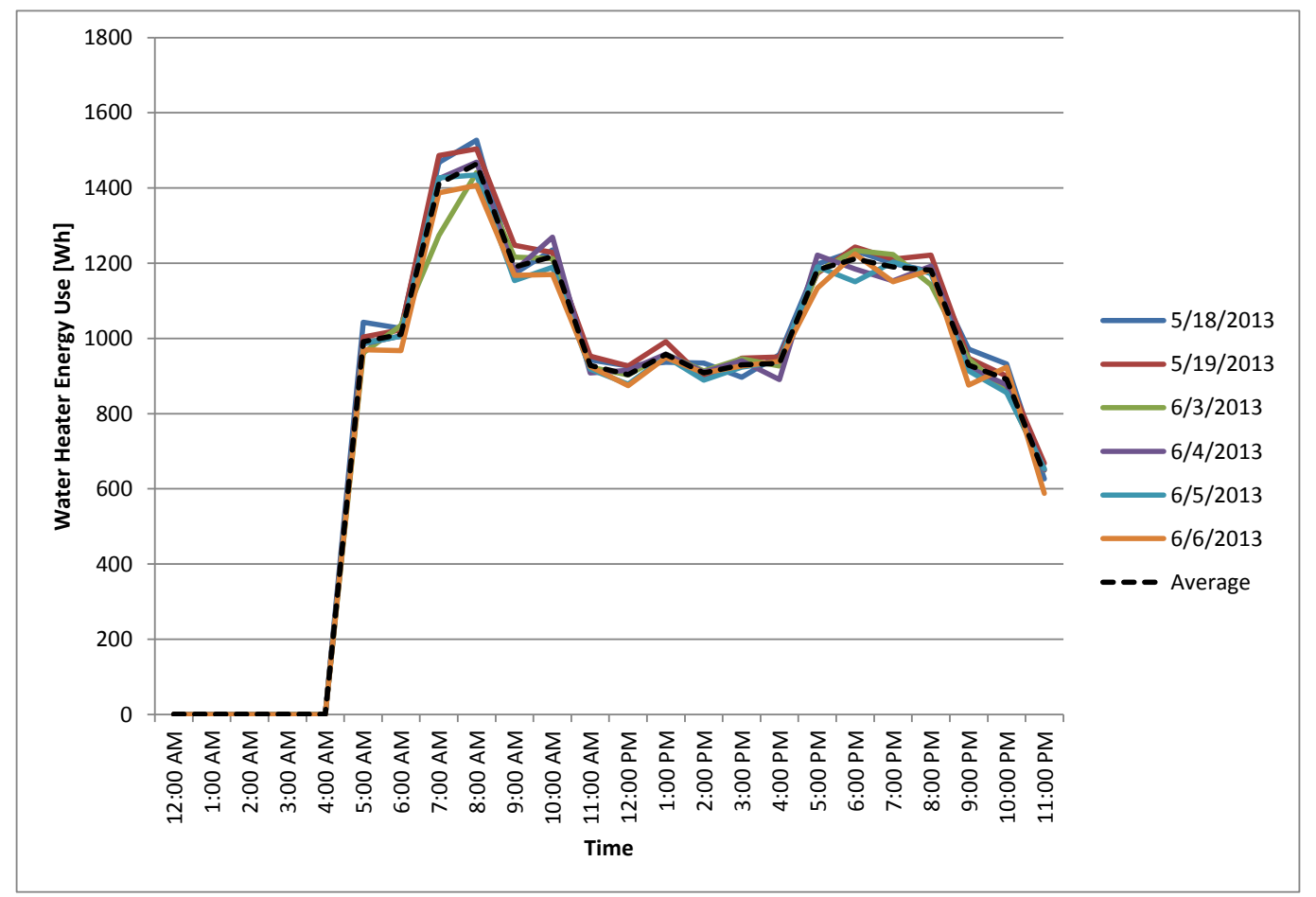

Figure 4.1. Lab Home A Electric Resistance Water Heater Daily and Average Load Profiles 


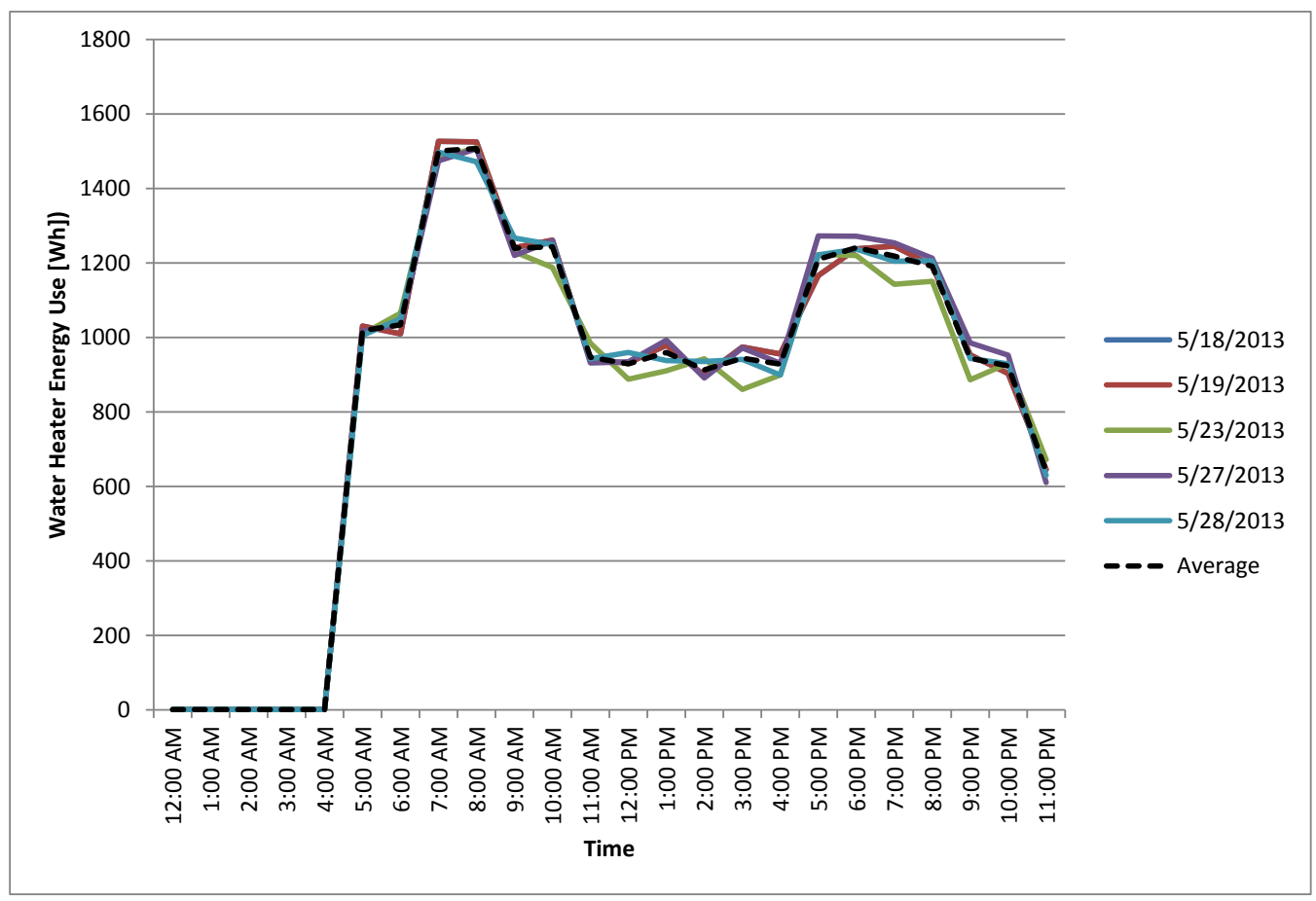

Figure 4.2. Lab Home B Electric Resistance Water Heater Daily and Average Load Profiles

Similarly, the heat pump mode baselines for Lab Home A and Lab Home B were compared over several days with both water heaters set to Heat Pump mode with a $125^{\circ} \mathrm{F}$ set point. The daily profiles and average for HPWH operation in Lab Home A and Lab Home B are shown in Figure 4.3 and Figure 4.4 , respectively.

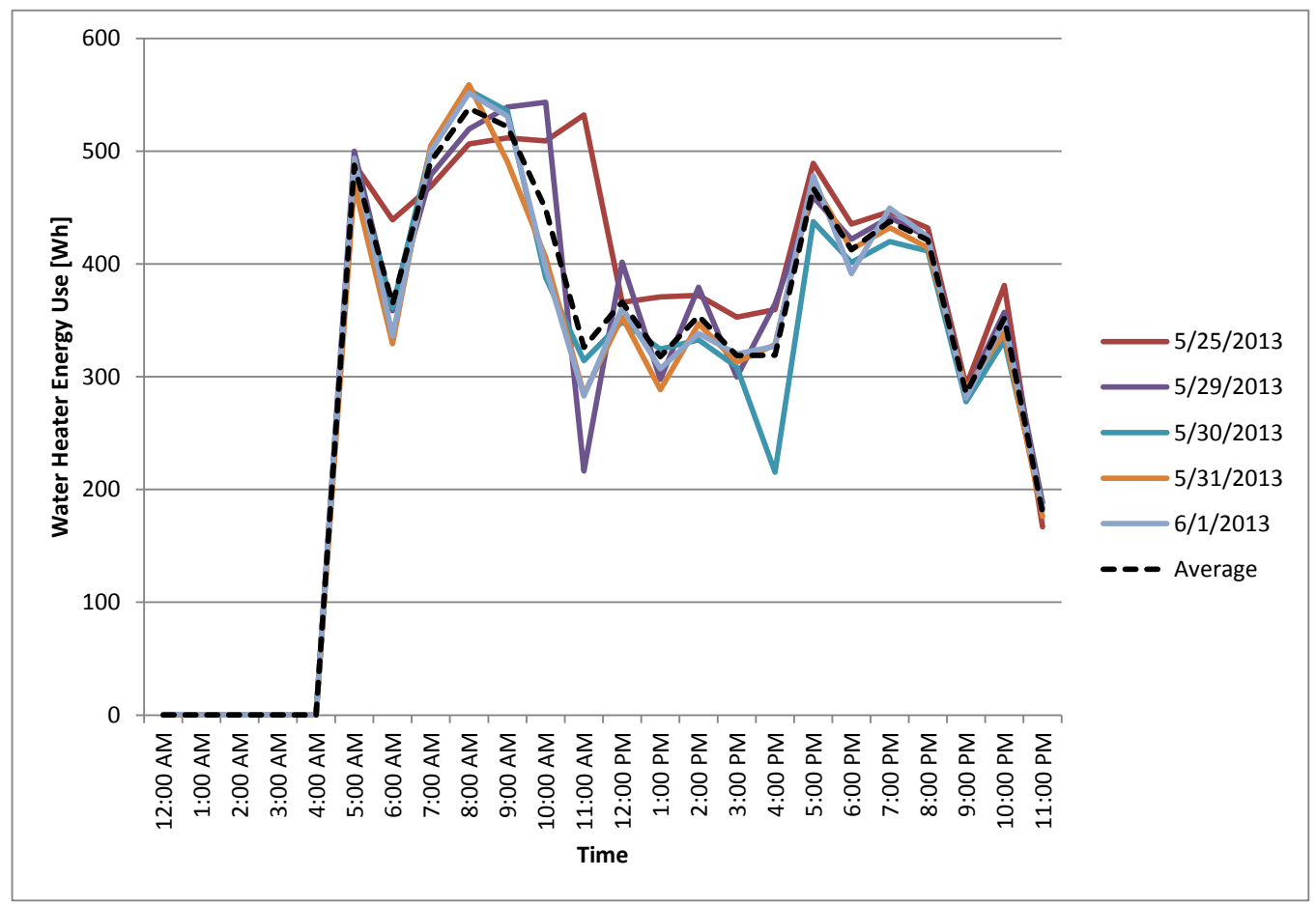

Figure 4.3. Lab Home A Heat Pump Water Heater Daily and Average Load Profiles 


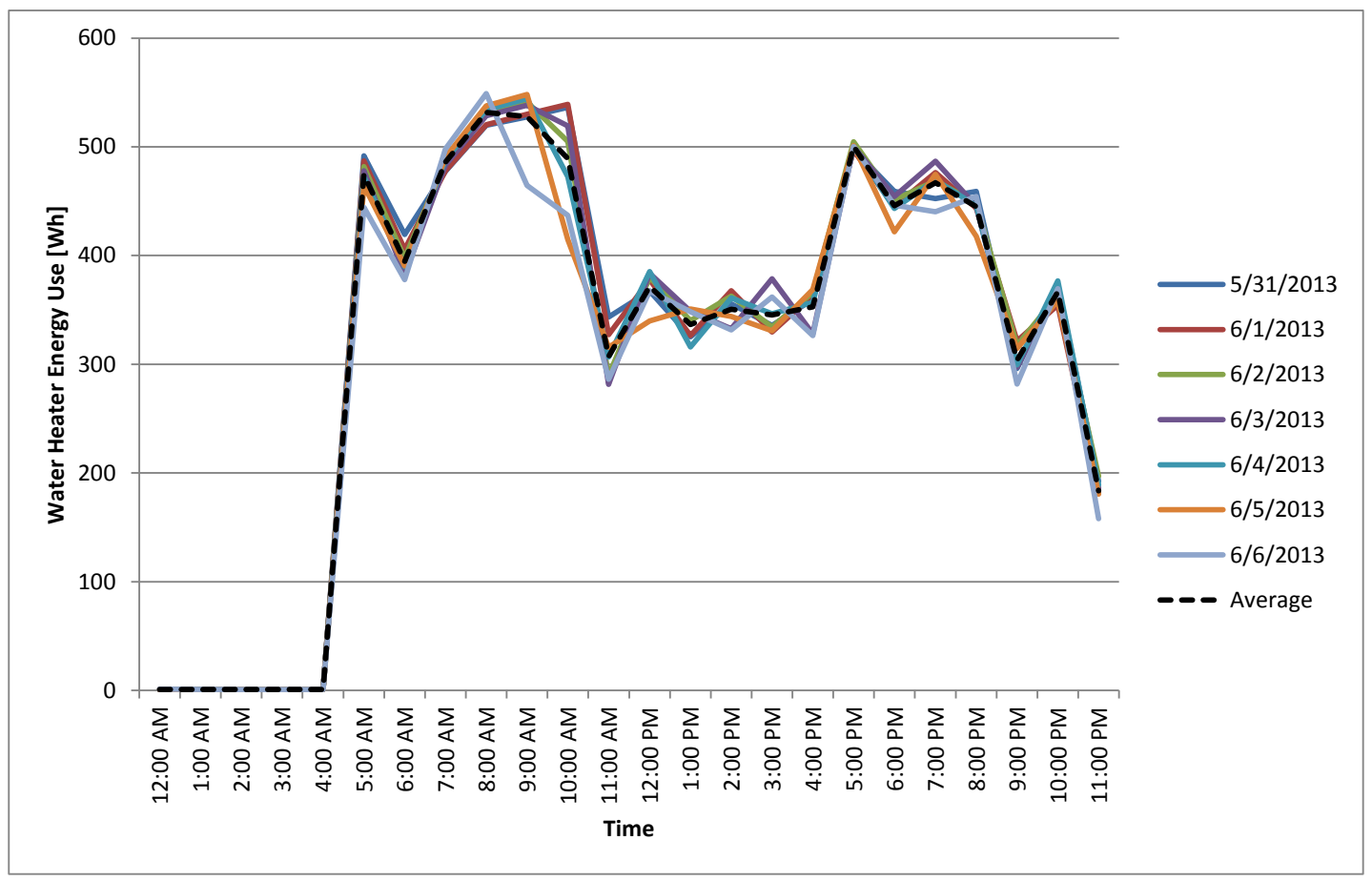

Figure 4.4. Lab Home B Heat Pump Water Heater Daily and Average Load Profiles

As can be seen in Figure 4.5 and Figure 4.6, the ERWH and HPWH operation are nearly identical for the two homes.

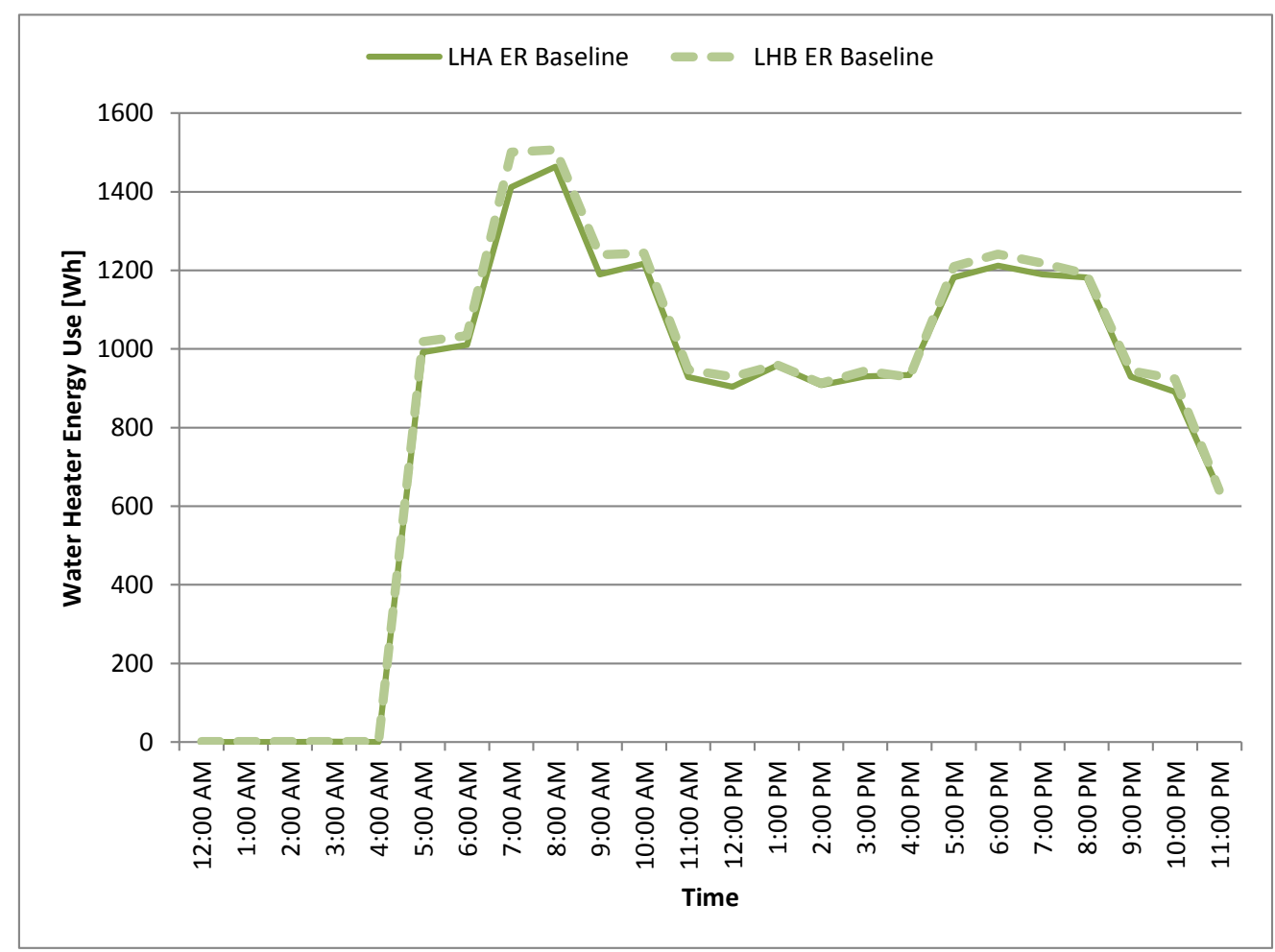

Figure 4.5. Average Daily Water Heater Energy Use Profile for Lab Home A and Lab Home B in Electric Resistance Mode 


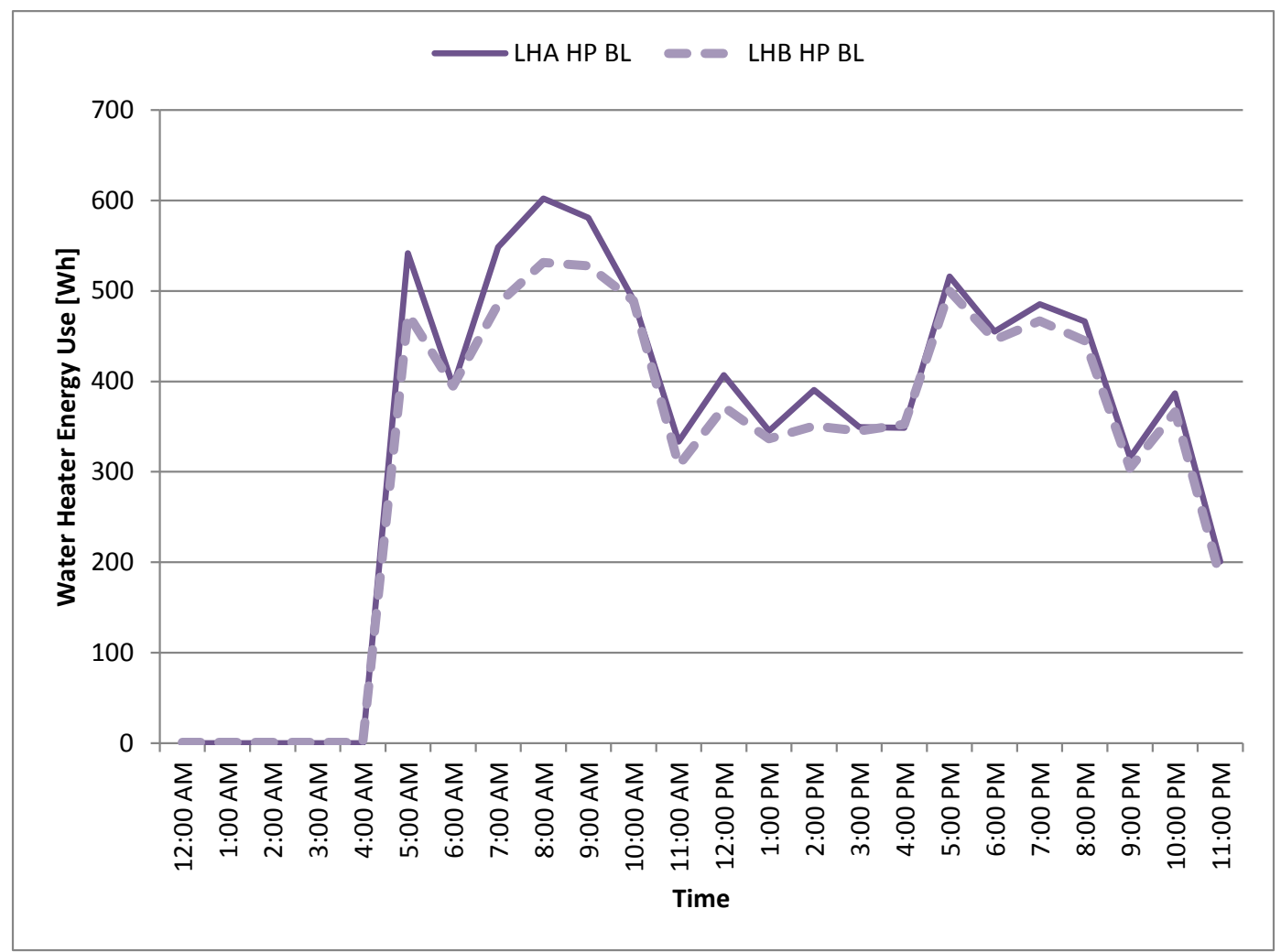

Figure 4.6. Average Daily Water Heater Energy Use Profile for Lab Home A and Lab Home B in Heat Pump Mode

In addition to verifying baseline energy use for the water heaters, the HPWH and ERWH baseline performance is important for determining the power and energy impact of a DR event, where the impact is assessed by comparing the average power or energy use during the DR period to the baseline power or energy use at that time and for that operating mode. In addition, these baseline energy use profiles determine the baseline daily energy use of the ERWH and HPWH, to determine the impact of DR events on daily energy use of the water heaters. The 95\% confidence interval is calculated based on the four-tosix days' data from the HPWH and ERWH baselines, in order to determine the significance of daily energy use impacts observed in the data. The baseline daily energy use and 95\% confidence interval are shown in Table 4.1.

Table 4.1. Baseline Daily Energy Use for HPWH and ERWH and 95\% Confidence Interval

\begin{tabular}{lc}
\hline Water Heater Type & $\begin{array}{c}\text { Baseline Daily Energy Use } \\
\text { (W.h/day) }\end{array}$ \\
\hline ERWH & $20,073 \pm 348$ \\
HPWH & $7,684 \pm 119$ \\
\hline
\end{tabular}

The hot water draw profile strongly impacts the ERWH and HPWH baseline energy use profiles. As such, hot water draw profiles were also compared daily to ensure consistent draw patterns and volumes and were typically within $1 \%$, after the increased draw volume was implemented (see section 3.7.1). Hourly hot water draw volumes and associated water heater energy use for a day during the baseline 
period are shown in Figure 4.7. On this day, both water heaters were operating in electric resistance or Standard mode.

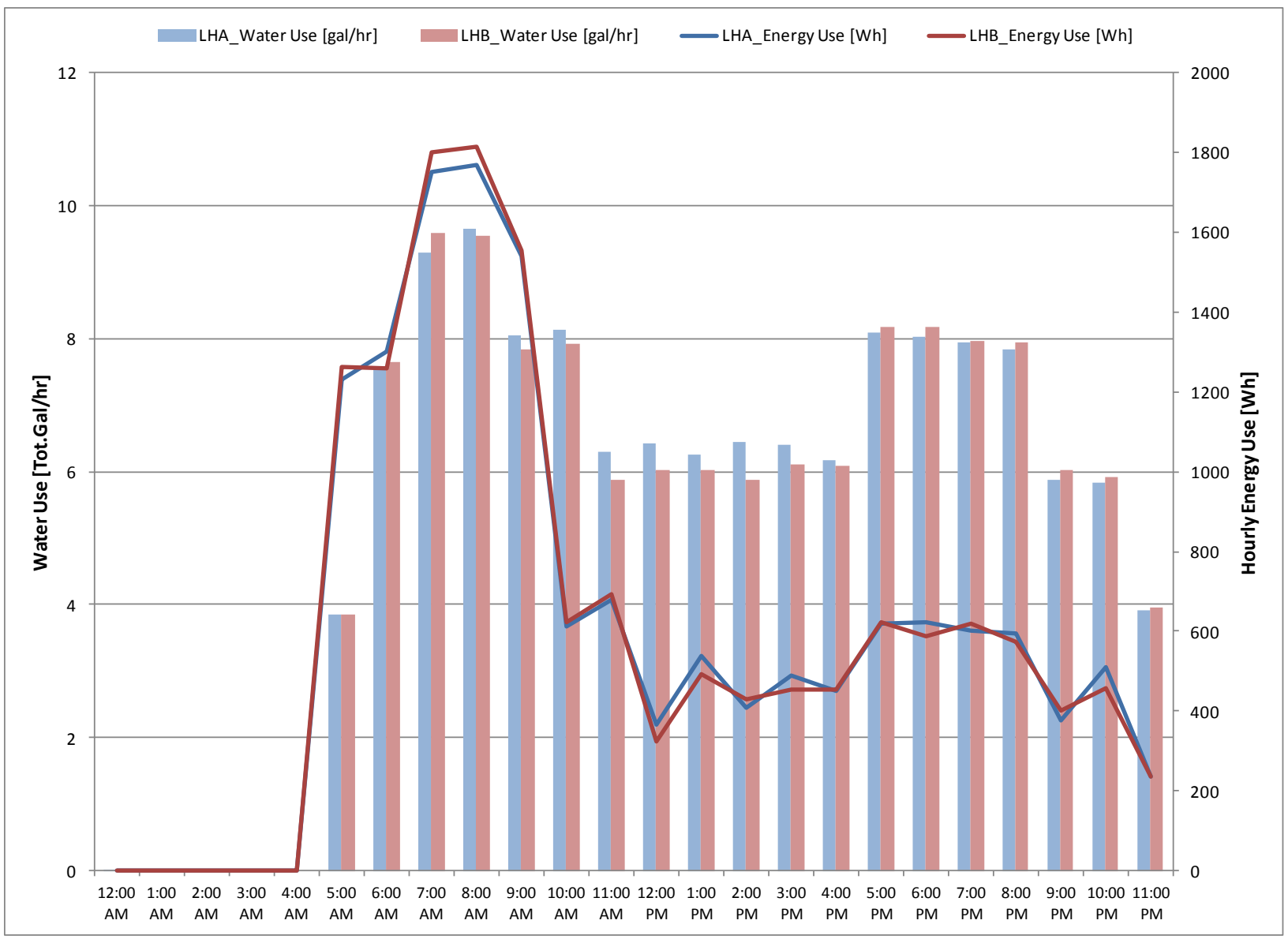

Figure 4.7. Hourly Water Use (gal/h) and Energy Use $(\mathrm{W} \cdot \mathrm{h})$ of Unducted HPWHs in Lab Home A (LHA) and Lab Home B (LHB) for One Day during the Baseline Period

\subsection{HPWH Energy Efficiency}

After the operation of the water heaters in both Lab Homes was proven to be virtually identical and identical occupancy patterns were verified, the improved efficiency of the HPWH as compared to the ERWH was verified independent of DR operation. In this experiment, the GE GeoSpring HPWH in Lab Home A was set to operate in electric-resistance-only mode to simulate an ERWH, and its operation was compared to the GE GeoSpring HPWH in Lab Home B operating in "Heat Pump" mode. Preliminary data on the energy use of the GE GeoSpring HPWH as compared to the ERWH indicates an average savings of $61.7 \pm 1.7 \%$, which is very close to the theoretical maximum of the HPWH based on the performance of the GE unit with an EF of 2.4, as tested ${ }^{1}$ in accordance with the DOE EF test procedure and stated on the Federal Trade Commission label. This agreement is expected, as the aggregate "smooth" hot water draw profile selected for the experiments does not induce the backup electric resistance elements to energize with the HPWH operating in Hybrid mode, as shown in Figure 4.8.

\footnotetext{
${ }^{1}$ Confirmed in communication with GE engineers. January 2013.
} 


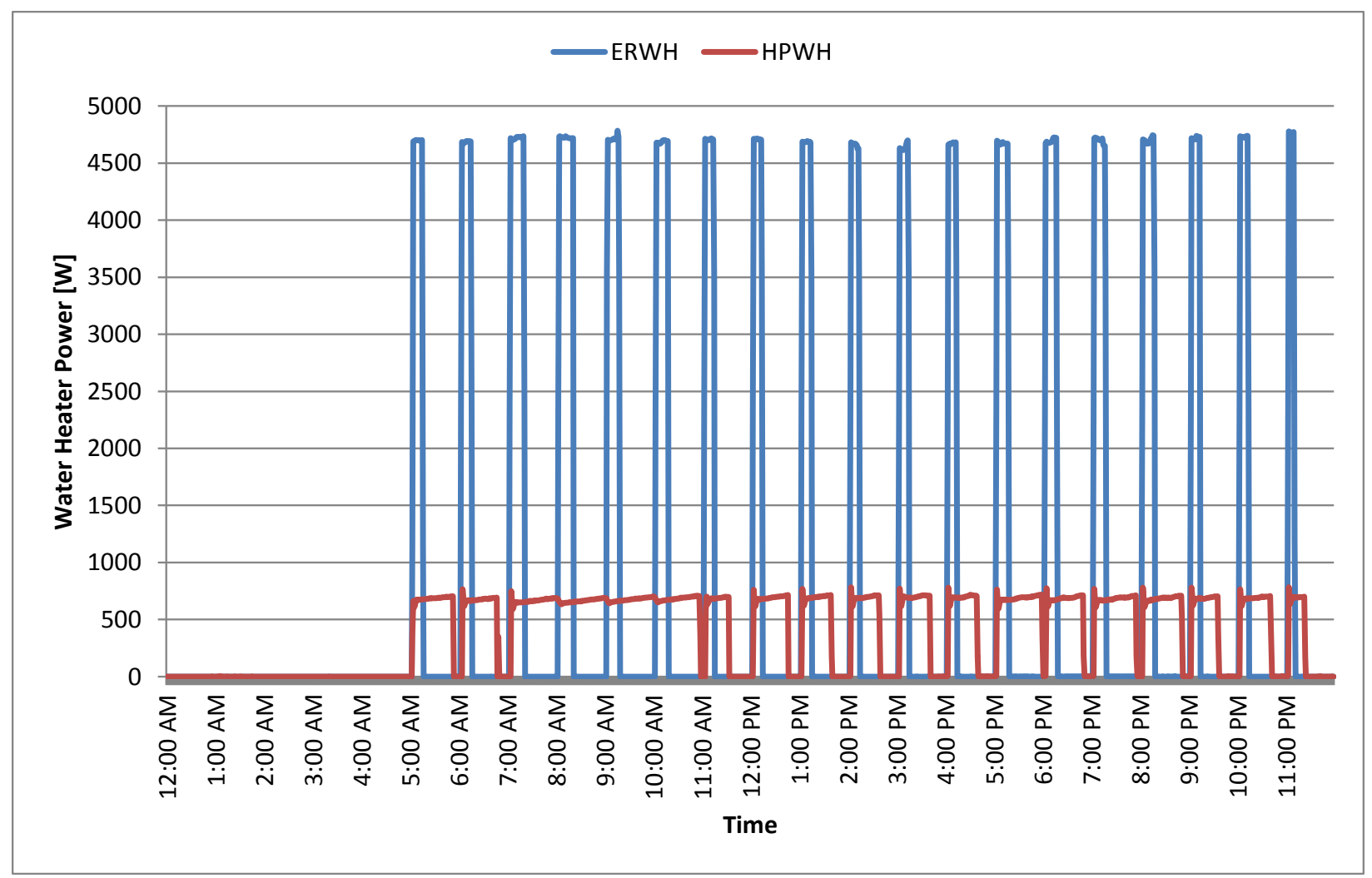

Figure 4.8. GE GeoSpring HPWH Energy Use (Red) as Compared to an ERWH (Blue) Under Baseline Operation with no DR Response.

\subsection{Peak Curtailment Events}

The first type of DR event evaluated was load shifting or peak curtailment, which entails turning off the water heaters for three-hour periods during periods of peak power to help relieve electricity grid congestion. The peak curtailment events were to be implemented in the morning (7:00 a.m.), afternoon (2:00 p.m.), and evening (6:00 p.m.). However, the morning curtailment event was not successfully implemented due to communication issues between the GE Nucleus and the GE servers.

\subsubsection{Afternoon Peak Curtailment}

The afternoon peak curtailment turned the water heaters off by sending a $60^{\circ} \mathrm{F}$ set point signal in vacation mode for three hours, from 2:00 p.m. to 5:00 p.m. The experiment was performed three times and resulted in an average peak savings of 4,650 W for the ERWH and $587 \mathrm{~W}$ for the HPWH, as can be seen in Figure 4.9. However, as Figure 4.8 illustrates, this peak power is not sustained for the duration of the DR event for a particular appliance. In fact, as shown in Figure 4.8, the electric resistance elements are only engaged for an average of $18 \%$ of the time between the hours of 2:00 p.m. and 5:00 p.m. The heat pump in the HPWH, however, is engaged 54\% of the time between the hours of 2:00 p.m. and 5:00 p.m., based on the hot water draw profile implemented in the experiments. 


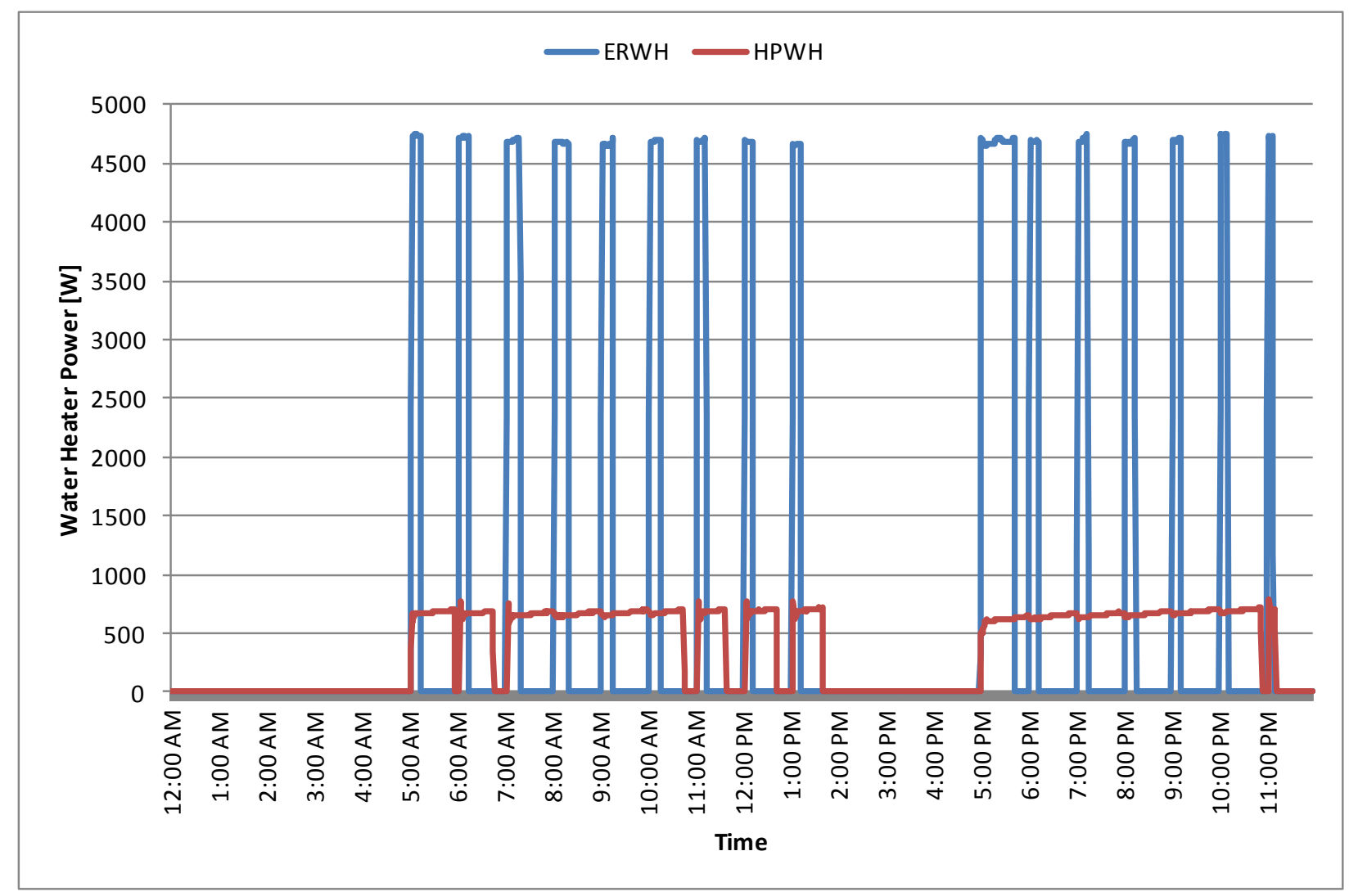

Figure 4.9. Power Draw from ERWH (blue) and HPWH (red) for One Day during the Peak Curtailment Events

Because an "average" or aggregate water draw profile was selected for the experiment, one can also observe the average $\mathrm{W} \cdot \mathrm{h}$ savings for the water heater, as a means of estimating the average power reduction over a population of water heaters, accounting for the fact that the heating elements or heat pump are not engaged all the time. For the ERWH, the average power savings as compared with the baseline is approximately $924 \mathrm{~W}$ over the three-hour DR event, which is approximately $20 \%$ of the 4650 $\mathrm{W}$ average power draw. The HPWH provided an average power reduction of $350 \mathrm{~W}$, or $60 \%$ of the 587 $\mathrm{W}$ average power draw for the HPWH. These average power reductions are depicted in Figure 4.10 and tabulated in Table 4.2. 


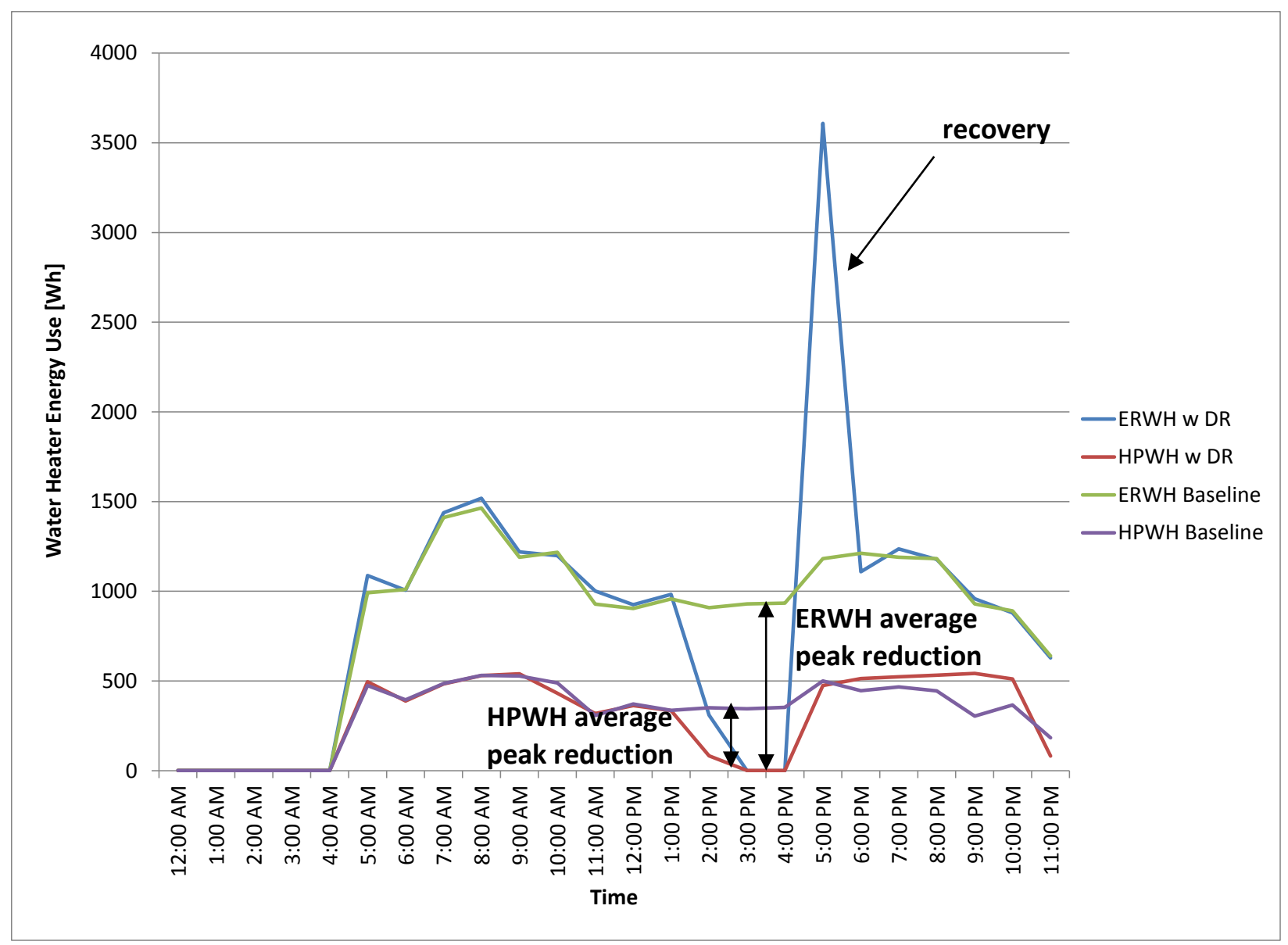

Figure 4.10. Afternoon Peak Curtailment Hourly Average Water Heater Energy Use Profile for the HPWH and ERWH with and without DR Signals $(W \cdot h)$

Table 4.2. Average Power Draw Impact $(W)$, Average Energy Impact during DR Event $(W \cdot h)$, and Average Daily Energy Impact (W.h/day) of Afternoon Peak Curtailment (2:00 p.m. to 5:00 p.m.) for the HPWH and ERWH. ${ }^{1}$

\begin{tabular}{lccccc}
\hline Experiment & $\begin{array}{c}\text { WH } \\
\text { Mode }\end{array}$ & Duration & $\begin{array}{c}\text { Average } \\
\text { Power Draw } \\
\text { Impact }(\mathbf{W})\end{array}$ & $\begin{array}{c}\text { Average Energy } \\
\text { Impact during DR } \\
\text { Event } \\
(\mathbf{W} \cdot \mathbf{h})\end{array}$ & $\begin{array}{c}\text { Average Daily } \\
\text { Energy Impact } \\
(\mathbf{W} \cdot \mathbf{h} / \mathbf{d a y})\end{array}$ \\
\hline $\begin{array}{l}\text { P.M. Peak } \\
\text { Curtailment }\end{array}$ & HP & 3 hours & -350 & -965 & -533 \\
\cline { 2 - 6 } & ER & 3 hours & -924 & $-2,463$ & 213 \\
\hline
\end{tabular}

In addition to average power, one can also consider the energy savings during the DR period, as well as calculate the impact on the daily water heating energy use. The energy savings for the ERWH during

${ }^{1}$ Positive numbers indicate increased energy use and negative numbers indicate decreased energy use. 
the DR period was $2,463 \mathrm{~W} \cdot \mathrm{h}$ and the average daily impact on water heating energy use was an increase of $213 \mathrm{~W} \cdot \mathrm{h}$ for the ERWH, which is not significant relative to the variability in the data. For the HPWH, the average daily energy savings was $533 \mathrm{~W} \cdot \mathrm{h}$ and the energy savings during the DR period was 965 $\mathrm{W} \cdot \mathrm{h}$. It is expected that the DR will not appreciably affect overall energy use for the ERWH, since the efficiency of the elements is static and the same amount of water is heated and used in both cases. In the HPWH, the decreased energy use is due to the inability of the HPWH to maintain temperature following the DR event, so some of the water is delivered at a temperature lower than the set point.

The three-hour peak curtailment event impacts the hot water delivery temperature for the HPWH versus the ERWH, based on this extreme or worst-case hot water draw scenario. As Figure 4.11 shows, both hot water supply temperatures are slightly reduced by the time the DR event concludes at 5:00 p.m.: around $120^{\circ} \mathrm{F}$ versus the tank set point of $125^{\circ} \mathrm{F}$. In the ERWH, the electric resistance elements engaged as soon as the DR period concluded to reheat the water to the set point temperature within the next hour. However, as Figure 4.10 illustrates, this results in significantly higher than normal energy use. This recovery period causes the ERWH to run for 40 minutes out of the hour following 5:00 p.m., for an average peak impact of almost 3,600 W. This aggressive temperature recovery can cause additional grid instability following DR events and must be managed properly in successful DR programs.

Conversely, the HPWH is in heat-pump-only mode and thus the electric resistance elements are disabled. Because of this, no recovery spike in energy use is observed for the HPWH. However, the reduced capacity of the HPWH causes increased recovery time to return to the original set point. In addition, the significant hot water draws, which are likely to occur in the early evening, compounded with the tank recovery load overwhelm the capacity of the heat pump, causing the outlet hot water temperature to drop to $108^{\circ} \mathrm{F}$. It is not known whether this would be acceptable to homeowners or not. However, it should be noted that more typical draw profiles would probably not exhibit this behavior. A drop in hot water delivery temperature of only $15^{\circ} \mathrm{F}$ using only the heat pump to heat the water with such extreme hot water draw volume is actually remarkable and indicates that for the majority of single-family homeowners, even for large families, a single 50-gallon HPWH is sufficient to maintain a minimum water temperature of $110^{\circ} \mathrm{F}$, even for peak curtailment events of three hours. A typical temperature at the tap in residential homes is $110^{\circ} \mathrm{F}$ (Hendron and Engebrecht 2010). For the vast majority of households, little to no deviation in hot water delivery temperature would likely be experienced. 


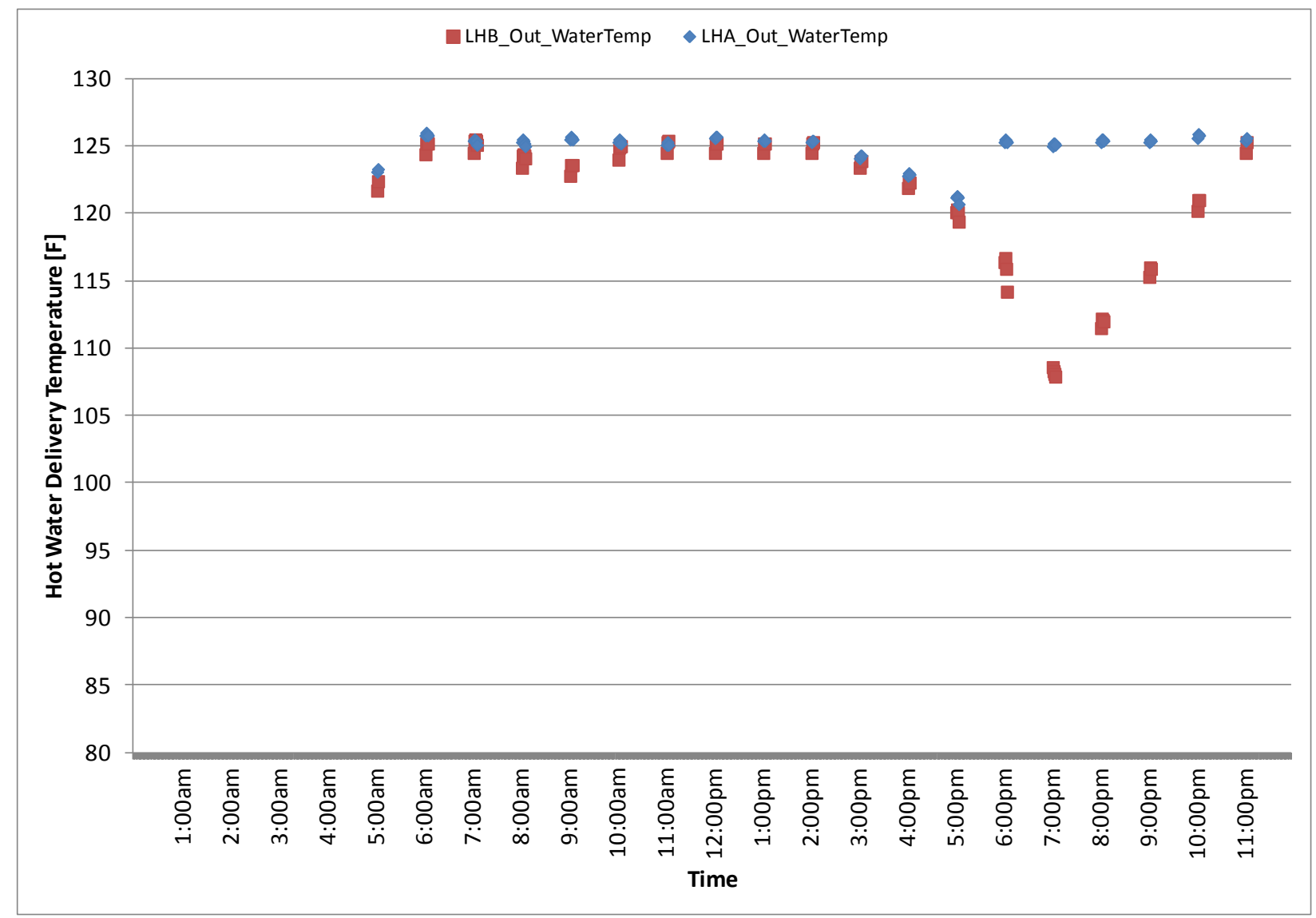

Figure 4.11. Hot Water Outlet Temperature of ERWH $(\mathrm{LHA}=$ blue $)$ and HPWH $(\mathrm{LHB}=$ red $)$ during an Afternoon (2:00 p.m. to 5:00 p.m.) Peak Curtailment

\subsubsection{Evening Peak Curtailment}

A similar analysis can be applied to the evening curtailment event, occurring from 6:00 p.m. to 9:00 p.m. The peak power reduction remains the same in both cases, 4,650 W for the ERWH and $587 \mathrm{~W}$ for the HPWH, as the power draw of the water heaters has not changed. However, the average power reduction is $1,194 \mathrm{~W}, 26 \%$ of the total potential power draw of 4,650 W, for the ERWH due to the higher hot water demand ( 24 gallons) experienced in the evening. For the HPWH, the average power reduction is approximately $453 \mathrm{~W}$, or $77 \%$ of the maximum power draw of the water heater. This indicates that the HPWH is energized approximately 77\% of the time between the hours of 6:00 p.m. and 9:00 p.m. These data are depicted and tabulated in Figure 4.12 and Table 4.3, respectively. 


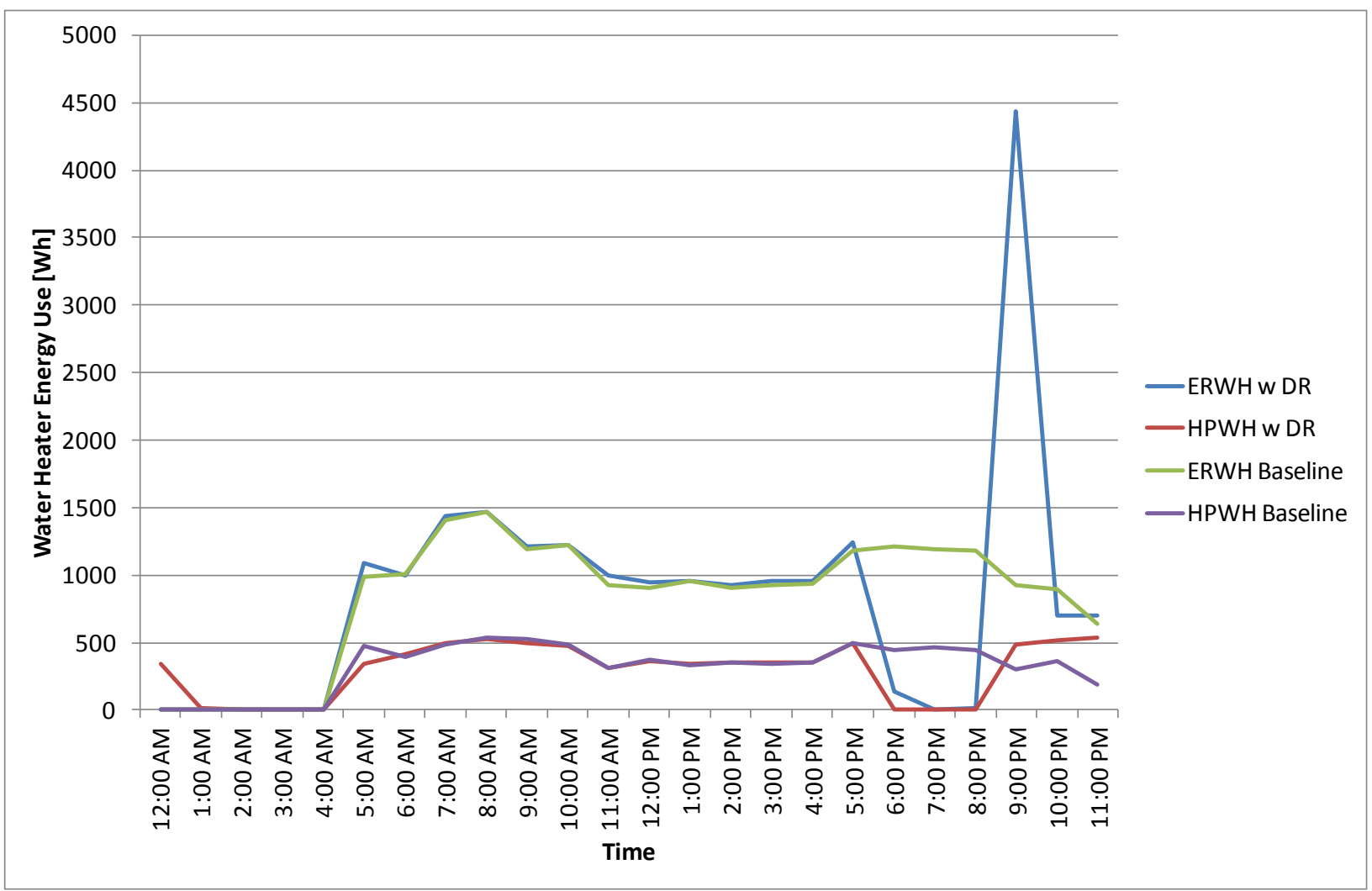

Figure 4.12. Evening Peak Curtailment Hourly Average Water Heater Energy Use Profile for the HPWH and ERWH with and without DR Signals $(\mathrm{W} \cdot \mathrm{h})$

Table 4.3. Average Power Draw Impact (W), Average Energy Impact during DR Event $(\mathrm{W} \cdot \mathrm{h})$, and Average Daily Energy Impact (W·h/day) of Evening Peak Curtailment (6:00 p.m. to 9:00 p.m.) for the HPWH and ERWH. ${ }^{1}$

\begin{tabular}{lccccc}
\hline Experiment & $\begin{array}{c}\text { WH } \\
\text { Mode }\end{array}$ & Duration & $\begin{array}{c}\text { Average Power } \\
\text { Draw Impact } \\
(\mathbf{W})\end{array}$ & $\begin{array}{c}\text { Average Energy } \\
\text { Impact during } \\
\text { DR Event } \\
(\mathbf{W} \cdot \mathbf{h})\end{array}$ & $\begin{array}{c}\text { Average Daily } \\
\text { Energy Impact } \\
(\mathbf{W} \cdot \mathbf{h} / \mathbf{d a y})\end{array}$ \\
\hline $\begin{array}{l}\text { EVE Peak } \\
\text { Curtailment }\end{array}$ & HP & 3 hours & -453 & $-1,345$ & -463 \\
\cline { 2 - 6 } & ER & 3 hours & $-1,194$ & $-3,433$ & 303 \\
\hline
\end{tabular}

The energy savings experienced during the DR period was $3,433 \mathrm{~W} \cdot \mathrm{h}$ for the ERWH and $1,345 \mathrm{~W} \cdot \mathrm{h}$ for the HPWH. For the ERWH, the DR event increased daily energy use by $303 \mathrm{~W} \cdot \mathrm{h}$, or $1.5 \%$, which is not significant relative to the variability in the data. The daily energy use impact of the HPWH, however, was $-463 \mathrm{~W} \cdot \mathrm{h}$, which is significant and means the HPWH used less energy under the DR control regime. This, again, is due to reduced hot water delivery temperature occurring immediately following the DR event because the HPWH does not have sufficient capacity to recover the hot water delivery temperature and keep up with the large simulated hot water draws. However, following the evening curtailment event,

\footnotetext{
${ }^{1}$ Positive numbers indicate increased energy use and negative numbers indicate decreased energy use.
} 
these decreased hot water delivery temperatures occur late at night, when it is unlikely that homeowners will have significant demand for hot water. The effect on hot water delivery temperature is shown in Figure 4.13. Again, this indicates the significant potential of a 50-gallon HPWH to provide peak curtailment with minimal to no impact on the homeowner for most reasonable hot water use profiles.

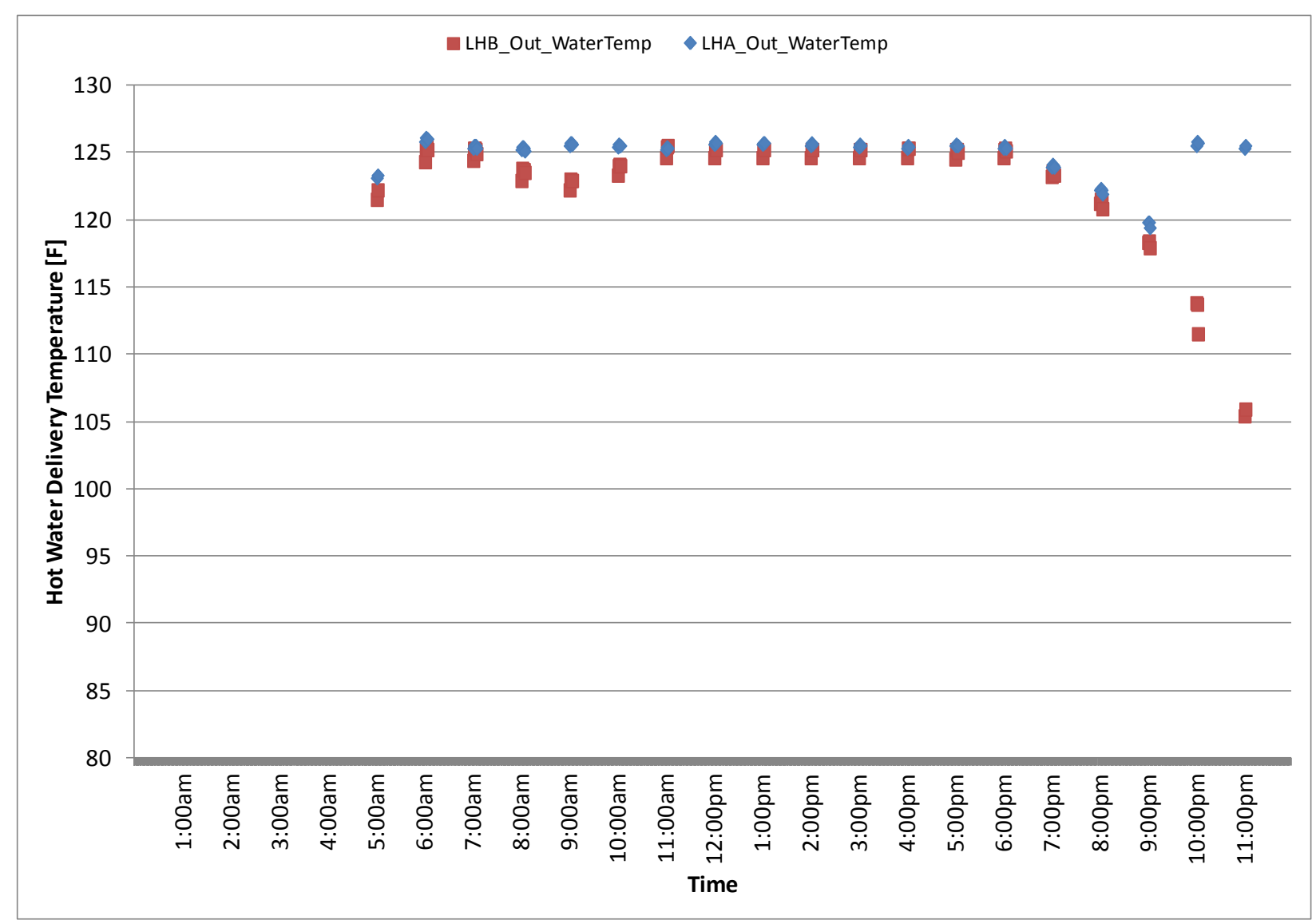

Figure 4.13. Hot Water Outlet Temperature of ERWH $(\mathrm{LHA}=$ blue $)$ and HPWH $(\mathrm{LHB}=$ red $)$ during an Afternoon (6:00 p.m. to 9:00 p.m.) Peak Curtailment

\subsubsection{Morning Peak Curtailment}

As mentioned previously, internet connectivity issues prevented the collection of robust data to evaluate the performance of a morning peak curtailment experimentally. However, the DR performance of the HPWH and ERWH can be estimated based on data from the afternoon and evening peak curtailment events. The average power use during the morning curtailment period, from 7:00 a.m. to 10:00 a.m., is 1,355 W, as measured in the baseline case. This indicates that the water draw profile and standby losses are causing the electric elements to turn on $29 \%$ of the time in the ERWH. Therefore, assuming that the DR curtailment signal is successful, each water heater would deliver an average of $1,355 \mathrm{~W}$ throughout the three-hour period. For the HPWH, the demand reduction would be $515 \mathrm{~W}, 88 \%$ of the theoretical maximum DR potential of the HPWH, since the HPWH is in use $88 \%$ of the time to keep up with morning water use.

The energy savings achieved during the DR period are $4,065 \mathrm{~W} \cdot \mathrm{h}$ and $1,545 \mathrm{~W} \cdot \mathrm{h}$ for the ERWH and HPWH, respectively. Estimating the daily energy impact of the morning curtailment would be much 
more complicated because it is difficult to estimate the recovery of the tanks accounting for stratification and mixing, as well as the significant water draws during the morning period. Therefore the calculation was not attempted here. However, it is probable that the decreased hot water delivery temperature observed in the HPWH for the afternoon and evening peak curtailment events would be even more pronounced for the morning event due to the increased water draws in the morning period ( 28 gallons; see Figure 4.7) and may affect the occupants more because the decreased hot water delivery temperature would occur during the day when the home was occupied. However, it is important to remember that the water draw implemented in the Lab Homes represents an extreme case, and normal usage would result in reduced impact on hot water delivery temperature, without requiring the use of electric resistance elements.

Table 4.4. Average Power Draw Impact (W), Average Energy Impact during DR Event $(\mathrm{W} \cdot \mathrm{h})$, and Average Daily Energy Impact (W.h/day) of Morning Peak Curtailment (7:00 a.m. to 10:00 a.m.) for the HPWH and ERWH. ${ }^{1}$

\begin{tabular}{lccccc}
\hline Experiment & $\begin{array}{c}\text { WH } \\
\text { Mode }\end{array}$ & Duration & $\begin{array}{c}\text { Average Power } \\
\text { Draw Impact } \\
(\mathbf{W})\end{array}$ & $\begin{array}{c}\text { Average Energy } \\
\text { Impact during } \\
\text { DR Event } \\
(\mathbf{W} \cdot \mathbf{h})\end{array}$ & $\begin{array}{c}\text { Average Daily } \\
\text { Energy Impact } \\
(\mathbf{W} \cdot \mathbf{h} / \mathbf{d a y})\end{array}$ \\
\hline $\begin{array}{l}\text { A.M. Peak } \\
\text { Curtailment }\end{array}$ & HP & 3 hours & -515 & $-1,545$ & N/A \\
\cline { 2 - 6 } & ER & 3 hours & $-1,355$ & $-4,065$ & N/A \\
\hline
\end{tabular}

\subsection{Balancing Reserves}

The other type of DR evaluated in this experiment was balancing reserves, where the water heater is turned on or turned off depending on the needs of the grid to better match demand to available generation. Unlike peak curtailment, balancing reserves can occur in two directions. Balancing reserves can be called on when there is excess load or insufficient supply for a short (1-2 hour) period of time. In this case, called an INC event, demand is decreased to better match supply. The other type of balancing reserves is a DEC event, where available generation is in excess of demand and it is advantageous to increase load to use available power. This is typical of power generated by renewable resources, which is inherently less predictable, but can also be caused by supply and/or demand estimates being slightly different from realized levels.

While balancing reserve experiments can occur at any time of day, four representative times were chosen for evaluation in this study: morning (8:00 a.m.), afternoon (2:00 p.m.), evening (8:00 p.m.), and late night (2:00 a.m.). Typically two balancing reserve events were simulated in one day, but were spaced 12 hours apart so that one event would not affect the results of the other event. For example, the 8:00 a.m. and 8:00 p.m. events occurred on the same day.

\footnotetext{
${ }^{1}$ Positive numbers indicate increased energy use and negative numbers indicate decreased energy use.
} 


\subsubsection{Generation INC Balancing Events}

The first type of balancing reserves simulated were INC events, where it is advantageous to drop load to balance a shortage in supply. This type of DR event can be important for integration of more variable renewable generation, or for unanticipated generation interruptions or failures.

\subsubsection{Morning INC Balancing Event}

The morning INC balancing event simulated a "conserve" signal being sent to the water heaters by setting the tank temperature set point to $60^{\circ} \mathrm{F}$ in Vacation mode at 8:00 a.m. Following the 1-hour balancing event, the thermostat set point and operating mode was returned to the previous set point of $125^{\circ} \mathrm{F}$ and Standard or Heat Pump mode for Lab Home A and Lab Home B, respectively, at 9:00 a.m. following the event. The experiment was performed twice and resulted in an average power reduction of 1,464 W for the ERWH and $532 \mathrm{~W}$ for the HPWH, as shown in Figure 4.14. Because the events occur over a one-hour period, the average peak energy saved, in $\mathrm{W} \cdot \mathrm{h}$, is the same as the average peak power avoided over the hour, as indicated in Table 4.5.

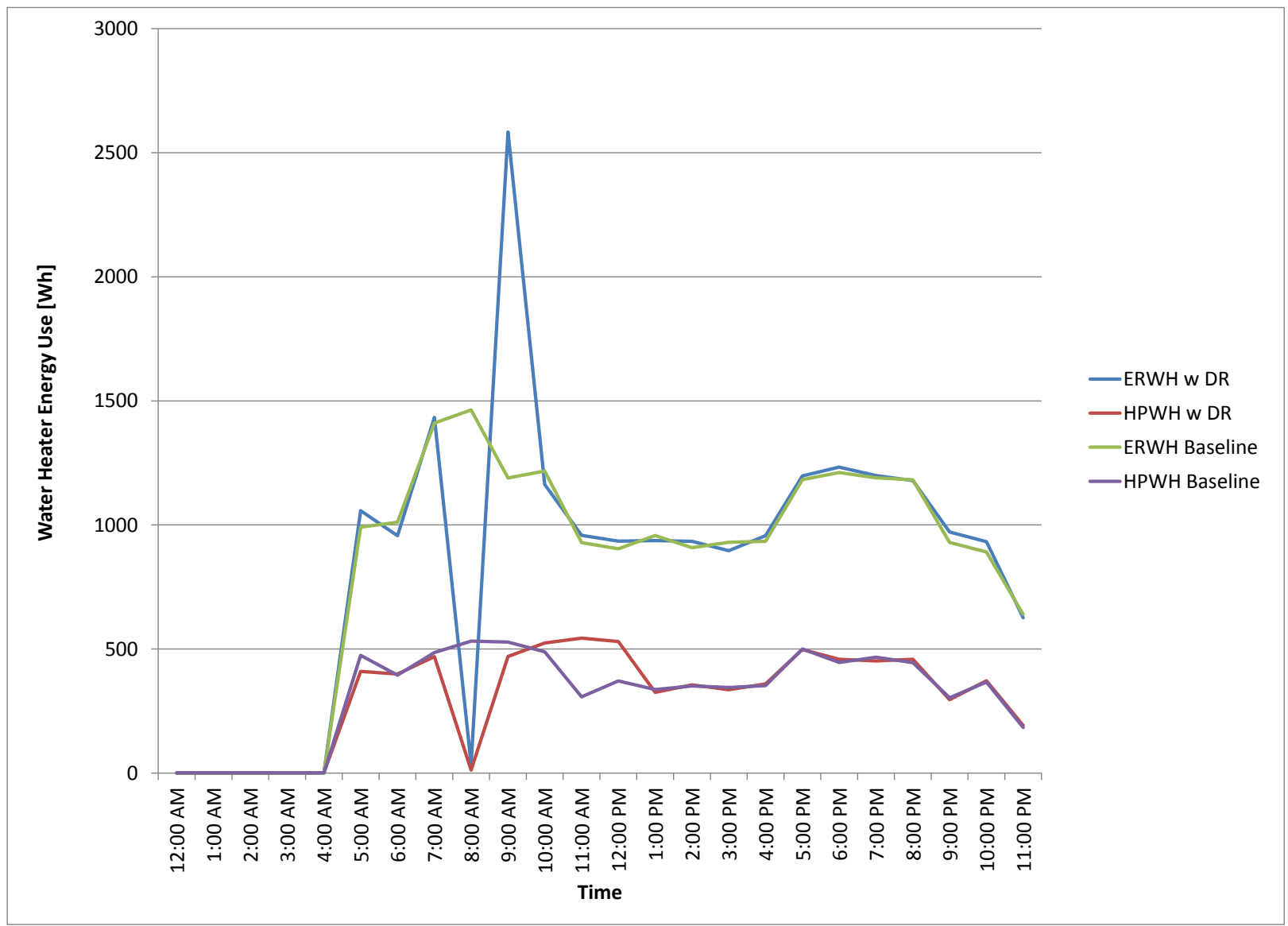

Figure 4.14. Morning INC Balancing Event Hourly Average Water Heater Energy Use Profile for the HPWH and ERWH with and without DR Signals $(\mathrm{W} \cdot \mathrm{h})$ 
Table 4.5. Average Power Draw Impact (W), Average Energy Impact during DR Event $(\mathrm{W} \cdot \mathrm{h})$, and Average Daily Energy Impact (W.h/day) of Morning INC Balancing Event (8:00 a.m. to 9:00 a.m.) for the HPWH and ERWH. ${ }^{1}$

\begin{tabular}{lccccc}
\hline Experiment & $\begin{array}{c}\text { WH } \\
\text { Mode }\end{array}$ & Duration & $\begin{array}{c}\text { Average Power } \\
\text { Draw Impact } \\
\text { (W) }\end{array}$ & $\begin{array}{c}\text { Average Energy } \\
\text { Impact during } \\
\text { DR Event } \\
(\mathbf{W} \cdot \mathbf{h})\end{array}$ & $\begin{array}{c}\text { Average Daily } \\
\text { Energy Impact } \\
(\mathbf{W} \cdot \mathbf{h} / \text { day })\end{array}$ \\
\hline $\begin{array}{l}\text { Morning } \\
\begin{array}{l}\text { INC } \\
\text { Balancing } \\
\text { Event }\end{array}\end{array}$ & HP & 1 hour & -532 & -532 & -216 \\
\cline { 2 - 6 } & ER & 1 hour & $-1,464$ & $-1,464$ & 118 \\
\hline
\end{tabular}

The INC balancing event increased the daily energy use of the ERWH by $118 \mathrm{~W} \cdot \mathrm{h}$, or $0.6 \%$, which is not significant relative to the variability in the data. For the HPWH, the event decreased the daily energy use by $-270 \mathrm{~W}$ or $1.1 \%$ of the baseline daily energy use of the HPWH. The impact on daily energy use from the HPWH DR behavior was significant and, as in the peak curtailment events, was probably due to the decreased hot water delivery temperature observed in the HPWH following the balancing event, as the HPWH does not have sufficient capacity to satisfy the extreme hot water draws on the system and recover the tank temperature from the one-hour curtailment event without experiencing a drop on hot water delivery temperature, as shown in Figure 4.15. The hot water delivery temperature in the HPWH is recovered by 1:00 p.m.

\footnotetext{
${ }^{1}$ Positive numbers indicate increased energy use and negative numbers indicate decreased energy use.
} 


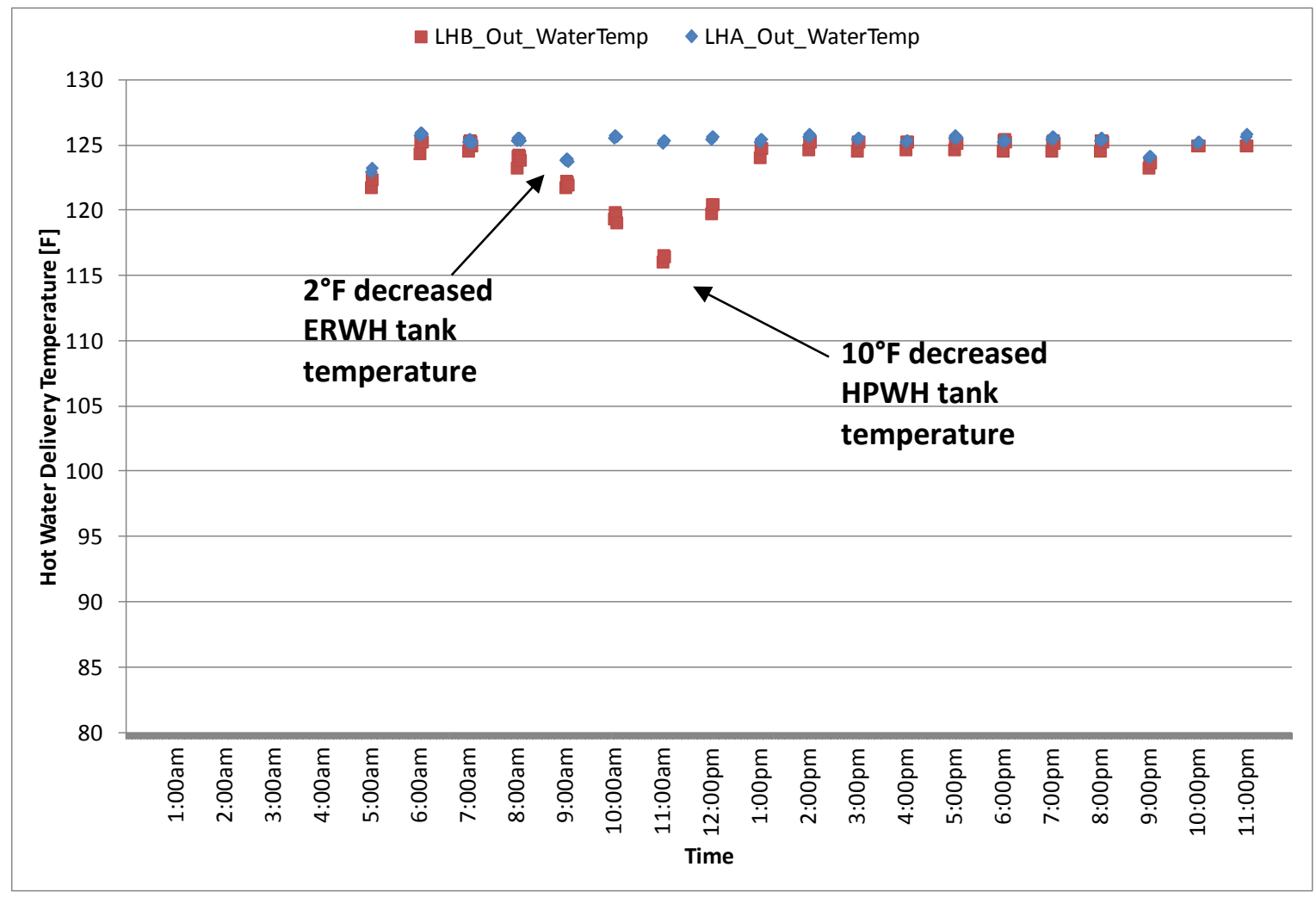

Figure 4.15. Hot Water Outlet Temperature of ERWH $(\mathrm{LHA}=$ blue $)$ and HPWH $(\mathrm{LHB}=$ red $)$ during Morning (8:00 a.m.) INC Balancing Event

In baseline operation, the HPWH is operating 91\% of the time between 8:00 a.m. and 9:00 a.m. to maintain the hot water delivery temperature during the significant hourly hot water use occurring in that time period. In fact, 8:00 a.m. to 9:00 a.m. is the period with the largest volume draw each day based on the simulated hot water draw profile (10 gallons; see Figure 4.7). With these significant draws, even the ERWH hot water delivery temperature is decreased slightly immediately following the balancing event, but the impact is very slight (approximately $1^{\circ} \mathrm{F}$ ). In the HPHW, the hot water delivery temperature drops to approximately $116^{\circ} \mathrm{F}$, which may or may not be noticeable by occupants. Hendron and Engebrecht (2010) note that the typical temperature of hot water used at the tap is homes is $110^{\circ} \mathrm{F}$, so it is possible that most homeowners could still achieve an acceptable tap temperature by mixing less cold water with the hot.

\subsubsection{Afternoon INC Balancing Event}

The afternoon INC balancing event simulated a "conserve" signal being sent to the water heaters by setting the tank temperature to $60^{\circ} \mathrm{F}$ in vacation mode at 2:00 $\mathrm{p} . \mathrm{m}$. and returning to the previous set point of $125^{\circ} \mathrm{F}$ and Standard or Heat Pump mode for Lab Home A and Lab Home B, respectively, at 3:00 p.m. following the event. The experiment was implemented four times and resulted in an average power reduction of $908 \mathrm{~W}$ for the ERWH and $351 \mathrm{~W}$ for the HPWH, as shown in Figure 4.16. Because the events occur over a one-hour period, the average peak energy saved, in $\mathrm{W} \cdot \mathrm{h}$, is the same as the average peak power avoided over the hour, as indicated in Table 4.6. 


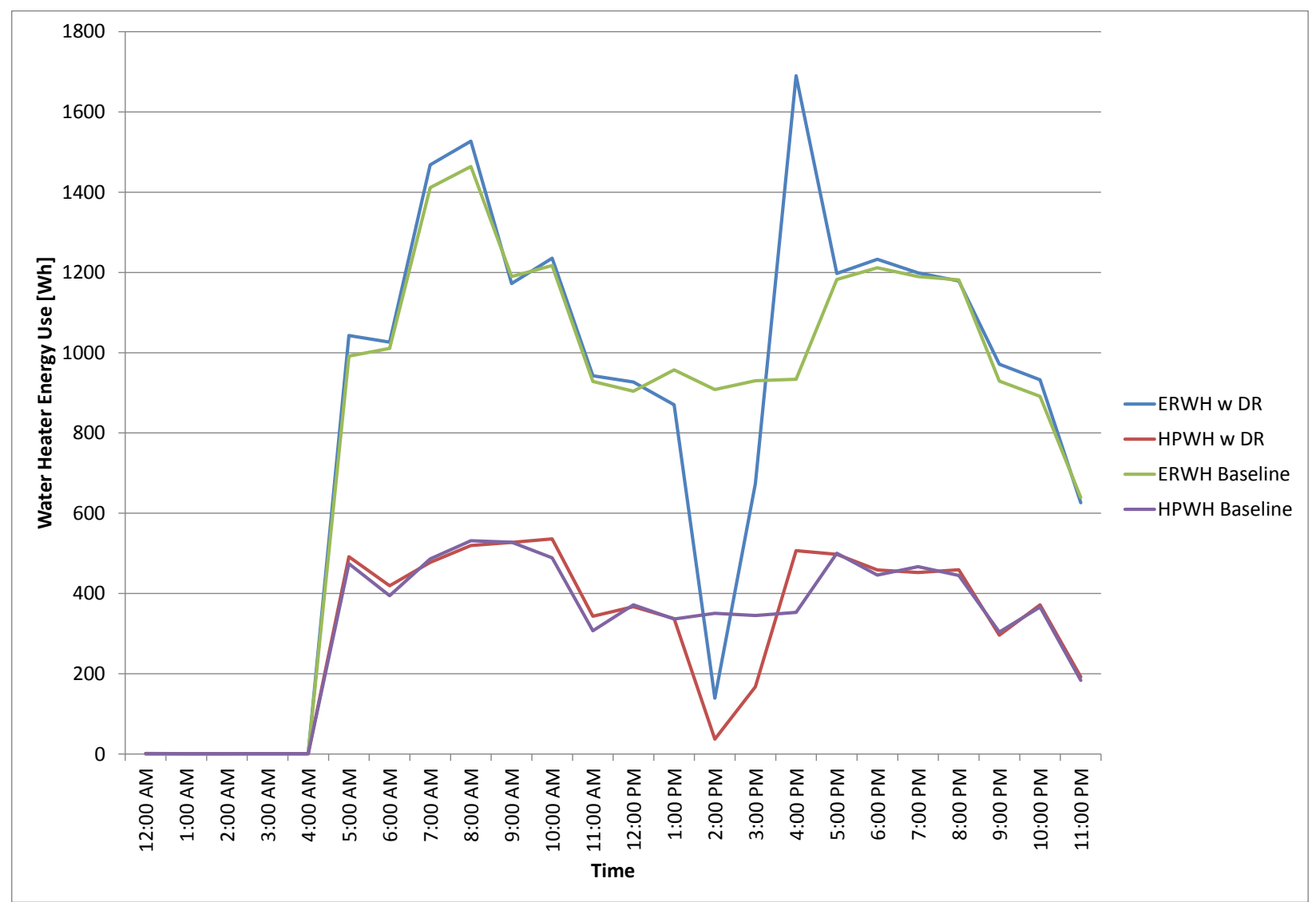

Figure 4.16. Afternoon INC Balancing Event Hourly Average Water Heater Energy Use Profile for the HPWH and ERWH with and without DR Signals $(\mathrm{W} \cdot \mathrm{h})$

Table 4.6. Average Power Draw Impact (W), Average Energy Impact during DR Event $(\mathrm{W} \cdot \mathrm{h})$, and Average Daily Energy Impact (W.h/day) of Afternoon INC Balancing Event (2:00 p.m. to 3:00 p.m.) for the HPWH and ERWH. ${ }^{1}$

\begin{tabular}{lccccc}
\hline Experiment & $\begin{array}{c}\text { WH } \\
\text { Mode }\end{array}$ & Duration & $\begin{array}{c}\text { Average Power } \\
\text { Draw Impact } \\
(\mathbf{W})\end{array}$ & $\begin{array}{c}\text { Average Energy } \\
\text { Impact during } \\
\text { DR Event }(\mathbf{W} \cdot \mathbf{h})\end{array}$ & $\begin{array}{c}\text { Average Daily } \\
\text { Energy Impact } \\
(\mathbf{W} \cdot \mathbf{h} / \mathbf{d a y})\end{array}$ \\
\hline $\begin{array}{l}\text { Afternoon } \\
\text { INC }\end{array}$ & HP & 1 hour & -351 & -351 & -218 \\
$\begin{array}{l}\text { Balancing } \\
\text { Event }\end{array}$ & ER & 1 hour & -908 & -908 & -15 \\
\cline { 2 - 5 } & & & & & \\
\hline
\end{tabular}

The afternoon INC balancing event decreased the daily energy use of the ERWH by $15 \mathrm{~W} \cdot \mathrm{h}$, or $0.1 \%$, which is not significant considering the variation in the data. For the HPWH, the event changed the daily energy use by $-218 \mathrm{~W}$ or $1.1 \%$ of the baseline daily energy use of the HPWH. This impact is significant and, similar to the morning INC balancing event, is probably due to the decreased hot water delivery temperature observed in the HPWH following the balancing event, as the HPWH does not have sufficient capacity to satisfy the draws on the system and maintain the hot water delivery temperature from the one-

\footnotetext{
${ }^{1}$ Positive numbers indicate increased energy use and negative numbers indicate decreased energy use.
} 
hour curtailment event with the extreme hot water draw scenario implemented in these experiments. However, it is surprising that the magnitude of the impact on daily energy use is similar $(216 \mathrm{~W} \cdot \mathrm{h}$ for the morning INC event and $218 \mathrm{~W} \cdot \mathrm{h}$ for the afternoon INC event), while the impact on hot water delivery temperature is much less severe in the afternoon INC event, a reduction of approximately $5^{\circ} \mathrm{F}$ for the afternoon event, as shown in Figure 4.17. The hot water delivery temperature drops to approximately $120^{\circ} \mathrm{F}$, which would probably not impact homeowner satisfaction, even high usage households, in a DR program using this type of DR and HPWH in heat-pump-only mode.

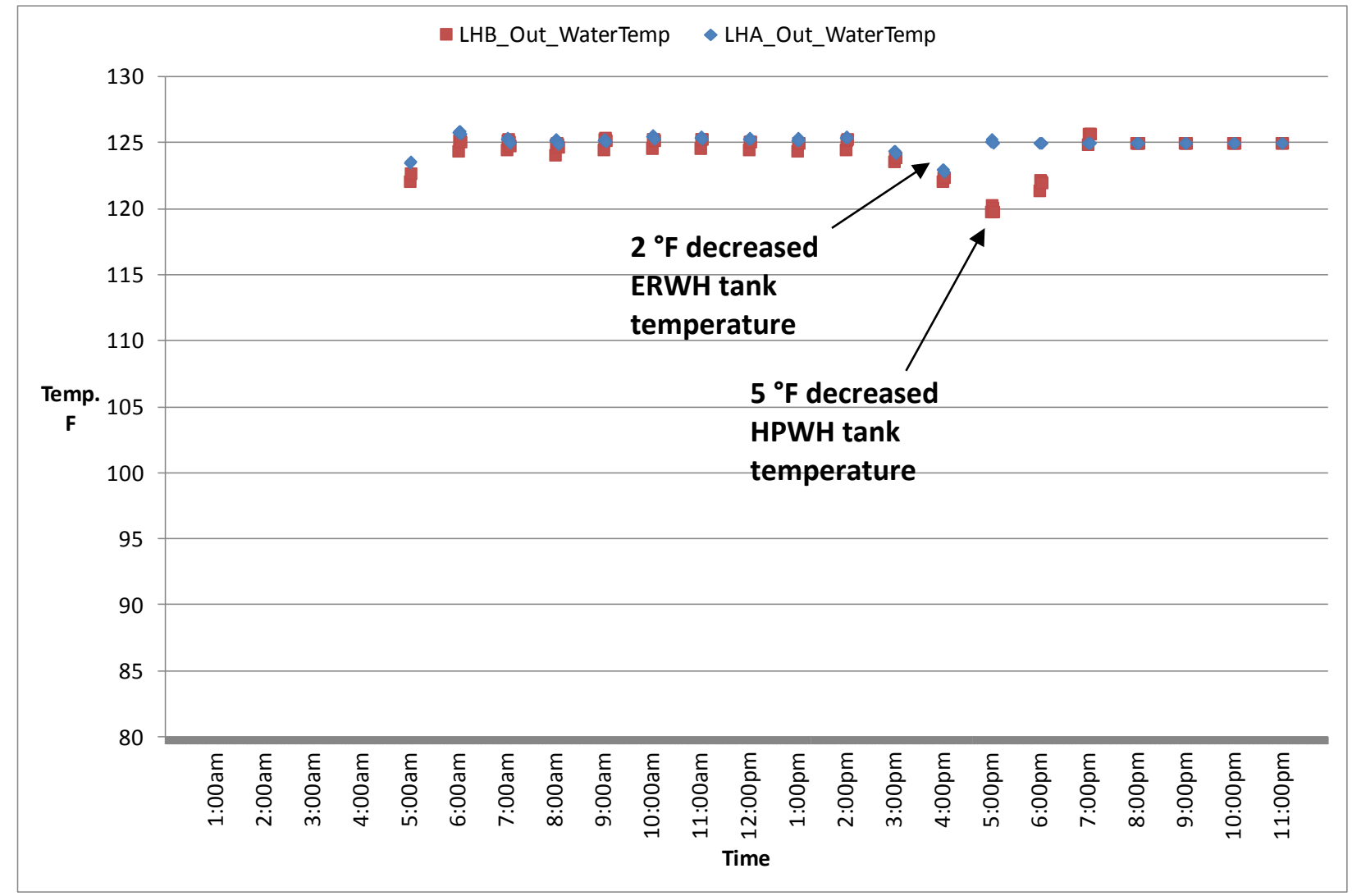

Figure 4.17. Hot Water Outlet Temperature of ERWH $(\mathrm{LHA}=$ blue $)$ and HPWH $(\mathrm{LHB}=$ red $)$ during Afternoon (2:00 p.m.) INC Balancing Event

\subsubsection{Evening INC Balancing Event}

The evening INC balancing event simulated a "conserve" signal being sent to the water heaters by setting the tank temperature to $60^{\circ} \mathrm{F}$ in Vacation mode at 8:00 p.m. and returning to the previous set point of $125^{\circ} \mathrm{F}$ and Standard or Heat Pump mode for Lab Home A and Lab Home B, respectively, at 9:00 p.m. The experiment was performed twice and resulted in an average power reduction of $1,182 \mathrm{~W}$ for the ERWH and $445 \mathrm{~W}$ for the HPWH, as shown in Figure 4.18. Because the events occur over a one-hour period, the average peak energy saved, in $\mathrm{W} \cdot \mathrm{h}$, is the same as the average peak power avoided over the hour, as indicated in Table 4.7. 


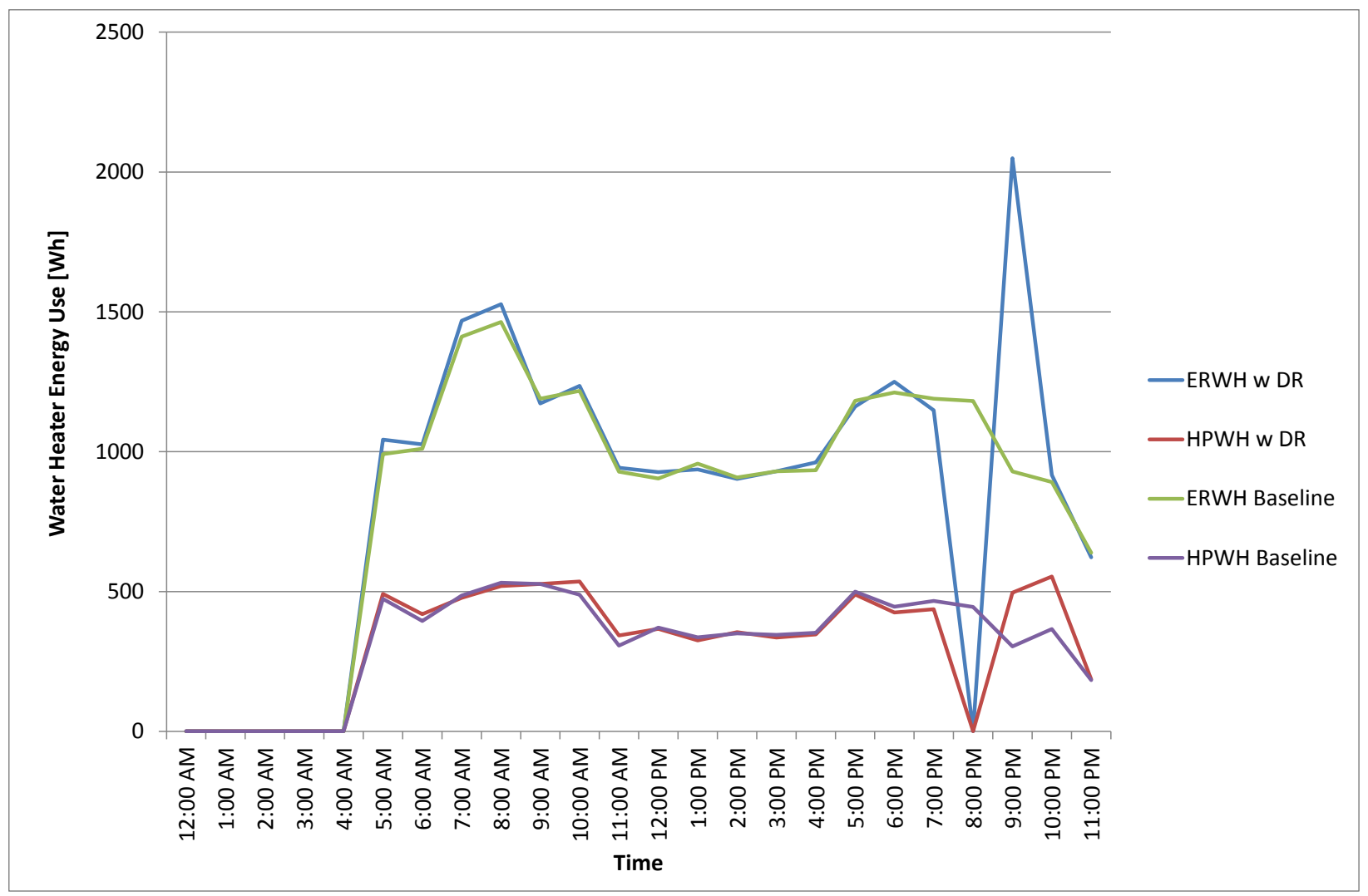

Figure 4.18. Evening INC Balancing Event Hourly Average Water Heater Energy Use Profile for the HPWH and ERWH with and without DR Signals $(W \cdot h)$

Table 4.7. Average Power Draw Impact (W), Average Energy Impact during DR Event $(\mathrm{W} \cdot \mathrm{h})$, and Average Daily Energy Impact (W.h/day) of Evening INC Balancing Event (2:00 p.m. to 3:00 p.m.) for the HPWH and ERWH. ${ }^{1}$

\begin{tabular}{lccccc}
\hline Experiment & $\begin{array}{c}\text { WH } \\
\text { Mode }\end{array}$ & Duration & $\begin{array}{c}\text { Average Power } \\
\text { Draw Impact } \\
(\mathbf{W})\end{array}$ & $\begin{array}{c}\text { Average Energy } \\
\text { Impact during } \\
\text { DR Event }(\mathbf{W} \cdot \mathbf{h})\end{array}$ & $\begin{array}{c}\text { Average Daily } \\
\text { Energy Impact } \\
(\mathbf{W} \cdot \mathbf{h} / \mathbf{d a y})\end{array}$ \\
\hline $\begin{array}{l}\text { Evening } \\
\text { INC }\end{array}$ & HP & 1 hour & -445 & -445 & -42 \\
$\begin{array}{l}\text { Balancing } \\
\text { Event }\end{array}$ & ER & 1 hour & $-1,182$ & $-1,182$ & 155 \\
\cline { 2 - 6 } & & & & & \\
\hline
\end{tabular}

The evening INC balancing event increased the daily energy use of the ERWH by $155 \mathrm{~W} \cdot \mathrm{h}$, or $0.8 \%$, which is not significant considering the variation in the data. For the HPWH, the event changed the daily energy use by $-42 \mathrm{~W}$ or $0.2 \%$ of the baseline daily energy use of the HPWH, which is not significantly different from the baseline energy consumption either. The DR event appears to have had a slight impact on hot water deliver temperature for the HPWH, as can be seen in Figure 4.19. However, the HPWH is able to recover quickly due to the decreased demand in the late evening hours and the decreased water temperature did not appreciably affect the daily energy use of the water heater. As such, this small

\footnotetext{
${ }^{1}$ Positive numbers indicate increased energy use and negative numbers indicate decreased energy use.
} 
decrease in hot water delivery temperature is not likely to impact homeowner satisfaction, even for this extremely high hot water draw profile.

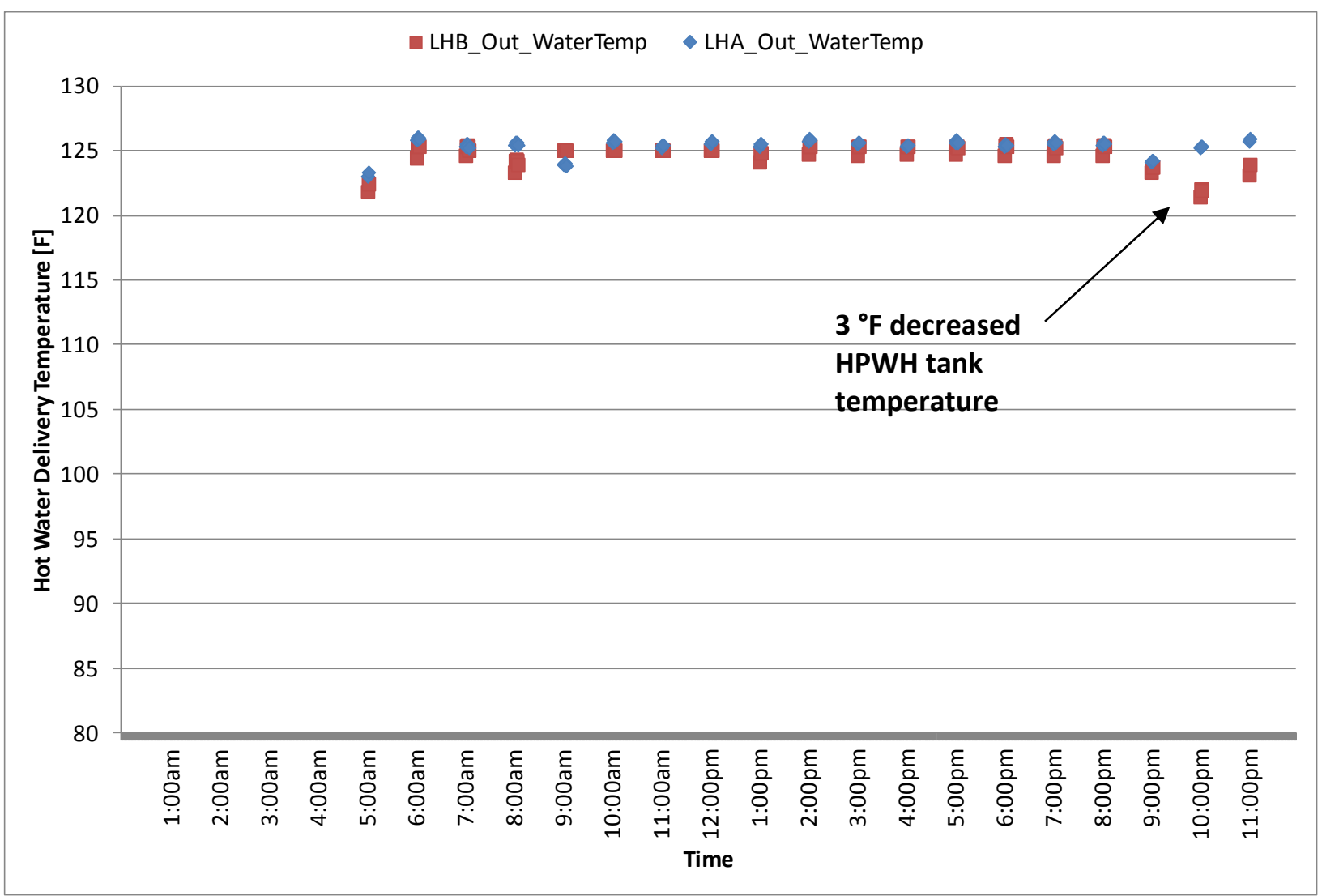

Figure 4.19. Hot Water Outlet Temperature of ERWH $(\mathrm{LHA}=$ blue $)$ and HPWH $(\mathrm{LHB}=$ red $)$ during Evening (8:00 p.m.) INC Balancing Event

\subsubsection{Late Night INC Balancing Event}

The late night INC balancing event simulated a "conserve" signal being sent to the water heaters by setting the tank temperature to $60^{\circ} \mathrm{F}$ in Vacation mode at 2:00 a.m. and returning to the previous set point of $125^{\circ} \mathrm{F}$ and Standard or Heat Pump mode for Lab Home A and Lab Home B, respectively, at 3:00 a.m. However, the late night INC balancing event does not change the power and energy use of the water heater, since both the HPWH and ERWH are both already off at 2:00 a.m. because there are no water draws in the middle of the night. Also, the standby tank losses are not significant enough to induce cycling during the nighttime either. Thus, there is not load to shed and the power and energy impact is zero, as indicated in Table 4.8. 
Table 4.8. Average Power Draw Impact (W), Average Energy Impact during DR Event $(\mathrm{W} \cdot \mathrm{h})$, and Average Daily Energy Impact (W.h/day) of Late Night INC Balancing Event (2:00 a.m. to 3:00 a.m.) for the HPWH and ERWH. ${ }^{1}$

\begin{tabular}{lccccc}
\hline Experiment & $\begin{array}{c}\text { WH } \\
\text { Mode }\end{array}$ & Duration & $\begin{array}{c}\text { Average Power } \\
\text { Draw Impact } \\
(\mathbf{W})\end{array}$ & $\begin{array}{c}\text { Average Energy } \\
\text { Impact during } \\
\text { DR Event }(\mathbf{W} \cdot \mathbf{h})\end{array}$ & $\begin{array}{c}\text { Average Daily } \\
\text { Energy Impact } \\
(\mathbf{W} \cdot \mathbf{h} / \mathbf{d a y})\end{array}$ \\
\hline $\begin{array}{l}\text { Late Night } \\
\text { INC } \\
\text { Balancing } \\
\text { Event }\end{array}$ & HP & 1 hour & 0 & 0 & 0 \\
\cline { 2 - 7 } & ER & 1 hour & 0 & 0 & 0 \\
\hline
\end{tabular}

\subsubsection{Generation DEC Balancing Events}

The other type of balancing reserves simulated were DEC events, where it is advantageous to increase load to balance an excess in generation capacity. These events are primarily for integration of renewable resources, which have intermittent, unpredictable, and highly-variable generation patterns.

\subsubsection{Morning DEC Balancing Event}

The morning DEC balancing event was simulated by sending a signal to the water heaters to increase load by setting the tank temperature to $135^{\circ} \mathrm{F}$ at $8: 00 \mathrm{a} . \mathrm{m}$. and returning to the previous set point of $125^{\circ} \mathrm{F}$ at 9:00 a.m. The operating modes of the water heaters, Standard or Heat Pump mode for Lab Home A and Lab Home B, respectively, were maintained during the DR event. A temperature of $135^{\circ} \mathrm{F}$ was chosen because it is achievable with controls on the commercially available residential water heaters and does not pose a scald risk to occupants in the absence of a thermal mixing valve. Thus, increasing the tank temperature to only $135^{\circ} \mathrm{F}$ will limit the amount of energy that can be used by the water heater or the duration of DR response from the water heater, but it will also limit the risk associated with a DEC balancing program.

The morning DEC balancing experiment was performed three times and resulted in an average power increase of 1,305 W for the ERWH and only $26 \mathrm{~W}$ for the HPWH, as shown in Figure 4.20. The potential to provide increased load for each water heater depends on the extent to which it is already engaged at full capacity in the baseline operation. For the ERWH, the ERWH is on for 31\% of the hour between 8:00 a.m. and 9:00 a.m to satisfy the 10 gallon hot water draw. The DEC event increased the operation of the

ERWH, at a fixed output of approximately $4,650 \mathrm{~W}$, to $60 \%$ of the hour for a total hourly demand of $2,769 \mathrm{~W}$. This can be seen by the increased width of the ERWH "band" at 8:00 a.m. for the ERWH in

Figure 4.21. The ERWH does not continue operating after 36 minutes (60\% of an hour) because the tank has reached $135^{\circ} \mathrm{F}$ and the thermostat is satisfied. For the HPWH, the heat pump was already operating $91 \%$ of the hour (54 minutes) just to keep up with the load induced by the 10 gallon hot water draw. Thus, the heat pump can only provide $39 \mathrm{~W}$ of increased energy use; essentially, the heat pump can increase operation from 54 minutes only an additional 6 minutes.

\footnotetext{
${ }^{1}$ Positive numbers indicate increased energy use and negative numbers indicate decreased energy use.
} 


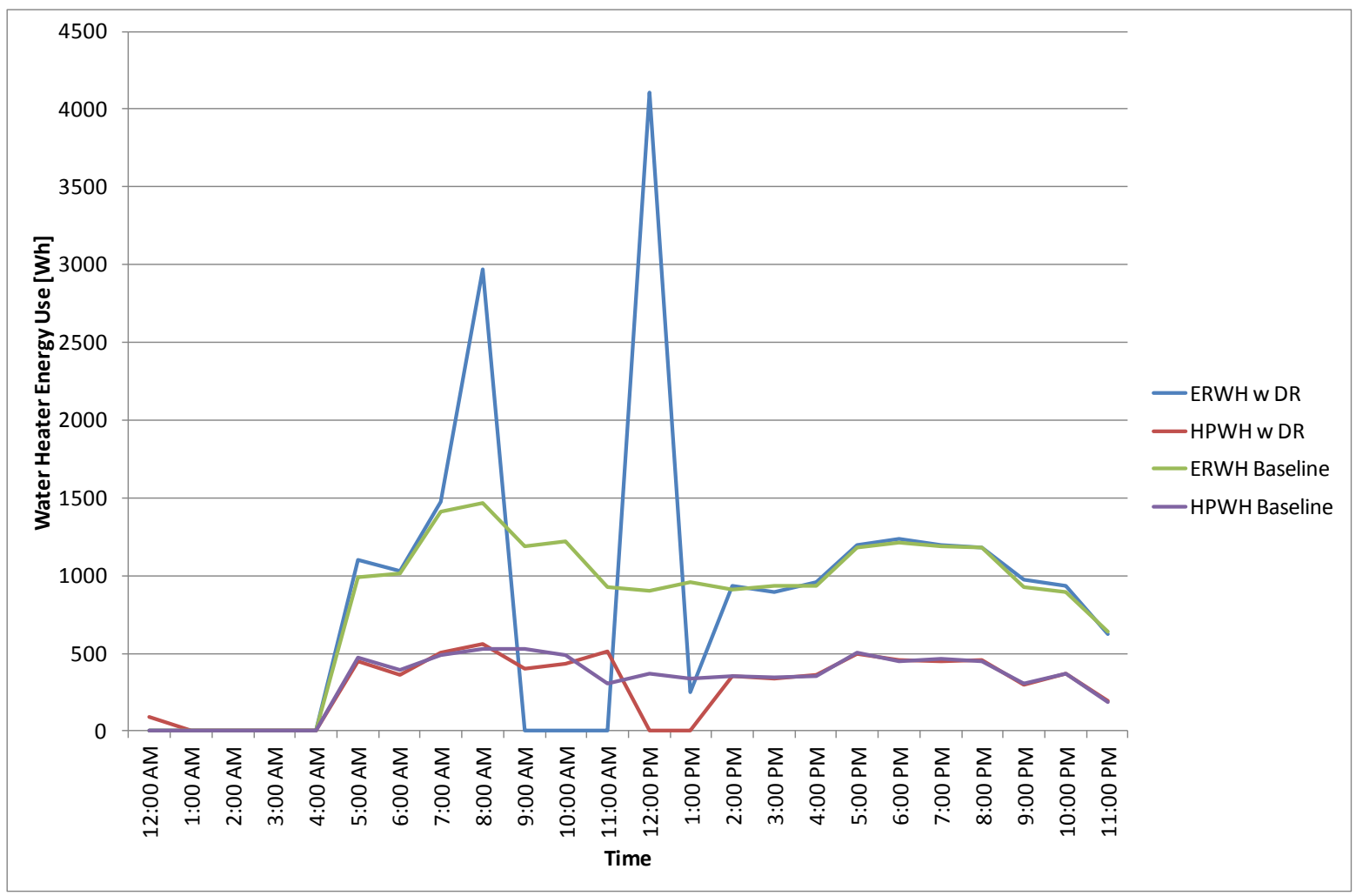

Figure 4.20. Morning DEC Balancing Event Hourly Average Water Heater Energy Use Profile for the HPWH and ERWH with and without DR Signals $(\mathrm{W} \cdot \mathrm{h})$

When the thermostat is set back to $125^{\circ} \mathrm{F}$, the ERWH coasts for several hours due to the increased thermal storage in the $135^{\circ} \mathrm{F}$ water. However, there is another period of increased energy use observed at approximately 1:00 p.m., as shown in

Figure 4.21. It is hypothesized that this is due to stratification in the tank such that the upper thermistor controlling the tank temperature continues to measure temperatures at or above the set point during the coasting period. However, water draws continue to occur, adding cold water back into the bottom of the tank. Then, when a certain volume of hot water has been used and replaced with cold water, the upper tank thermistor is brought below the set point; when heating is resumed, there is a large volume of unheated water, causing the higher than normal energy use following the coasting period. 


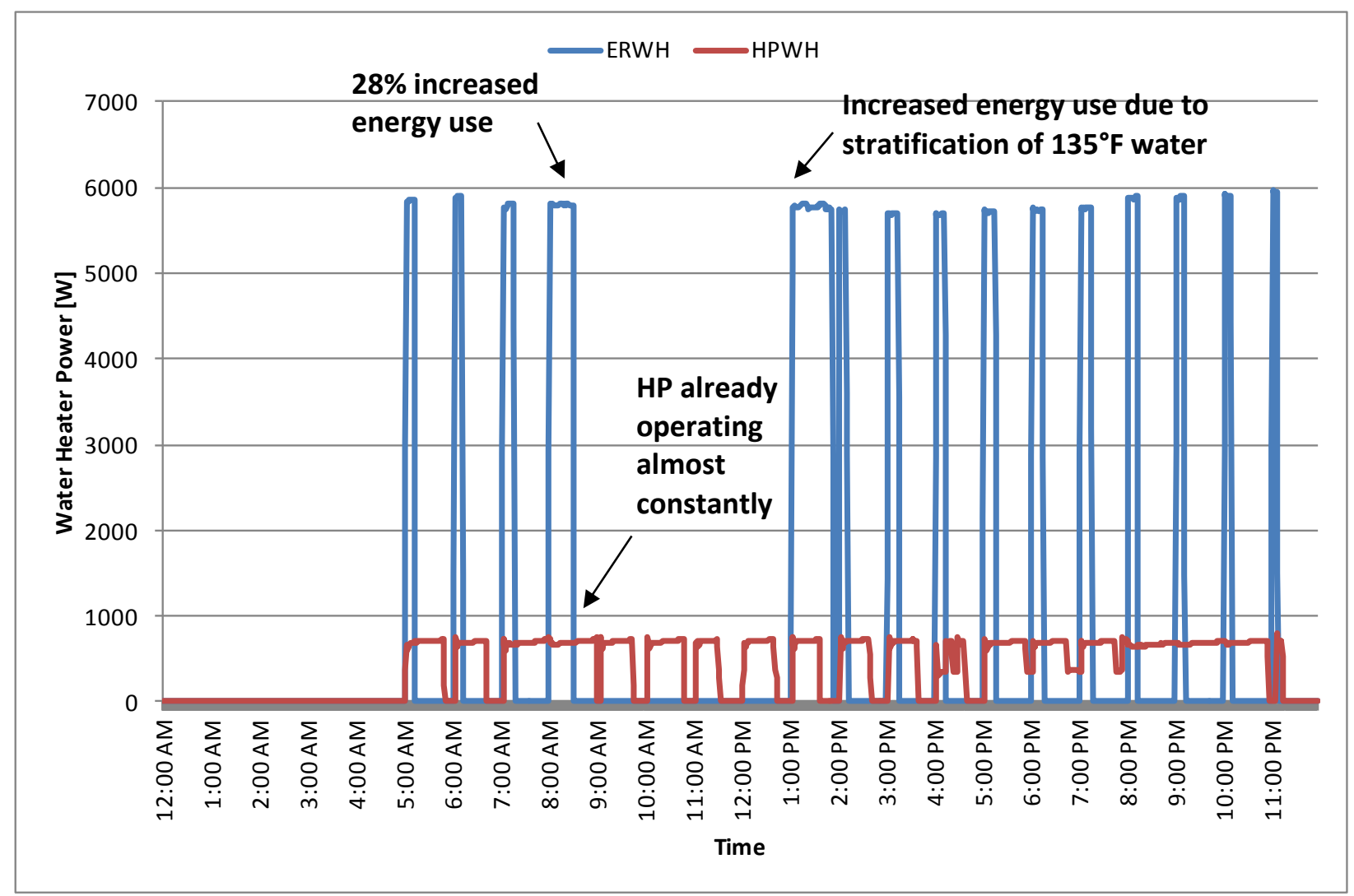

Figure 4.21. Power Draw from ERWH (blue) and HPWH (red) for One Day during the Morning DEC Balancing Event

This increased energy use was seen repeatedly on each of the three days this experiment was conducted, and thus is believed to be a real phenomenon rather than an aberration in the data. This "coast" and "rebound" phenomenon is caused by the function of the thermostat control strategy, which references a single thermistor (near the top element). This thermistor doesn't detect the temperature of the tank below the measurement point and doesn't sense the need for heating since the temperature measured at the thermistor point is still well above the tank set point. GE is aware that this response may be an issue when using GE GeoSpring Hybrid HPWHs as thermal storage devices at elevated temperature in Standard mode or Hybrid mode when the electric resistance elements are allowed to come on. GE is currently considering modifications to the control logic that would eliminate this behavior. ${ }^{1}$ In addition, this may not be a typical control strategy for a conventional ERWH and further experimentation would be required to determine the DEC balancing behavior with a standard ERWH. Repeating these experiments with a full insertion thermocouple tree to measure stratification within the tank as the tank temperature is raised and then coasts back to the set point would also provide interesting information to support future analysis and modeling efforts.

Conversely, the HPWH tank temperature was not elevated because the HPWH was only operating six extra minutes, as compared to the baseline energy use profile. Thus, there is no coasting or rebound effect observed in the HPWH data.

\footnotetext{
${ }^{1}$ S. Schaffer, Sr. Development Engineer, GE Appliances. Personal communication. July 30, 2013.
} 
Because the events occur over a one-hour period, the average peak energy saved, in $\mathrm{W} \cdot \mathrm{h}$, is the same as the average peak power avoided over the hour, as indicated in Table 4.9. The daily energy impact of the morning DEC event was an increase of $1,309 \mathrm{~W} \cdot \mathrm{h}$ for the ERWH $(6.5 \%)$ and a decrease of $689 \mathrm{~W} \cdot \mathrm{h}$ for the HPWH (0.8\%). It is expected that the increased energy use for the ERWH case is a result of the rebound effect experienced in the early afternoon and slightly increased thermal losses during the coasting period. On the other hand, the decreased daily water heater energy use in the case of the HPWH may be due to decreased compressor cycling in the morning hours. However, further analysis would be required to verify this preliminary hypothesis.

Table 4.9. Average Power Draw Impact (W), Average Energy Impact during DR Event $(\mathrm{W} \cdot \mathrm{h})$, and Average Daily Energy Impact (W.h/day) of Morning DEC Balancing Event (8:00 a.m. to 9:00 a.m.) for the HPWH and ERWH. ${ }^{1}$

\begin{tabular}{lccccc}
\hline Experiment & $\begin{array}{c}\text { WH } \\
\text { Mode }\end{array}$ & Duration & $\begin{array}{c}\text { Average Power } \\
\text { Draw Impact } \\
\text { (W) }\end{array}$ & $\begin{array}{c}\text { Average Energy } \\
\text { Impact during } \\
\text { DR Event }(\mathbf{W} \cdot \mathbf{h})\end{array}$ & $\begin{array}{c}\text { Average Daily } \\
\text { Energy Impact } \\
(\mathbf{W} \cdot \mathbf{h} / \mathbf{d a y})\end{array}$ \\
\hline $\begin{array}{l}\text { Morning } \\
\text { DEC } \\
\text { Balancing } \\
\text { Event }\end{array}$ & HP & 1 hour & 26 & 26 & -689 \\
\cline { 2 - 6 } & ER & 1 hour & 1,305 & 1,305 & 1,309 \\
\hline
\end{tabular}

\subsubsection{Afternoon DEC Balancing Event}

The afternoon DEC balancing event sent a signal to the water heaters to increase load by setting the tank temperature to $135^{\circ} \mathrm{F}$ at 2:00 p.m. and returning to the previous set point of $125^{\circ} \mathrm{F}$ at 3:00 p.m. The operating modes of the water heaters, Standard or Heat Pump mode for Lab Home A and Lab Home B, respectively, were maintained during the DR event. The afternoon DEC balancing experiment was performed twice; however, the signal was not successfully received by the ERWH. Therefore, the ERWH response was estimated based on the theoretical amount of energy that would need to be supplied to heat the tank to $135^{\circ} \mathrm{F}$ and heat the incoming cold water due to the 6 gallons hot water draw experienced during that hour (see Appendix $\mathrm{C}$ for more details). This calculation resulted in an average power increase of 1,381 W for the ERWH and only $182 \mathrm{~W}$ for the HPWH, as shown in Figure 4.22.

\footnotetext{
${ }^{1}$ Positive numbers indicate increased energy use and negative numbers indicate decreased energy use.
} 


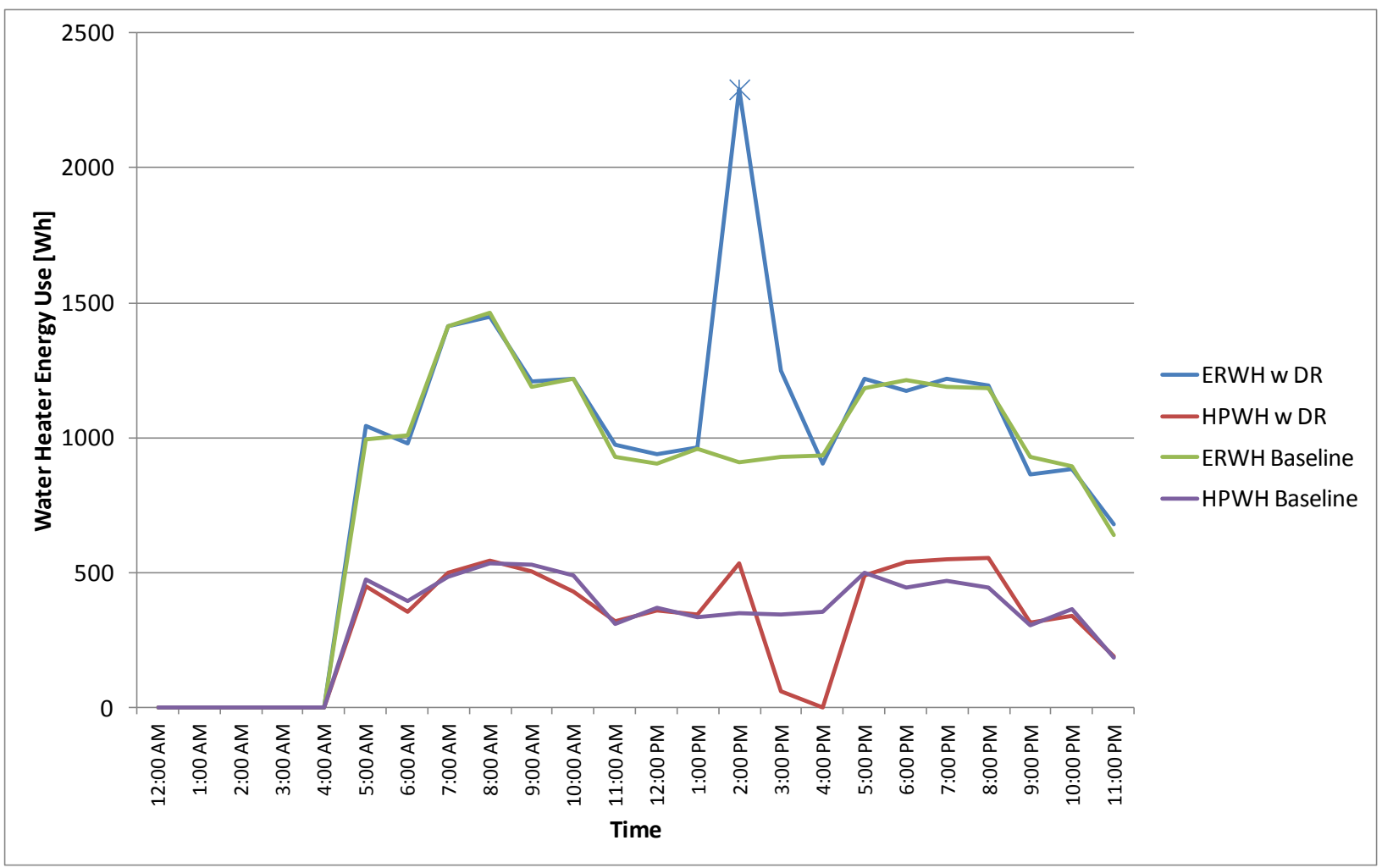

Figure 4.22. Afternoon DEC Balancing Event Hourly Average Water Heater Energy Use Profile for the HPWH and ERWH with and without DR Signals $(\mathrm{W} \cdot \mathrm{h}) . *$ = Data point is estimated based on theoretical calculation.

The potential to provide increased load for the ERWH was approximately the same as in the morning case, since the load was saturated at the $135^{\circ} \mathrm{F}$ set point in both cases, and thus the same amount of additional energy was consumed. However, for the HPWH, the water draws are lower in the middle of the day and the HPWH is operating only $60 \%$ of the time in baseline operation; thus the HPWH can increase its load another $40 \%$, or another 24 minutes. When the thermostat is set back to $125^{\circ} \mathrm{F}$, the rebound observed previously in the ERWH is not experienced, as that data is estimated. The approximate power and energy impacts are given in Table 4.10.

Table 4.10. Average Power Draw Impact (W), Average Energy Impact during DR Event $(\mathrm{W} \cdot \mathrm{h})$, and Average Daily Energy Impact (W.h/day) of Afternoon DEC Balancing Event (8:00 a.m. to 9:00 a.m.) for the HPWH and ERWH. ${ }^{1}$

\begin{tabular}{lccccc}
\hline Experiment & $\begin{array}{c}\text { WH } \\
\text { Mode }\end{array}$ & Duration & $\begin{array}{c}\text { Average } \\
\text { Power Draw } \\
\text { Impact } \\
\mathbf{( W )}\end{array}$ & $\begin{array}{c}\text { Average Energy } \\
\text { Impact during DR } \\
\text { Event } \\
\mathbf{( W \cdot h )}\end{array}$ & $\begin{array}{c}\text { Average Daily } \\
\text { Energy Impact } \\
\text { (W·h/day) }\end{array}$ \\
\hline $\begin{array}{l}\text { Afternoon } \\
\text { DEC }\end{array}$ & HP & 1 hour & 182 & 182 & -297 \\
\cline { 2 - 6 } Balancing & ER & 1 hour & $1,381 *$ & $1,381 *$ & $1,776^{*}$ \\
\cline { 2 - 6 } & $*$ data point is estimated based on theoretical calculation & \\
\hline
\end{tabular}

${ }^{1}$ Positive numbers indicate increased energy use and negative numbers indicate decreased energy use. 


\subsubsection{Evening DEC Balancing Event}

The evening DEC balancing event sent a signal to the water heaters to increase load by setting the tank temperature to $135^{\circ} \mathrm{F}$ at 8:00 p.m. and returning to the previous set point of $125^{\circ} \mathrm{F}$ at 9:00 p.m. The operating modes of the water heaters, Standard or Heat Pump mode for Lab Home A and Lab Home B, respectively, were maintained during the DR event. The experiment was performed three times and resulted in an average power increase of $786 \mathrm{~W}$ for the ERWH and $98 \mathrm{~W}$ for the HPWH, as shown in Figure 4.23.

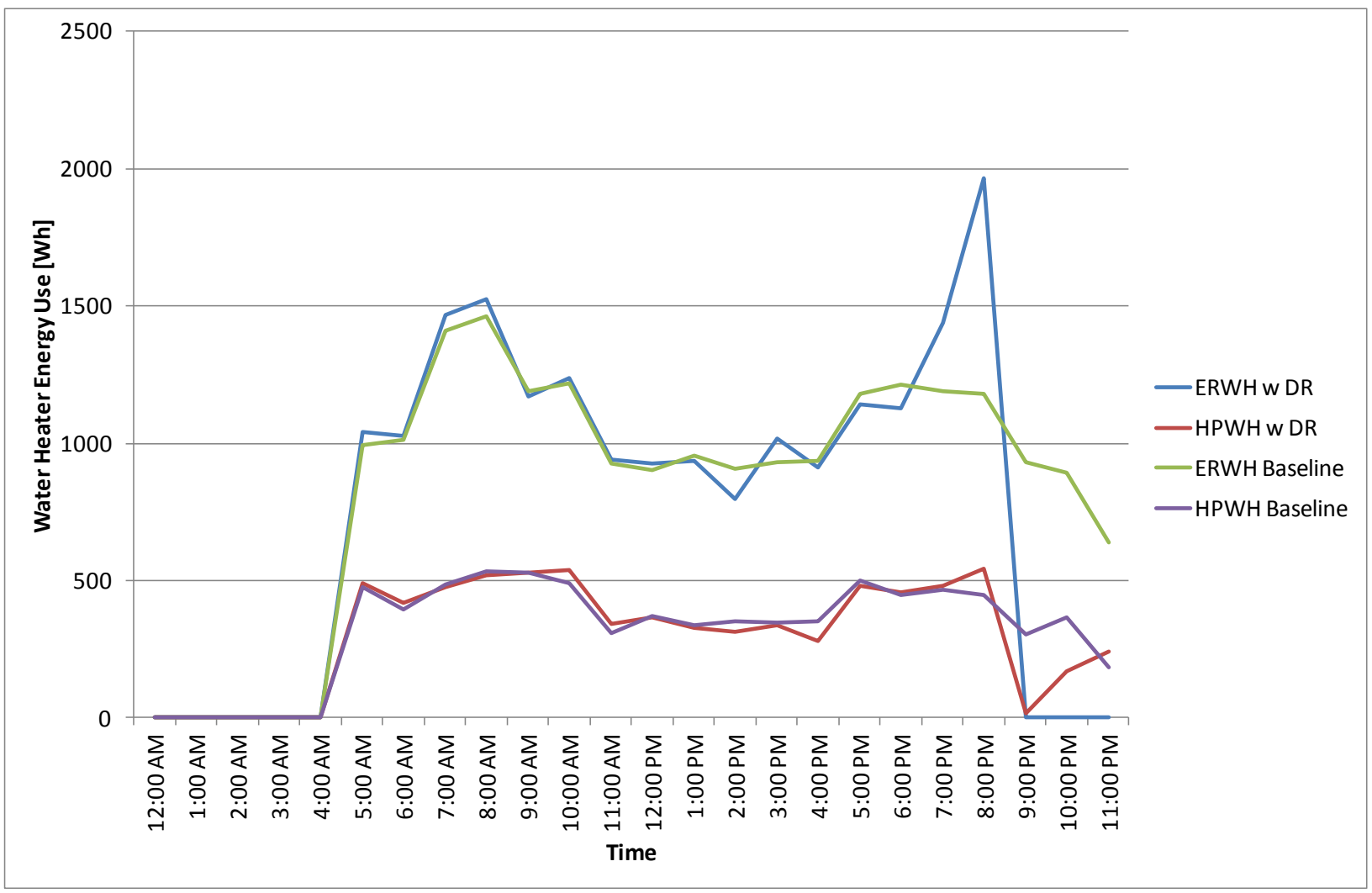

Figure 4.23. Evening DEC Balancing Event Hourly Average Water Heater Energy Use Profile for the HPWH and ERWH with and without DR Signals $(W \cdot h)$

The ERWH's potential to increase load is somewhat diminished from what is expected based on the previous experiments and theoretical calculations (see Appendix C). Theoretically, the energy use to increase the tank temperature to $135^{\circ} \mathrm{F}$ and account for the significant draws at 8:00 p.m. would be 2,557 $\mathrm{W} \cdot \mathrm{h}$. However, the measured energy use during the period from 8:00 p.m. to 9:00 p.m. was an average of only $1,968 \mathrm{~W} \cdot \mathrm{h}$ over the three days this experiment was implemented. As with the morning DEC balancing event, it is believed that this unexpected behavior is due to stratification and unusual thermocline behavior in the tank. Notably, the morning (8:00 a.m.) and evening (8:00 p.m.) DEC balancing experiments were performed in the same 24-hour period for three days. Thus, the morning increase in tank temperature, and subsequent usual "coast" and "rebound" period (see section 4.4.2.1) may have impacted the evening experiment. For example, if the tank is reheated to $135^{\circ} \mathrm{F}$ while there is 
still some residual elevated-temperature water in the tank (due to limited mixing and the location of the thermistors), less energy will be required to return to the elevated temperature. However, the hot water outlet temperature, shown in Figure 4.24, does not indicate elevated temperature water remaining in the tank past approximately 2:00 p.m. in the ERWH. The HPWH outlet temperature is elevated only slightly, $1-2^{\circ} \mathrm{F}$, at the times of the DEC DR events (8:00 a.m. and 8:00 p.m.) due to the decreased capacity of the heat pump. Based on the data collected in these experiments, it is not possible to identify the root cause of the unusual evening DEC behavior in the ERWH.

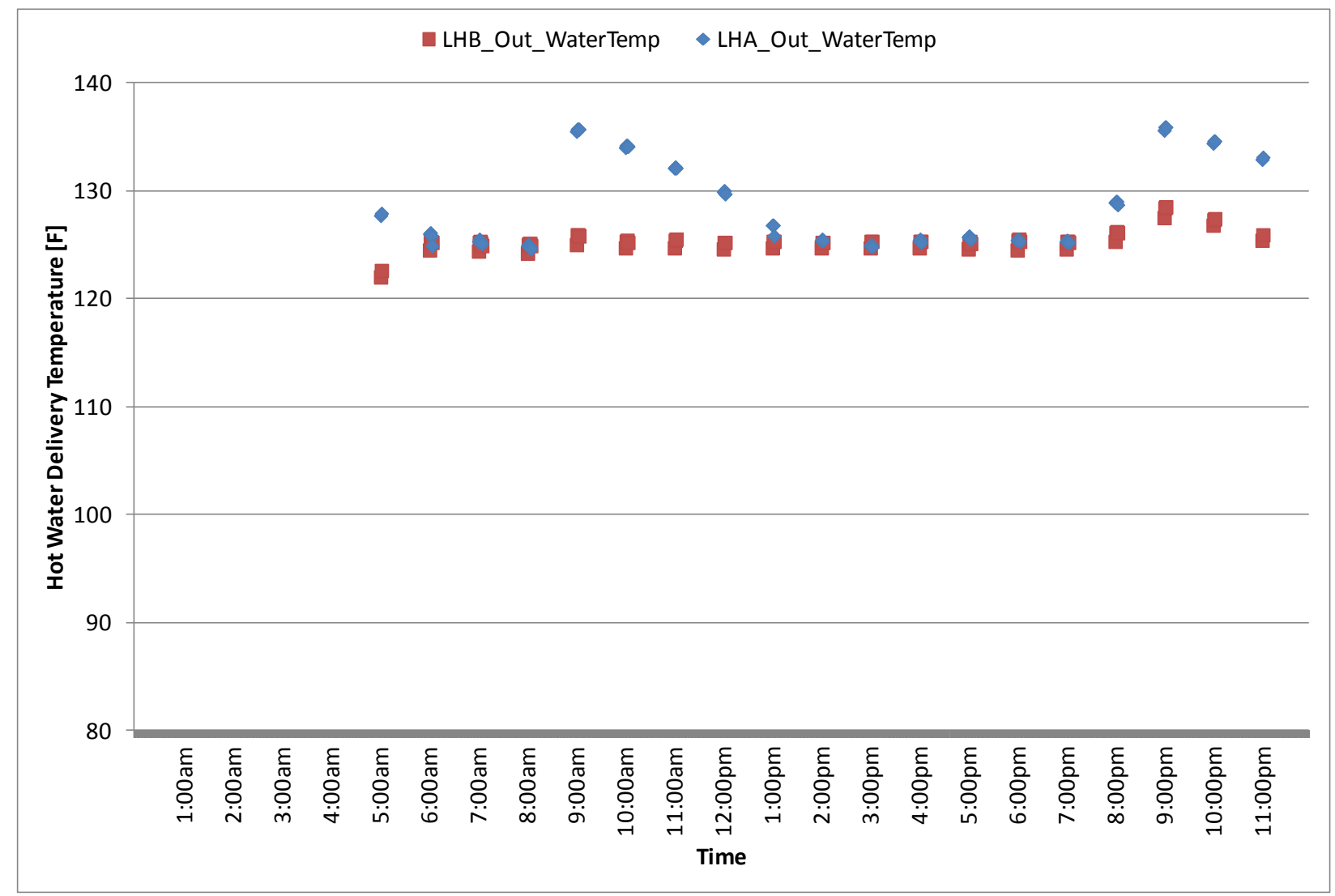

Figure 4.24. Hot Water Outlet Temperature of ERWH (LHA = blue) and HPWH (LHB = red) during a Day When Morning (8:00 a.m.) and Evening (8:00 p.m.) DEC Balancing Events Were Implemented

Figure 4.25 shows the average energy use profile for the ERWH and HPWH for the full experiment implemented at 8:00 a.m. and 8:00 p.m. for three days and the baseline for each. As the 24-hour experimental period was performed three days in a row, the rebound from the evening event occurs the following morning after a prolonged coast period which lasts overnight due to the limited or no draw activity overnight. We surmise that, like the morning DEC event, this is caused by stratification and the control strategy affecting the thermocline and heating element operation in the tank, but verifying this would require subsequent experimentation using a standard ERWH (with a more simplistic control strategy) and a full thermocouple tree in the tank to observe the tank stratification. 


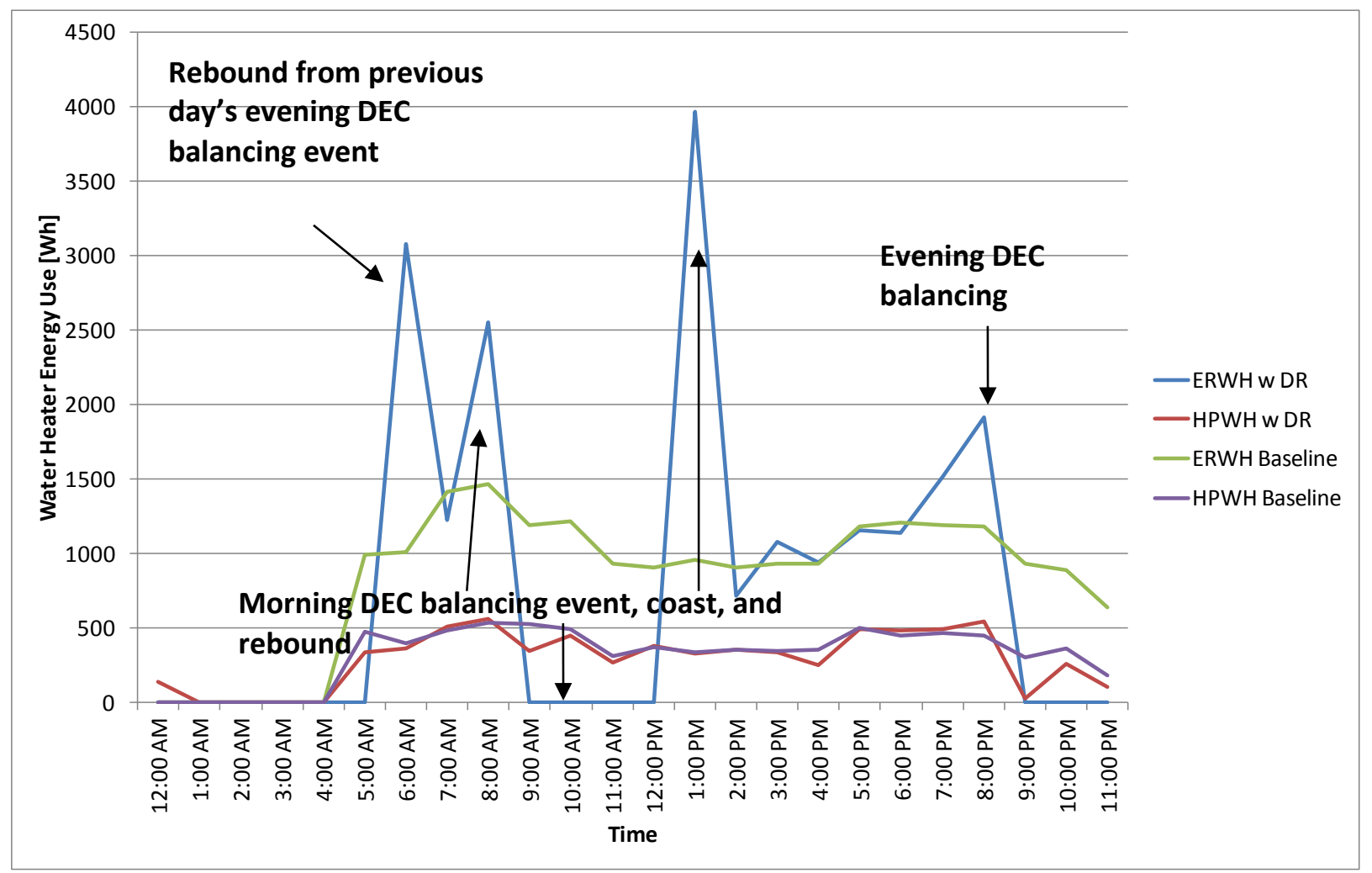

Figure 4.25. Evening DEC Balancing Event Hourly Average Water Heater Energy Use Profile for the HPWH and ERWH with and without DR Signals $(W \cdot h)$

Table 4.11 presents the average power draw impact, hourly energy use impact, and daily energy use impact for the HPWH and ERWH. For the peak power and average hourly energy impact, both the measured and theoretical values are provided for the ERWH. In addition, the unexpected tank stratification behavior impacted the measured daily energy use and made it difficult to disaggregate the daily energy impact of the evening DEC event only.

Table 4.11. Average Power Draw Impact (W), Average Energy Impact during DR Event $(\mathrm{W} \cdot \mathrm{h})$, and Average Daily Energy Impact (W.h/day) of Evening DEC Balancing Event (8:00 p.m. to 9:00 p.m.) for the HPWH and ERWH. ${ }^{1}$

\begin{tabular}{lccccc}
\hline Experiment & $\begin{array}{c}\text { WH } \\
\text { Mode }\end{array}$ & Duration & $\begin{array}{c}\text { Average } \\
\text { Power Draw } \\
\text { Impact } \\
(\mathbf{W})\end{array}$ & $\begin{array}{c}\text { Average Energy } \\
\text { Impact during DR } \\
\text { Event } \\
(\mathbf{W} \cdot \mathbf{h})\end{array}$ & $\begin{array}{c}\text { Average Daily } \\
\text { Energy Impact } \\
(\mathbf{W} \cdot \mathbf{h} / \mathbf{d a y})\end{array}$ \\
\hline $\begin{array}{l}\text { Morning } \\
\text { DEC } \\
\text { Balancing } \\
\text { Event }\end{array}$ & HP & 1 hour & 98 & 98 & -347 \\
\cline { 2 - 6 } & ER & 1 hour & $\begin{array}{c}787 \\
\left(1,222^{*}\right)\end{array}$ & $\begin{array}{c}787 \\
(1,222 *)\end{array}$ & Unable to calculate \\
\cline { 2 - 6 } & $*$ = data point is estimated based on theoretical calculation & \\
\hline
\end{tabular}

\footnotetext{
${ }^{1}$ Positive numbers indicate increased energy use and negative numbers indicate decreased energy use.
} 


\subsubsection{Late Night DEC Balancing Event}

The evening DEC balancing event sent a signal to the water heaters to increase load by setting the tank temperature set point to $135^{\circ} \mathrm{F}$ at 2:00 a.m. and returning to the previous set point of $125^{\circ} \mathrm{F}$ at 3:00 a.m. The operating modes of the water heaters, Standard or Heat Pump mode for Lab Home A and Lab Home B, respectively, were maintained during the DR event. The experiment was performed three times and resulted in an estimated average power increase of 1,222 W for the ERWH and a measured average power increase of $578 \mathrm{~W}$ for the HPWH, as shown in Figure 4.26. Due to connectivity issues and the difficulty of manually changing the tank temperature at 2:00 a.m., the ERWH data point is estimated based on the theoretical energy required to heat the tank to $135^{\circ} \mathrm{F}$.

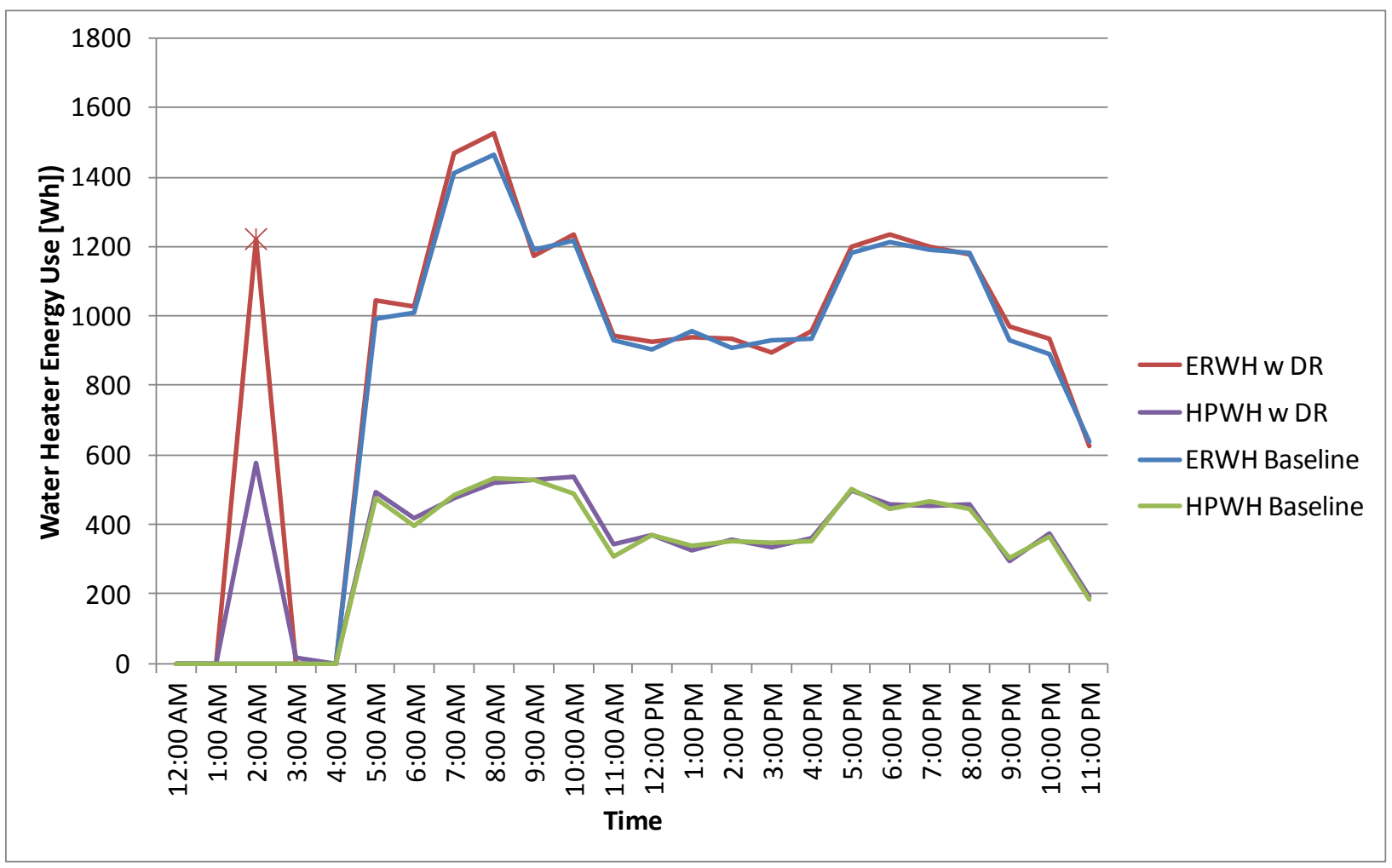

Figure 4.26. Late Night DEC Balancing Event Hourly Average Water Heater Energy Use Profile for the HPWH and ERWH with and without DR Signals $(W \cdot h)$

Because the events occur over a one-hour period, the average peak energy saved, in $\mathrm{W} \cdot \mathrm{h}$, is the same as the average peak power avoided over the hour, as indicated in Table 4.12. The late night DEC balancing event increased daily energy use $700 \mathrm{~W} \cdot \mathrm{h}$ for the HPWH, slightly more than the energy impact during the 1-hour DR period. This is probably due to increased thermal losses through the tank, which reaches $130^{\circ} \mathrm{F}$ over the 1 -hour DEC event. However, the ERWH average daily energy impact is not provided due to the difficulty of estimating the impact of the increased temperature on tank mixing and daily energy use. 
Table 4.12. Average Power Draw Impact (W), Average Energy Impact during DR Event $(\mathrm{W} \cdot \mathrm{h})$, and Average Daily Energy Impact (W.h/day) of Late Night DEC Balancing Event (2:00 a.m. to 3:00 a.m.) for the HPWH and ERWH. ${ }^{1}$

\begin{tabular}{lccccc}
\hline Experiment & $\begin{array}{c}\text { WH } \\
\text { Mode }\end{array}$ & Duration & $\begin{array}{c}\text { Average Power } \\
\text { Draw Impact } \\
\text { (W) }\end{array}$ & $\begin{array}{c}\text { Average Energy } \\
\text { Impact during } \\
\text { DR Event } \\
(\mathbf{W} \cdot \mathbf{h})\end{array}$ & $\begin{array}{c}\text { Average Daily } \\
\text { Energy Impact } \\
(\mathbf{W} \cdot \mathbf{h} / \mathbf{d a y})\end{array}$ \\
\hline $\begin{array}{l}\text { Late Night } \\
\text { DEC } \\
\text { Balancing } \\
\text { Event }\end{array}$ & HP & 1 hour & 577 & 577 & 700 \\
\cline { 2 - 6 } & ER & 1 hour & $1,222^{*}$ & $1,222^{*}$ & Unable to calculate \\
\cline { 2 - 5 } & $*$ data point is estimated based on theoretical calculation & \\
\hline
\end{tabular}

\subsubsection{Increased Temperatures}

In addition to more modest elevations in tank temperature (to $135^{\circ} \mathrm{F}$ ), more significant elevated temperatures are possible, which would result in increased DEC potential. Both the ERWH and the HPWH are capable of reaching temperatures of $170^{\circ} \mathrm{F}$ with modified controls and minimal hardware. Theoretically, heating the tank to $170^{\circ} \mathrm{F}$ would result in an increased energy use of $5,500 \mathrm{~W} \cdot \mathrm{h}$, or approximately 71 minutes of constant operation at 4,650 W. For the HPWH, increasing the temperature set point to $170^{\circ} \mathrm{F}$ would result in the same increase in energy use during the DR period, but would only increase power use $587 \mathrm{~W}$ and reaching $170^{\circ} \mathrm{F}$ would take approximately 4 hours. ${ }^{2}$

\footnotetext{
${ }^{1}$ Positive numbers indicate increased energy use and negative numbers indicate decreased energy use.

${ }^{2}$ S. Schaffer, Sr. Development Engineer, GE Appliances. Personal communication. August 5, 2013.
} 


\subsection{Conclusions}

Based on the data collected in these DR experiments, both ERWHs and HPWHs can perform peak curtailment and regulation services. However, their DR characteristics and energy use impacts differ, as can be seen in Table 5.1, which shows the average impact on power use during the DR event, energy use during the DR event, and daily energy use for the ERWH and HPWH for peak curtailment, INC events, and DEC events in general. The results from the temporally based experiments described above are averaged to provide a general characteristic response for each type of water heater for a given DR event. In Table 5.1, the number of HPWHs that would be required to participate in a DR program to provide the same magnitude of power increase or reduction as a single ERWH is also tabulated.

Table 5.1. Average Power Draw Impact $(W)$, Average Energy Impact during DR Event $(W \cdot h)$, and Average Daily Energy Impact (W·h/day) of Peak Curtailment, INC Balancing, and DEC Balancing Events for the HPWH and ERWH. ${ }^{1}$

\begin{tabular}{|c|c|c|c|c|c|c|}
\hline Experiment & Duration & $\begin{array}{c}\text { WH } \\
\text { Mode }\end{array}$ & $\begin{array}{l}\text { Average } \\
\text { Power Draw } \\
\text { Impact } \\
\text { (W) }\end{array}$ & $\begin{array}{c}\text { Average } \\
\text { Energy } \\
\text { Impact during } \\
\text { DR Event } \\
(\mathbf{W} \cdot \mathbf{h})\end{array}$ & $\begin{array}{c}\text { Average Daily } \\
\text { Energy Impact } \\
(\mathbf{W} \cdot \mathbf{h} / \text { day })\end{array}$ & $\begin{array}{c}\text { Number } \\
\text { Equivalent } \\
\text { HPWH/ERWH }\end{array}$ \\
\hline $\begin{array}{l}\text { Peak } \\
\text { Curtailment }\end{array}$ & 3 hours & $\begin{array}{l}\mathrm{HP} \\
\mathrm{ER}\end{array}$ & $\begin{array}{r}-439 \\
-1,158\end{array}$ & $\begin{array}{l}-1,285 \\
-3,320\end{array}$ & $\begin{array}{r}-498 \\
258\end{array}$ & 2.64 \\
\hline $\begin{array}{l}\text { INC } \\
\text { Balancing } \\
\text { Event* }\end{array}$ & 1 hour & $\begin{array}{l}\text { HP } \\
\text { ER }\end{array}$ & $\begin{array}{r}-442 \\
-1,185\end{array}$ & $\begin{array}{r}-442 \\
-1,185\end{array}$ & $\begin{array}{r}-159 \\
86\end{array}$ & 2.67 \\
\hline $\begin{array}{l}\text { DEC } \\
\text { Balancing } \\
\text { Event }\end{array}$ & 1 hour & $\begin{array}{l}\text { HP } \\
\text { ER }\end{array}$ & $\begin{array}{r}220 \\
1,174\end{array}$ & $\begin{array}{r}220 \\
1,174\end{array}$ & $\begin{array}{l}-158 \\
1,543\end{array}$ & $17.1 * *$ \\
\hline \multicolumn{7}{|c|}{$\begin{array}{l}*=\text { does not include } 2 \text { a.m. INC Balancing Event, for which both water } \\
\text { heaters had no hot water draw and thus zero load. } \\
* *=\text { ranges from } 2.12 \text { for } 2 \text { a.m. event to } 50.6 \text { for } 8 \text { a.m. DEC event, } \\
\text { when HPWH ramping capability was significantly decreased. }\end{array}$} \\
\hline
\end{tabular}

\subsection{Peak Curtailment Events}

For peak curtailment experiments, both the HPWH and ERWH could reduce load in response to "conserve" signals sent from the grid. In addition, the response was fairly consistent for the morning, afternoon, and evening periods. The ERWH has greater capacity to reduce load than the HPWH, due to the increased power draw per ERWH. However, an HPWH operates more often and for longer duration than the ERWHs, so the HPWH has a higher likelihood of being energized and able to respond when the "conserve" signal is sent. The HPWH is energized approximately 2.68 times as often as the ERWH. Therefore, in a population of water heaters, an HPWH is 2.68 times more likely to respond, which decreases the number of HPWHs required to provide the same magnitude of $\mathrm{kW}$ reduction as a single ERWH.

\footnotetext{
${ }^{1}$ Positive numbers indicate increased energy use and negative numbers indicate decreased energy use.
} 
The peak curtailment events appeared to increase daily energy use slightly for the ERWH, although not significantly, and decrease HPWH energy use. The decreased daily energy use experienced in the HPWH is due to decreased hot water delivery temperatures observed following the peak curtailment events when the heat pump could not maintain the tank temperature and meet the significant hourly draws as well. During the HPWH peak curtailment event, hot water delivery temperatures as low as $110^{\circ} \mathrm{F}$ were experienced using the heat pump as the only heating source under the high hot water draw profile implemented in these experiments. More typical draw volumes would result in a decreased effect, which may not be noticeable by occupants. The electric resistance elements in the HPWH could also be engaged to recover the tank temperature more quickly; however this would result in a significant spike in power use during the recovery period, as seen in the ERWH, which may not be advantageous from a grid stability or energy efficiency perspective.

The efficiency of the HPWH compared to the ERWH results in an inherent peak power reduction of $61.7 \pm 1.7 \%$, which may reduce the magnitude of peak curtailment resources. Accounting for the inherent efficiency of the HPWH, the same power reduction is possible during peak periods. However, population modeling of this response would be required to determine whether the need for peak load reduction scales linearly with decreases in peak load due to efficiency improvements for a population of HPWH.

\subsection{Generation INC Balancing Events}

For INC balancing events, both the HPWH and ERWH were successful in reducing load for the 1hour INC periods and demonstrated fairly consistent responses for the morning, afternoon, and evening events. The magnitude of the response was based on the hot water draw volume experienced at any given time. Greater potential was seen in both the HPWH and the ERWH during hours when there were larger hot water demands (8:00 a.m. and 8:00 p.m.) than times when there was less hot water usage - in the middle of the day (2:00 p.m.). There was no INC potential in the middle of the night (2:00 a.m.), as there was no hot water demand at that time and the water heaters were not energized.

Similar to the peak curtailment events, the peak power reduction was lower for the HPWH than for the ERWH, as can be seen in Table 5.1. However, due to the increased operating time of the HPWH during the DR periods, there is an increased propensity for an HPWH to be available to respond to a call to decrease load. This reduces the number of HPWHs required to provide the same load reduction potential as a given ERWH to 2.67, as compared to the theoretical number (8) based on the power draw of the water heaters alone (see Appendix C).

The INC balancing events did not have a significant impact on daily energy use for the ERWH and decreased the daily energy use approximately $2 \%$ for the HPWH. As with the peak curtailment events, this decreased HPWH energy use could be due to reductions in hot water delivery temperature, although the impact on hot water delivery temperature is not as pronounced. In this high hot water use case, with hot water draws of $130 \mathrm{gal} /$ day and a heat pump as the only heating element, hot water delivery temperatures were maintained above $115^{\circ} \mathrm{F}$ in all cases, which would probably not be detectable to occupants. In addition, the tank would recover much faster with only the heat pump under more typical hot water draw volumes. Based on these experiments, decreased hot water delivery temperature from a HPWH with a set point of $125^{\circ} \mathrm{F}$ is not likely to be an issue for the majority of households participating in a DR program providing peak curtailment or INC balancing services. 


\subsection{Generation DEC Balancing Events}

In general, the ERWH had significantly better dynamic ramping capability to increase load in response to DEC balancing events, as compared to the HPWH. This is because the HPWH was already operating for a majority of each hour when a DEC event was initiated and, thus, had a limited capacity to increase load. Conversely, the ERWH was energized an average of 25\% of every hour, had significant capacity to increase load. However, it is important to note that this response is very dependent on the hot water draw profile and hourly water draw volumes experienced by the water heaters. For example, during the highest hot water usage period in the morning (8:00 a.m.) the load ramping capability of the ERWH was 50 times greater than that of the HPWH because the HPWH was already operating almost the entire hour just to satisfy the load generated by the 10 gallon hot water draw in that hour. In the afternoon and evening, 2:00 p.m. and 8:00 p.m. respectively, the water draw volumes were decreased (6 and 8 gallons, respectively) and the capacity of the ERWH to increase load was only approximately 8 times greater than the HPWH. While the ERWH will always have greater capability to increase load, both water heaters would have greater load-following ability under more typical hot water draw profiles.

At times when there were no hot water draws, both water heaters had the maximum capability to increase load in response to DEC events. During the late night DEC event (2:00 a.m.), when there are not hot water draws, the ERWH's ability to increase load was only 2.12 times greater than that of the HPWH, despite the significant difference in power draw. This is because the ERWH satisfied the request to increase the tank temperature to $135^{\circ} \mathrm{F}$ in 16 minutes after which it de-energized. Conversely, the HPWH was energized the entire 1-hour period, as the ramp rate of the HPWH with no water draws is approximately $9^{\circ} \mathrm{F}$ per hour for the GE GeoSpring HPWH in heat-pump-only mode. Higher tank set point temperatures would result in increased DEC response for the ERWH in a 1-hour period and could increase the duration of the DEC event; for example, for a load increase of 4,650 W for 71 minutes per water heater it is possible to reach a final temperature of $170^{\circ} \mathrm{F}$. For the $\mathrm{HPWH}$, the hourly DEC response cannot be increased beyond that experienced at $135^{\circ} \mathrm{F}$ per water heater. However, significantly longer DEC events are possible - as long as 4 hours to heat the tank to $170^{\circ} \mathrm{F}$ using only the heat pump.

\subsection{Future Experiments}

In general, the HPWH provides approximately $38 \%$ of the peak reduction or INC balancing response compared to the ERWH, when accounting for differences in power use and use profiles of the water heaters. However, the DR performance explored in these experiments represents only an initial indication of the relative response of HPWHs as compared to ERWHs under a given, high hot water use draw profile and with the GE GeoSpring Hybrid HPWH. To validate the extrapolation of these results to other sizes and types of water heaters and the variety of draw profiles experienced in the field, further research is required. These future experiments include the following:

- Explore the ERWH response to DEC balancing events where the simulated events are more spread out, so as not to affect one another, and with a standard ERWH to better characterize the existence of the coast and rebound phenomenon following the DEC event. For example, conduct only one DEC balancing event per day.

- Characterize the DEC response of the ERWH and HPWH with elevated temperatures. For example, bring the tank to $170^{\circ} \mathrm{F}$ with a thermostatic mixing valve to maintain a safe delivery 
temperature $\left(120-125^{\circ} \mathrm{F}\right)$, and for extended periods of three or more hours when the HPWH would have the opportunity to reach full potential. This could be especially beneficial at night to fill valleys in typically low power use/high generation periods.

- Determine the effect of different hot water draw profiles on the results, especially the impact of lower volume and/or more variable (i.e., "spiky") hot water usage.

- Extrapolate experimental results from individual water heaters to populations of water heaters to determine the feasibility of HPWHs for performing DR functions at the program level using population models, such as PNNL's GridLAB-D. ${ }^{1}$

${ }^{1}$ GridLAB-D ${ }^{\text {TM }}$ is a new power distribution system simulation and analysis tool that provides valuable information to users who design and operate distribution systems, and to utilities that wish to take advantage of the latest energy technologies. See http://www.gridlabd.org/ 


\subsection{References}

10 CFR 430.23(e). Test Procedures for the Measurement of Energy and Water Consumption - Water Heaters. Code of Federal Regulations, Washington, D.C. Accessed August 6, 2013, at: http://www.gpo.gov/fdsys/pkg/CFR-2012-title10-vol3/pdf/CFR-2012-title10-vol3-sec430-23.pdf.

AirGenerate. AirTap Hybrid. Available at: http://www.airgenerate.com/products/hybrid

BPA - Bonneville Power Administration. 2010. Residential Heat Pump Water Heater Evaluation Project Measurement \& Verification Plan. Prepared by Ecotope, Inc., for the Bonneville Power Administration, Portland, OR. Accessed August 6, 2013, at http://www.bpa.gov/energy/n/emerging technology/pdf/HPWH MV Plan Final 012610.pdf.

BPA - Bonneville Power Administration. 2011. Residential Heat Pump Water Heater Evaluation: Lab Testing \& Energy Use Estimates. Prepared by Ecotope, Inc., for the Bonneville Power Administration, Portland, OR. Accessed August 6, 2013, at http://www.bpa.gov/energy/n/emerging_technology/pdf/HPWH_Lab_Evaluation_Final_Report_2011 1109.pdf.

CSA - Canadian Standards Association. 2012; DRAFT. Testing Method for Measuring Energy Consumption and Determining Efficiencies of Gas-Fired and Fuel Oil-Fired Storage Water Heaters. Canadian Standards Association, Ontario, Canada.

Christian J, T Gehl, P Bourdreaux, J New, and R Dockery. 2010. Tennessee Valley Authority's Campbell Creek Energy Efficiency Homes Project: 2010 First Year Performance Report July 1, 2009 - August 31, 2010. ORNL/TM-2010/206, Oak Ridge National Laboratory, Oak Ridge, Tennessee. Accessed August 6, 2013, at http://info.ornl.gov/sites/publications/files/pub26374.pdf

Diao R, S Lu, M Elizondo, E Mayhorn, Y Zhang, and N Samaan. 2012. Electric Water Heater Modeling and Control Strategies for Demand Response. IEEE Power and Energy Society General Meeting, 2012, pp.1-8, July 22-26 2012. DOI: 10.1109/PESGM.2012.6345632. Accessed August 6, 2013, at http://ieeexplore.ieee.org/xpls/abs_all.jsp?arnumber=6345632.

EIA - U.S. Energy Information Administration. 2009. Residential Energy Consumption Survey. Accessed August 6, 2013, at http://www.eia.gov/consumption/residential/ ..

GE Appliances, Inc. 2012. GE Appliances Technical Service Guide: GE Hybrid Water Heater. Knoxville, TN.

E. Ela, M. Milligan, and B. Kirby, "Operating Reserves and Variable Generation," NREL/TP-550051978, National Renewable Energy Laboratory, Golden Colorado, August 2011. Accessed August 7 , 2013 at: http://www.nrel.gov/docs/fy11osti/51978.pdf

GE Appliances, Inc. 2013. GeoSpring ${ }^{T M}$ Hybrid Electric Residential Water Heaters Owner's Manual \& Installation Instructions. Knoxville, TN. Accessed August 6, 2013, at http://products.geappliances.com/MarketingObjectRetrieval/Dispatcher?RequestType=PDF\&Name= 49-50292.pdf.

General Electric Company. February 2012. Hybrid electric water heater with external discharge ducting. US 20120023990 A1. Accessed August 6, 2013, at http://www.google.com/patents/US20120023990.

Hadley A, B Larson and J Harris. 2012. High Performance Manufactured Homes. Presented to the Pacific Northwest Regional Technical Forum, May 15, 2012, by Adam Hadley and Ben Larson, Portland, OR. Accessed August 6, 2013, at http://rtf.nwcouncil.org/meetings/2012/05/HPMH Proposal 20120515 v2a.ppt. 
Hendron and Burch. 2010. Tool for Generating Realistic Residential Hot Water Event Schedules. NREL/CP-550-47685. National Renewable Energy Laboratory; Golden, CO. Accessed August 6, 2013, at http://www1.eere.energy.gov/buildings/residential/ba_analysis_spreadsheets.html

Hendron and Engebrecht. 2010. Building America House Simulation Protocols. TP-550-49426. National Renewable Energy Laboratory, Golden, CO. Accessed August 6, 2013, at http://www.nrel.gov/docs/fy11osti/49246.pdf.

Konodoh J, L Ning and D Hammerstrom. 2010. An Evaluation of the Water Heater Load Potential for Providing Regulation Service. IEEE Transactions on Power Systems. 26(3). Accessed August 6, 2013, at http://ieeexplore.ieee.org/xpls/abs_all.jsp?arnumber=5668519\&tag=1.

Kresta, D. 2012. Heat Pump Water Heater Market Transformation Update. Northwest Energy Efficiency Alliance. Portland, OR.

Larson B, T Hewes and A Hadley. 2012. Heat Pump Water Heaters: Tier 2 - Ducted Interior Installations. Presented to the Pacific Northwest Regional Technical Forum February 14, 2012, by Adam Hadley and Jeff Harris, Portland, OR. Accessed August 6, 2013, at http://rtf.nwcouncil.org/meetings/2012/02/HPWH Ducted Interior Installations Provisional Propos al_021412_v5.pptx.

Larson, B and M Logsdon. 2012. NEEA Report: Laboratory Assessment of General Electric GeoSpring ${ }^{T M}$ Hybrid Heat Pump Water Heater. REPORT \#09282012. Ecotope Inc. for the Northwest Energy Efficiency Alliance, Portland, OR.

Loutan C, T Yong, S Chowdhury, AA Chowdhury, and G Rosenblum, Impacts of integrating wind resources into the California ISO market construct, in Proceedings of 2009 IEEE PES General Meeting, July 2009. Accessed August 7, 2013 at:

http://xplqa30.ieee.org/xpl/articleDetails.jsp?tp=\&arnumber=5275196\&contentType=Conference $+\mathrm{Pu}$ $\underline{\text { blications }}$

Lu S, N Samaan, R Diao, M Elizondo, C Jin, E Mayhorn, Y Zhang and H Kirkham. 2011. Centralized and Decentralized Control for Demand Response. Innovative Smart Grid Technologies (ISGT), 2011 IEEE PES, 17-19 Jan. 2011. DOI: 10.1109/ISGT.2011.5759191. Accessed August 6, 2013, at http://ieeexplore.ieee.org/xpls/abs_all.jsp?arnumber=5759191.

Lutz J and M Melody. 2012. Typical Hot Water Draw Patterns Based on Field Data. Lawrence Berkeley National Laboratory, Berkeley, CA.

Makarov YV, C. Loutan, J Ma, and P De Mello. 2009. "Operational impacts of wind generation on California power systems," IEEE Transactions on Power Systems 24(2): 1039-1050. Accessed August 7, 2013 at: http://ieeexplore.ieee.org/xpls/abs_all.jsp?arnumber=4808228\&tag=1

Mathieu J, M Dyson and D Callaway. 2012. Using Residential Electric Loads for Fast Demand Response: The Potential Resource and Revenues, the Costs, and Policy Recommendations. ACEEE Summer Study on Energy Efficiency in Buildings. Pacific Grove, CA. Accessed August 6, 2013, at http://www.aceee.org/files/proceedings/2012/data/papers/0193-000009.pdf.

NEEA - Northwest Energy Efficiency Alliance. 2012a. Northern Climate Heat Pump Water Heater Specification. Northwest Energy Efficiency Alliance, Portland, OR. Accessed August 6, 2013, at http://neea.org/northernclimatespec

NEEA - Northwest Energy Efficiency Alliance. 2012b. Northern Climate Qualified Heat Pump Water Heaters. Northwest Energy Efficiency Alliance. Portland, OR. Accessed August 6, 2013, at http://smartwaterheat.org/sites/default/files/NCS_Qualified_Product_List.pdf

Saker N, M Petit and J Coullon. 2011. Demand Side Management of Electrical Water Heaters and Evaluation of the Cold Load Pick-Up Characteristics (CLPU). 2011 IEEE Trondheim Power Tech, 
19-23 June 2011. DOI: 10.1109/PTC.2011.6019312. Accessed August 6, 2013, at http://ieeexplore.ieee.org/xpls/abs_all.jsp?arnumber=6019312.

Sepulveda, A; L Paull, W Morsi, H Li, C Diduch, and L Chang. 2010. A Novel Demand Side Management Program using Water Heaters and Particle Swarm Optimization. 2010 IEEE Electrical Power \& Energy Conference (EPEC), August 25-27, 2010. DOI: 10.1109/EPEC.2010.5697187. Accessed August 6, 2013, at http://ieeexplore.ieee.org/xpls/abs all.jsp?arnumber=5697187.

U.S. Energy Information Administration (EIA). 2009. Residential Energy Consumption Survey. U.S. Department of Energy, Washington, D.C. Available at: http://www.eia.gov/consumption/residential/.

Widder SH, GB Parker, MC Baechler and NN Bauman. 2012. Side-by-Side Field Evaluation of Highly Insulating Windows in the PNNL Lab Homes. PNNL-21678, Pacific Northwest National Laboratory, Richland, WA. Accessed August 6, 2013, at http://labhomes.pnnl.gov/resources.stm 

Appendix A

Occupancy Simulation: Electrical Loads 



\section{Appendix A}

\section{Occupancy Simulation: Electrical Loads}

Controllable breakers were programmed to activate connected loads on schedules to simulate human occupancy. The bases for occupancy simulation were data and analysis developed in previous residential simulation activities (Hendron and Engebrecht, 2010; Christian et al., 2010). The occupancy simulations and schedules developed here were derived specific to the home style, square footage, and an assumed occupancy of three adults. The per-person sensible heat generation and occupancy profiles were mapped from previous studies to be applicable to this demonstration.

Occupancy and connected-lighting heat generation were simulated by activating portable and fixed lighting fixtures throughout the home. Each bedroom was equipped with a table lamp to simulate human occupancy; occupancy and lighting loads in other areas of the home were simulated via fixed lighting. In both cases (portable and fixed lighting), schedules were programmed into the electrical panel for run times commensurate with identified use profiles. The enabled profiles sought to match daily total occupancy characteristics with less emphasis on defined hourly simulation. Equipment loads were simulated identically in both homes using electric resistance wall heaters in the living/dining room: one $500 \mathrm{~W}$ and one 1,500 W heater run simultaneously for a set number of minutes each hour. This set of experiments focused on sensible loads only; latent loads were not simulated and were not anticipated to significantly impact the performance of the heat pump water heater (HPWH). Table A.1, Table A.2, and Table A.3 present the load simulation and occupancy schedules for the Lab Homes HPWH experiments.

The occupancy simulation protocol was robustly commissioned and verified daily throughout the baselining and data collection periods. Following each table, an example of occupancy schedule agreement is depicted from real data collected during the baseline period (Figure A.1, Figure A.2, and Figure A.3). The loads agree between homes and across days within approximately $1 \%$.

Table A.1. Daily Occupancy Schedules and Simulated Load

\begin{tabular}{|c|c|c|c|}
\hline Hours of Day & Simulation Strategy & Simulated Watts & Load Locations \\
\hline 1 a.m. -7 a.m. & 360 -Watt table lamps & 180 & Lamps in master and each bedroom \\
\hline 7 a.m. -8 a.m. & 360 -Watt table lamps & 180 & Lamps in master and each bedroom \\
\hline 8 a.m. -9 a.m. & 160 -Watt table lamp & 60 & Lamp in master bedroom \\
\hline 9 a.m. -4 p.m. & 160 -Watt table lamp & 60 & Lamp in master bedroom \\
\hline 4 p.m. -5 p.m. & 160 -Watt table lamp & 60 & Lamp in master bedroom \\
\hline 5 p.m. -6 p.m. & 260 -Watt table lamps & 120 & Lamps in master and East bedroom \\
\hline 6 p.m. -9 p.m. & 360 -Watt table lamps & 180 & Lamps in master and each bedroom \\
\hline 9 p.m. -12 p.m. & 360 -Watt table lamps & 180 & Lamps in master and each bedroom \\
\hline Wattage Totals & & 3180 & \\
\hline
\end{tabular}




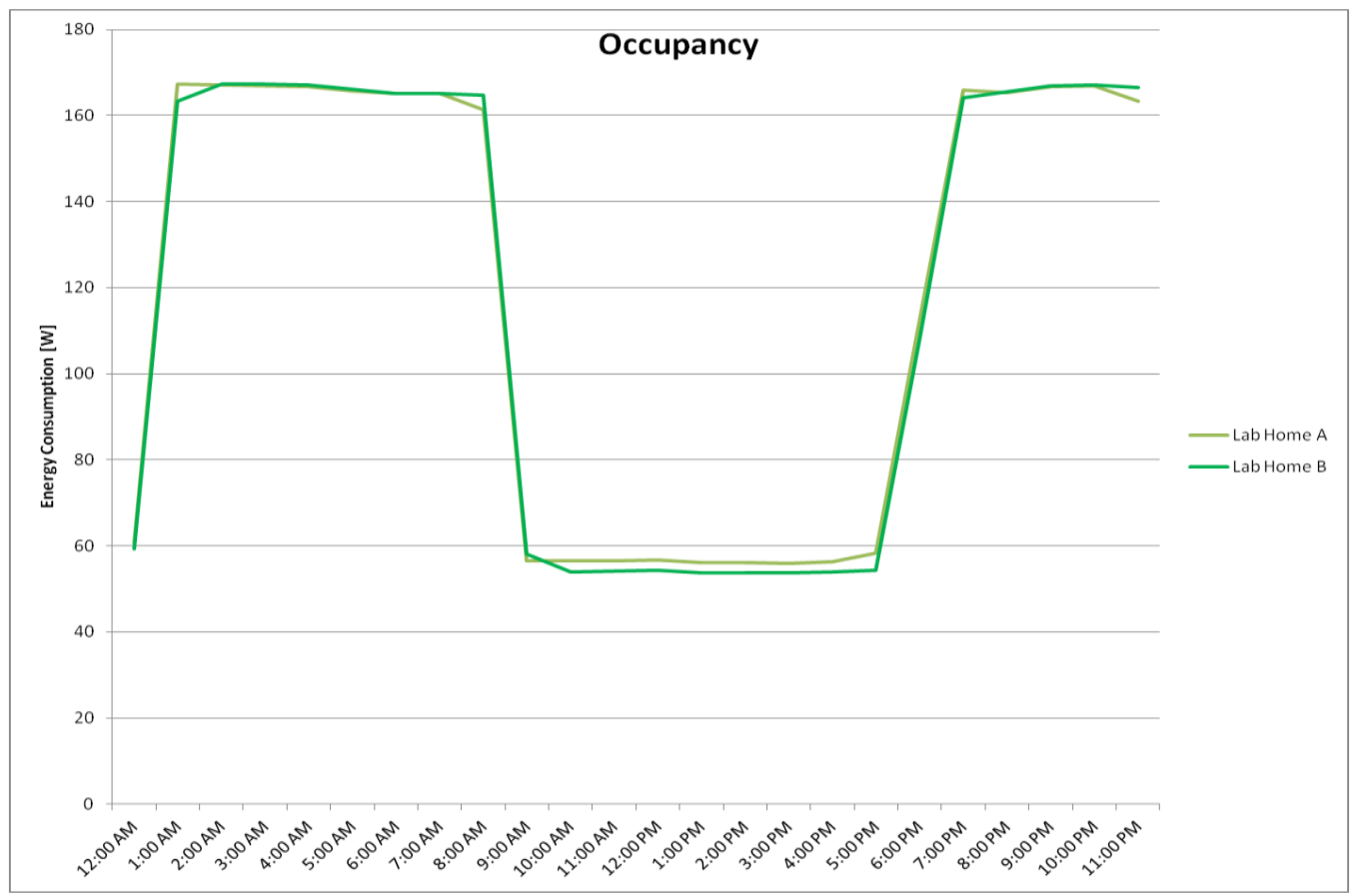

Figure A.1. Hourly Average Energy Consumption (W) Associated with Human Occupancy for an Example Day during the Baseline Period

Table A.2. Daily Lighting Schedules and Simulated Load

\begin{tabular}{|c|c|c|c|}
\hline Hours of Day & Simulation Strategy & $\begin{array}{l}\text { Simulated } \\
\text { Watts }\end{array}$ & Load Locations \\
\hline 1 a.m. -4 a.m. & Ceiling fixture, 1 60-Watt lamp & 60 & Hall fixture \\
\hline 4 a.m. -5 a.m. & Ceiling fixture, 2 60-Watt lamps & 120 & Entry and living room fixtures \\
\hline 5 a.m. -6 a.m. & 2 ceiling fixtures, 260 -Watt lamps each & 240 & Kitchen fixtures \\
\hline 6 a.m. -7 a.m. & 2 ceiling fixtures, 260 -Watt lamps each & 240 & Kitchen fixtures \\
\hline 7 a.m. -8 a.m. & 2 ceiling fixtures, 260 -Watt lamps each & 240 & Kitchen fixtures \\
\hline 8 a.m. -9 a.m. & Ceiling fixture, 2 60-Watt lamps & 120 & Kitchen fixtures \\
\hline 9 a.m. -3 p.m. & Ceiling fixture, 1 60-Watt lamp & 60 & Hall fixture \\
\hline 3 p.m. -4 p.m. & Ceiling fixture, 2 60-Watt lamps & 120 & Entry and living room fixtures \\
\hline 4 p.m. -5 p.m. & 2 ceiling fixtures, 260 -Watt lamps each & 240 & Kitchen fixtures \\
\hline 5 p.m. -6 p.m. & 3 ceiling fixtures, 2 60-Watt lamps each & 360 & Kitchen and entry fixtures \\
\hline 6 p.m. -7 p.m. & 5 ceiling fixtures, 260 -Watt lamps each & 600 & $\begin{array}{l}\text { Master, kitchen, and } 2 \text { bedroom } \\
\text { fixtures }\end{array}$ \\
\hline 7 p.m. -8 p.m. & 5 ceiling fixtures, 260 -Watt lamps each & 600 & $\begin{array}{l}\text { Master, kitchen, and } 2 \text { bedroom } \\
\text { fixtures }\end{array}$ \\
\hline 8 p.m. -9 p.m. & 5 ceiling fixtures, 260 -Watt lamps each & 600 & $\begin{array}{l}\text { Master, kitchen, and } 2 \text { bedroom } \\
\text { fixtures }\end{array}$ \\
\hline 9 p.m. -10 p.m. & 4 ceiling fixtures, 3 60-Watt lamps each & 420 & Master, kitchen and hall fixtures \\
\hline 10 p.m. -11 p.m. & 2 ceiling fixtures, 2 60-Watt lamps each & 240 & Kitchen fixtures \\
\hline 11 p.m. -12 p.m. & Ceiling fixture, 1 60-Watt lamp & 60 & Hall fixture \\
\hline Wattage Totals & & 4800 & \\
\hline
\end{tabular}




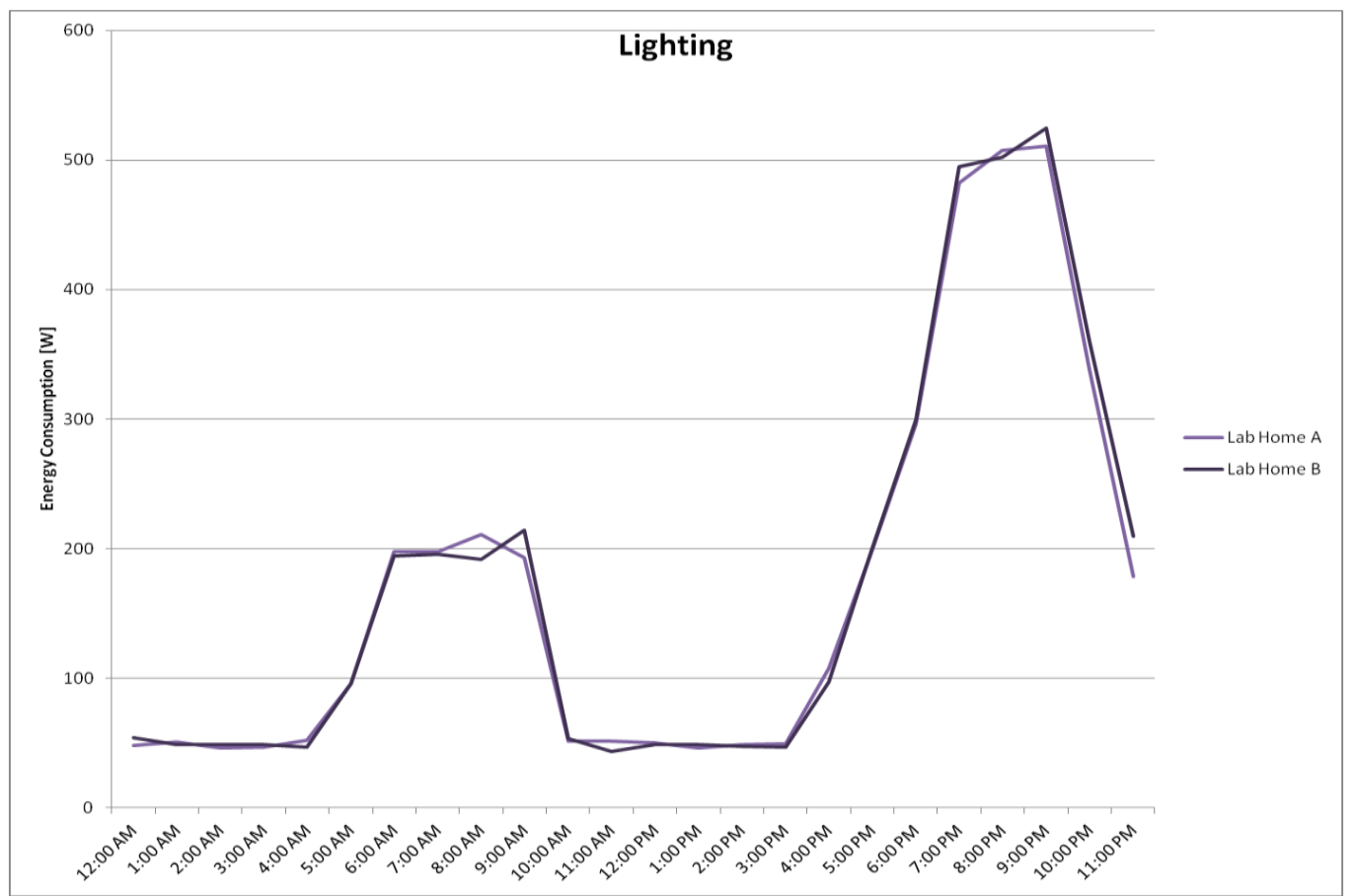

Figure A.2. Hourly Average Energy Consumption (W) Associated with Lighting for an Example Day During the Baseline Period

Table A.3. Daily Equipment Schedules and Simulated Load

\begin{tabular}{|c|c|c|c|c|}
\hline Hours of Day & Simulation Strategy & $\begin{array}{c}\text { Duration } \\
\text { of Load } \\
\text { (Minutes) }\end{array}$ & $\begin{array}{c}\text { Simulated } \\
\text { Watts }\end{array}$ & Load Locations \\
\hline 1 a.m. -2 a.m. & One $500 \mathrm{~W} \&$ one $1,500 \mathrm{~W}$ wall heater & 5 & 170 & Living/dining room \\
\hline 2 a.m. -3 a.m. & One $500 \mathrm{~W} \&$ one $1,500 \mathrm{~W}$ wall heater & 5 & 157 & Living/dining room \\
\hline 3 a.m. -4 a.m. & One $500 \mathrm{~W} \&$ one $1,500 \mathrm{~W}$ wall heater & 4 & 149 & Living/dining room \\
\hline 4 a.m. -5 a.m. & One $500 \mathrm{~W} \&$ one $1,500 \mathrm{~W}$ wall heater & 4 & 148 & Living/dining room \\
\hline 5 a.m. -6 a.m. & One $500 \mathrm{~W} \&$ one $1,500 \mathrm{~W}$ wall heater & 4 & 147 & Living/dining room \\
\hline 6 a.m. -7 a.m. & One $500 \mathrm{~W} \&$ one $1,500 \mathrm{~W}$ wall heater & 5 & 181 & Living/dining room \\
\hline 7 a.m. -8 a.m. & One $500 \mathrm{~W} \&$ one $1,500 \mathrm{~W}$ wall heater & 8 & 258 & Living/dining room \\
\hline 8 a.m. -9 a.m. & One $500 \mathrm{~W} \&$ one $1,500 \mathrm{~W}$ wall heater & 9 & 284 & Living/dining room \\
\hline 9 a.m. -3 p.m. & One $500 \mathrm{~W} \&$ one $1,500 \mathrm{~W}$ wall heater & 8 & 268 & Living/dining room \\
\hline 3 p.m. -4 p.m. & One $500 \mathrm{~W} \&$ one $1,500 \mathrm{~W}$ wall heater & 8 & 250 & Living/dining room \\
\hline 4 p.m. -5 p.m. & One $500 \mathrm{~W} \&$ one $1,500 \mathrm{~W}$ wall heater & 7 & 243 & Living/dining room \\
\hline 5 p.m. -6 p.m. & One $500 \mathrm{~W} \&$ one $1,500 \mathrm{~W}$ wall heater & 7 & 236 & Living/dining room \\
\hline 6 p.m. -7 p.m. & One $500 \mathrm{~W} \&$ one $1,500 \mathrm{~W}$ wall heater & 7 & 229 & Living/dining room \\
\hline 7 p.m. -8 p.m. & One $500 \mathrm{~W} \&$ one $1,500 \mathrm{~W}$ wall heater & 7 & 222 & Living/dining room \\
\hline 8 p.m. -9 p.m. & One $500 \mathrm{~W} \&$ one $1,500 \mathrm{~W}$ wall heater & 7 & 235 & Living/dining room \\
\hline 9 p.m. -10 p.m. & One $500 \mathrm{~W} \&$ one $1,500 \mathrm{~W}$ wall heater & 7 & 220 & Living/dining room \\
\hline 10 p.m. -11 p.m. & One $500 \mathrm{~W} \&$ one $1,500 \mathrm{~W}$ wall heater & 8 & 282 & Living/dining room \\
\hline 11 p.m. -12 p.m. & One $500 \mathrm{~W} \&$ one $1,500 \mathrm{~W}$ wall heater & 11 & 356 & Living/dining room \\
\hline Wattage Totals & & & 5,875 & \\
\hline
\end{tabular}




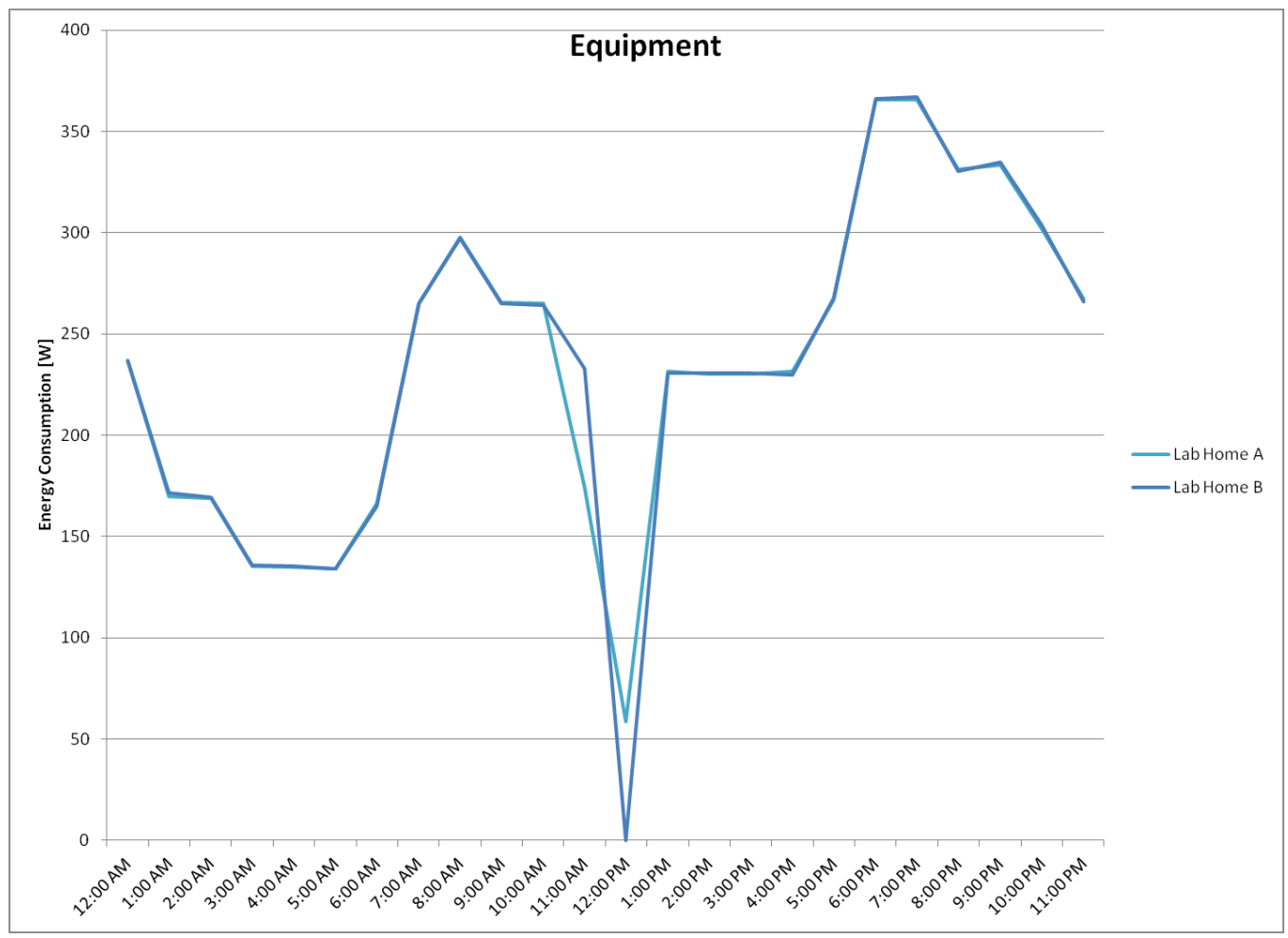

Figure A.3. Hourly Average Energy Consumption (W) Associated with Equipment Loads for an Example Day during the Baseline Period

Throughout the experiment, the heating, ventilating and air conditioning systems were operated identically in the two homes. The 2.5-ton SEER ${ }^{1} 13$ heat pumps maintain an interior set point of $76^{\circ} \mathrm{F}$ with no setback, as per Building America House Simulation Protocols (Hendron and Engebrecht 2010).

\footnotetext{
${ }^{1}$ Seasonal Energy Efficiency Ratio.
} 


\section{Appendix B}

\section{Alternate Hot Water Draw Profiles}





\section{Appendix B}

\section{Alternate Hot Water Draw Profiles}

In selecting a representative hot water draw profile for the Lab Homes, PNNL also examined the hot water draw profile implemented in BPA's evaluation of HPWHs (BPA 2010). The BPA evaluation exercised two draw profiles, one similar to the DOE Building America Protocol, with moderate usage throughout the day, and one that was more representative of a typical household where the occupants are gone during the day. The first profile assumes $90 \mathrm{gal} /$ day of hot water for four persons while the second profile assumes $80 \mathrm{gal} /$ day hot water. Both profiles are similar, exhibiting increased water use in the morning and evening, but the "typical household" profile is more spiky, with dramatic increases and decreases in water throughout the day. This profile may be more representative of a single home or occupant, but is not necessarily better for understanding a "typical" home, or population of homes, from a utility perspective. In addition, with a tank water heater, efficiency depends more on total volume of draw than the variable rate or frequency of draws. Also, the flow rates and durations of draws required to simulate such a variable profile are quite large, from 0.5 to $3 \mathrm{gpm}$ with durations of 1 to 9 minutes. While this may be representative of average usage in a home, it is difficult to simulate reliably in the Lab Homes.

The draft Canadian Standards Association (CSA) Standard testing method for domestic hot water heaters, which was recently revised to be more representative of typical use cases, recommends a hot water draw profile for the "high usage" case targeting 68.8 gal/day (CSA 2012). The CSA test is similar to the DOE Energy Factor (EF) Test (10 CFR 430.23(e)) profile in that it requires a $77^{\circ} \mathrm{F}$ temperature differential between inlet and outlet water and a $135^{\circ} \mathrm{F}$ tank temperature, but more "representative" draw volumes and flow rates throughout the 24-hour period, specified as 20 unique water draw events throughout a 24-hour period. The CSA profile also exhibits increased water use in the morning and evening and a similar total volume, but larger evening draws than the other profiles. A table of the CSA hot water draws is given in Table B.1.

PNNL also explored using the DHW Event Generator (Hendron and Burch, 2010), a spreadsheet tool developed by NREL that produces an entire year of simulated draw profiles. However, the simulated draw pattern changes daily, which is extremely difficult to accomplish in a physical test, and some of the daily profiles did not appear to reasonably represent realistic daily draw patterns. Because the draw profile simulated in the Lab Homes needs to remain constant throughout the experiment to remove water draw profile as a variable from the comparison, choosing a draw pattern representative of aggregate average hot water use, such as the Building America House Simulation Protocol, seemed most appropriate. Future work could explore the performance of HPWH as a function of variable draw patterns. 
Table B.1. CSA Standard Hot Water Draws. Source: CSA 2012.

\begin{tabular}{|c|c|c|c|c|c|c|c|}
\hline \multirow[b]{3}{*}{$\begin{array}{l}\text { Draw } \\
\text { No. }\end{array}$} & \multirow[b]{3}{*}{$\begin{array}{l}\text { TIME OF DAY } \\
\text { (HH:MM:SS) }\end{array}$} & \multicolumn{6}{|c|}{ WATER HEATER CLASSIFICATION } \\
\hline & & \multicolumn{2}{|c|}{ LOW USAGE } & \multicolumn{2}{|c|}{ MEDIUM USAGE } & \multicolumn{2}{|c|}{ HIGH USAGE } \\
\hline & & $\begin{array}{l}\text { VOLUME } \\
\text { DRAWN } \\
\text { (gal) }\end{array}$ & $\begin{array}{l}\text { FLOWRATE } \\
\text { (gal / Min) }\end{array}$ & $\begin{array}{c}\text { VOLUME } \\
\text { DRAWN } \\
\text { (gal) }\end{array}$ & $\begin{array}{l}\text { FLOWRATE } \\
\text { (gal / Min) }\end{array}$ & $\begin{array}{c}\text { VOLUME } \\
\text { DRAWN } \\
\text { (gal) }\end{array}$ & $\begin{array}{c}\text { FLOWRATE } \\
\text { (gal / Min) }\end{array}$ \\
\hline & & & & & & & \\
\hline 1 & $00: 00: 00$ & 2.6 & 1.0 & 4 & 1.0 & 4.0 & 1.0 \\
\hline 2 & $3: 00: 00$ & 2.6 & 1.0 & 2.6 & 1.0 & 2.6 & 1.0 \\
\hline 3 & 3:07:38 & 2.6 & 1.0 & 2.6 & 1.0 & 2.6 & 1.0 \\
\hline 4 & 3:13:17 & 2.6 & 1.0 & 2.6 & 1.0 & 2.6 & 1.0 \\
\hline 5 & $8: 00: 00$ & -- & -- & 4 & 1.0 & 5.3 & 1.0 \\
\hline 6 & 9:00:00 & 1.3 & 1.0 & 4 & 1.0 & 4.0 & 1.0 \\
\hline 7 & 10:00:00 & 1.3 & 1.0 & 2.6 & 1.0 & 4.0 & 1.0 \\
\hline 8 & 11:00:00 & 1.3 & 1.0 & 2.6 & 1.0 & 4.0 & 1.0 \\
\hline 9 & \begin{tabular}{|l|l|}
$12: 00: 00$ \\
\end{tabular} & -- & -- & 2.6 & 1.0 & 4.0 & 1.0 \\
\hline 10 & 13:00:00 & -- & -- & -- & -- & 11.9 & 3.0 \\
\hline 11 & 17:00:00 & 4.0 & 3.0 & 9.2 & 3 & 9.2 & 1.0 \\
\hline 12 & \begin{tabular}{|l|}
$17: 06: 19$ \\
\end{tabular} & & 1.0 & -- & -- & -- & -- \\
\hline 13 & \begin{tabular}{|l|}
$17: 08: 05$ \\
\end{tabular} & -- & -- & 4.0 & 1.0 & -- & -- \\
\hline 14 & \begin{tabular}{|l|l}
$17: 13: 16$ \\
\end{tabular} & 4.0 & 1.0 & -- & -- & -- & -- \\
\hline 15 & \begin{tabular}{|l|}
$17: 14: 14$ \\
\end{tabular} & -- & -- & -- & -- & 5.3 & 1.0 \\
\hline 16 & \begin{tabular}{|l|}
$17: 15: 02$ \\
\end{tabular} & -- & -- & 4.0 & 1.0 & -- & -- \\
\hline 17 & \begin{tabular}{|l|}
$17: 21: 13$ \\
\end{tabular} & 4.0 & 1.0 & -- & -- & -- & -- \\
\hline 18 & \begin{tabular}{|l|l|}
$17: 21: 59$ \\
\end{tabular} & -- & -- & 4.0 & 1.0 & -- & -- \\
\hline 19 & \begin{tabular}{|l|}
$17: 22: 41$ \\
\end{tabular} & -- & -- & -- & -- & 5.3 & 1.0 \\
\hline 20 & \begin{tabular}{|l|}
$17: 30: 58$ \\
\end{tabular} & -- & -- & -- & -- & 4.0 & 1.0 \\
\hline * & $18: 15: 00$ & End Test & & & & & \\
\hline
\end{tabular}

In addition, the DOE EF test procedure specifies the use of 64 gallons hot water for the purposes of evaluating the efficiency of residential water heaters (10 CFR 430.23(e)), although the draw profile is not representative of typical use.

Figure B.1 shows a comparison between the four hot water use profiles. 


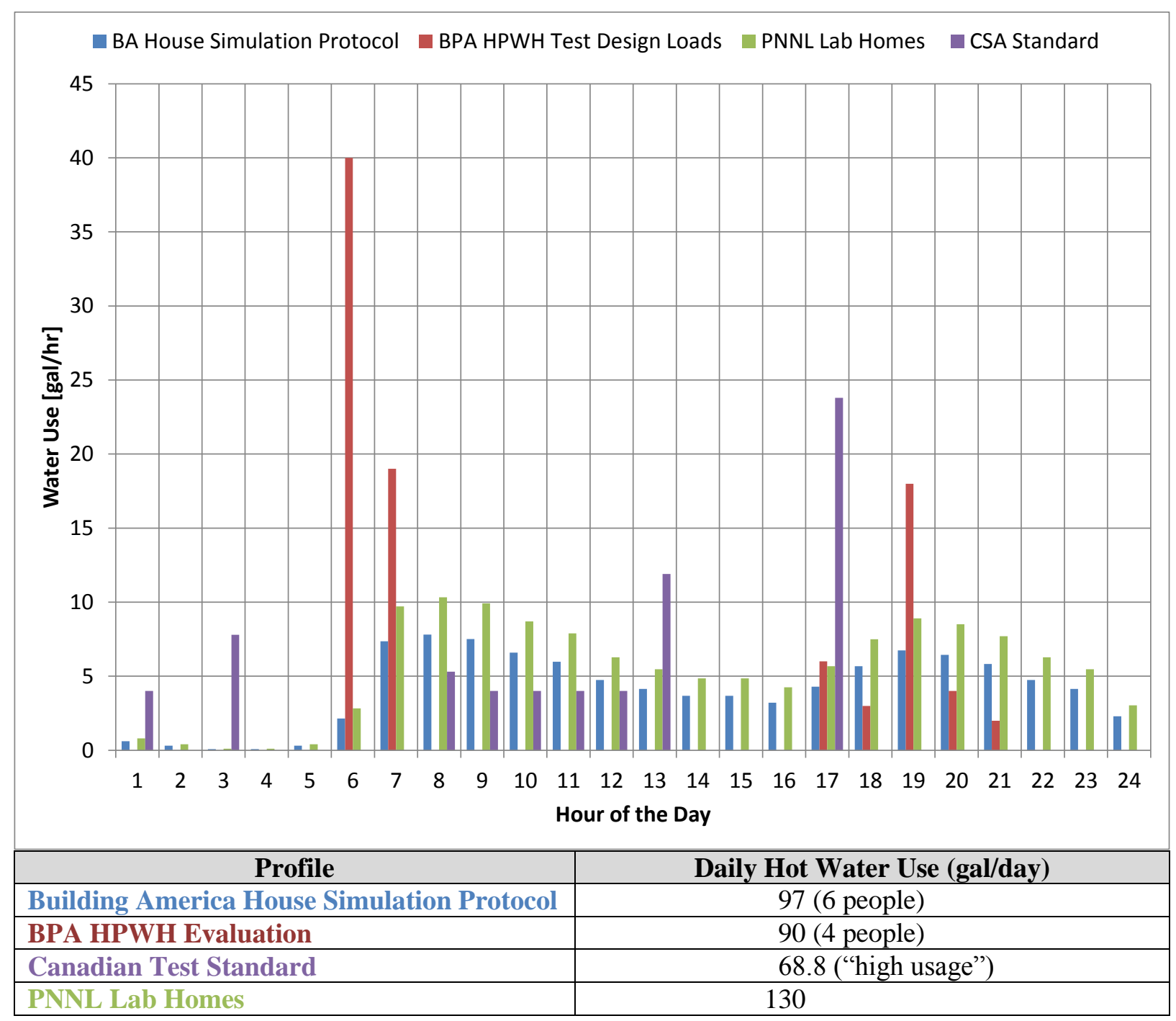

Figure B.1. Comparison of the Four Hot-Water Use Profiles 

Appendix C

Calculations 



\section{Appendix C}

\section{Calculations}

Calculation of theoretical hourly demand was determined using the following equation:

$$
Q=m \times C_{p} \times\left(T_{\text {setpoint }}-T_{o}\right) \times 0.293 \mathrm{Wh} / \mathrm{Btu}
$$

where:

$$
\begin{aligned}
& Q \quad=\text { energy in } \mathrm{Wh} \\
& m \quad=\text { mass of water in pounds } \\
& C_{p} \quad=\text { specific heat capacity of water }\left(1 \mathrm{Btu} / l b \times{ }^{\circ} \mathrm{F}\right) \\
& T_{\text {setpoint }}=\text { the desired set point of the water heater tank in }{ }^{\circ} \mathrm{F} \\
& T_{o} \quad=\text { the initial temperature of the water (i.e., the previous tank set point) in }{ }^{\circ} \mathrm{F}
\end{aligned}
$$

For periods with draws occurring (e.g., 2:00 p.m.), $m$ should account for the mass of water in the tank as well as the draws during that period, as follows:

$$
Q=\left[m_{\text {tank }} \times C_{p} \times\left(T_{\text {setpoint }}-T_{o}\right)+m_{\text {draw }} \times C_{p} \times\left(T_{\text {setpoint }}-T_{\text {in }}\right)\right] \times 0.293 \mathrm{Wh} / \text { Btu }
$$

where:

$T_{\text {in }}=$ the incoming water temperature in ${ }^{\circ} \mathrm{F}$

and other variables are as described previously.

Theoretical number of HPWHs required to provide the same DR potential as a single ERWH is calculated as:

$$
\frac{E R W H \text { Power Use }[W]}{H P W H \text { Power Use }[W]}=\frac{4,650 W}{587 W}=7.9 \rightarrow 8 H P W H / E R W H
$$





\section{Appendix D \\ Data Files}





\section{Appendix D}

\section{Data Files}

Power, water flow, and temperature data are provided for each DR related tests, including: baseline, peak curtailments; INC balancing events, and DEC balancing events. A data file, in csv (comma separated value) format, with 1-minute data for the following variables is available at labhomes.pnnl.gov for other researchers or interested parties to perform their own additional analysis:

- Total electric real power to each water heater $(\mathrm{kW}), 1$ minute average.

- Total electric apparent power to each water heater (kVA), 1 minute average.

- Hot water flow rate out of the water heater (gallons per minute), 1 minute average.

- Temperature of the cold water supply into the water heaters $\left({ }^{\circ} \mathrm{F}\right), 1$ minute average.

- Temperature of the water at the outlet of the water heaters $\left({ }^{\circ} \mathrm{F}\right), 1$ minute average. 


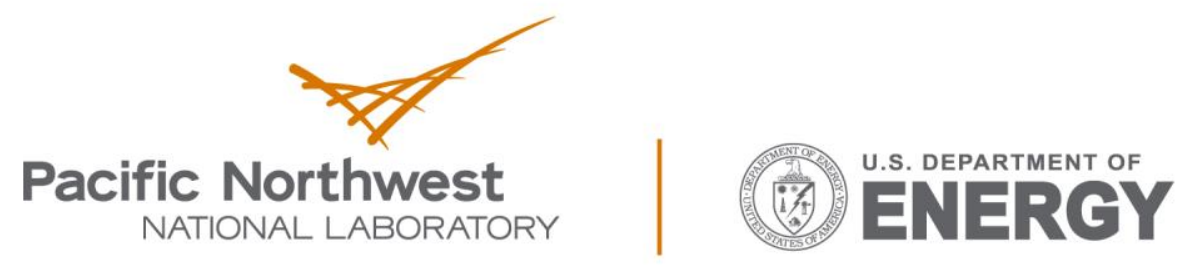

Proudly Operated by Battelle Since 1965

902 Battelle Boulevard

P.O. Box 999

Richland, WA 99352

1-888-375-PNNL (7665)

www.pnnl.gov 